\title{
DESIGN, FABRICATION AND TESTING OF DIAMOND RADIATION DETECTORS FOR CHARGED PARTICLE AND NEUTRON DETECTION
}

A Dissertation
presented to
the Faculty of the Graduate School
at the University of Missouri-Columbia
In Partial Fulfillment
of the Requirements for the Degree
Doctor of Philosophy
HARUETAI KASIWATTANAWUT
Dr. Mark Prelas, Dissertation Supervisor
MAY 2017


(C) Copyright by Haruetai Kasiwattanawut 2017

All Rights Reserved 
The undersigned, appointed by the dean of the Graduate School, have examined the Dissertation entitled

\section{DESIGN, FABRICATION AND TESTING OF DIAMOND RADIATION DETECTORS FOR CHARGED PARTICLE AND NEUTRON DETECTION}

presented by Haruetai Kasiwattanawut,

a candidate for the degree of

Doctor of Philosophy

and hereby certify that, in their opinion, it is worthy of acceptance.

Professor Mark Prelas

Professor Sudarshan Loyalka

Professor Tushar Ghosh

Professor Robert Tompson

Professor Stephen Montgomery-Smith 
To my family, my husband and my little daughter. 


\section{ACKNOWLEDGEMENTS}

I would like to thank everybody who supported my academic accomplishments.

First of all, my advisor, Professor Mark Prelas, for giving me the opportunity and supporting me in everything over the years. His guidance, kindness and truly understanding made me successful today. I would like to extend my thanks to my committee, Dr. Sudarshan Loyalka, Dr. Tushar Ghosh, Dr. Robert Tompson and Dr. Stephen Montgomery-Smith for their guidance and generosity.

I would like to thank the following for providing financial support for my study and research: Royal Thai Government Scholarship and Sidney Kimmel Institute for Nuclear Renaissance (SKINR).

I would like to thank Dr. Joseph Mathai and Dr, Haisheng Zheng for their knowledge and help at the Department of Electrical Engineering and Computer Science. I would like to thank Dr. Tommi White for her support at the Electron Microscopy Core Facility. I am also thankful for my academic mentors, Dr. Eric Lukosi, Dr. Charles Weaver, Michael Reinig, and Dr. Matthew Watermann for their laboratory assistant and support.

I am truly grateful to the faculty members and staff at Nuclear Science and Engineering Institute. I would like to thank Latricia Vaughn and James Bennett for their meaningful facilitation and welcome. I am grateful for my lab partners, Joongmoo Shim and Modeste Tchakoua for their infinite patience and friendship. Thank you to my NSEI friends, Amal, Eben, and JD for sharing amazing times together. 
My thanks also goes to Ms. Siriratana Biramontri, a Former Deputy Secretary General of Office of Atoms for Peace, Thailand for her encouragement and giving me the opportunity to apply the scholarship program.

I am so grateful for my Thai community at Mizzou, espeically, Dr. Bic, Dr. Suree, Dr. Toh, Bay and Avalynn, Gift, Paolo, Pi Rocky, Pitcha and Pie, Dr. Tar and Pann, Dr. Ying, Dr. Pui and Dr. Tan, Wit, Ohm, Dr. Kim, Pam, Ploy, Chin, Dr. Got, Dr. Nat, Dr. Ann, Meow, Jo, Bo, Deer, Pi Aui, Note and Nony for their good laughs and help. I would like to thank my parents, Vichien and Sureeporn Kasiwattanawut, for their everlasting love and my sisters Viyada and Siriluk for being forever friends of mine. Finally, my deeply thanks goes to my husband, Sirichai Theirrattanakul, for being my best friend, my lover and for strongly supporting me. And to my beautiful daughter, Lynyada Theirrattanakul, you are my angel. Thank you for coming into my life. I love you so much. 


\section{TABLE OF CONTENTS}

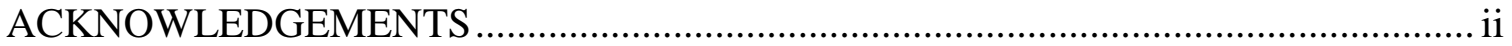

LIST OF FIGURES …………………........................................................... vi

LIST OF TABLES .................................................................................................... ix

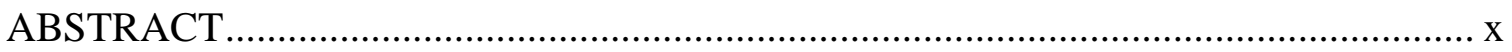

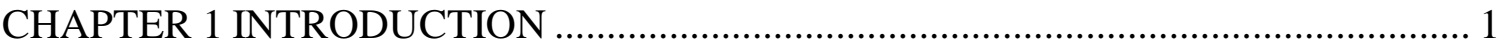

1.1 Rationale and Background Research .................................................................... 1

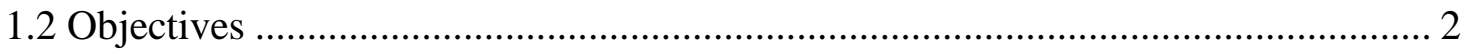

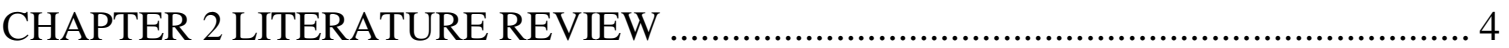

2.1 Low energy nuclear reaction (LENR).................................................................... 4

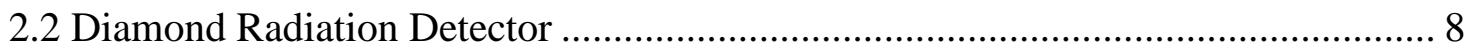

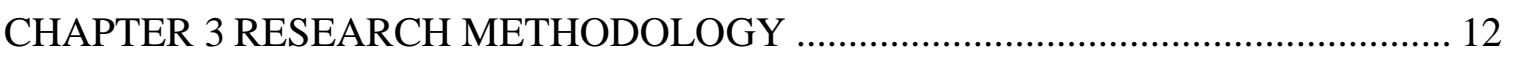

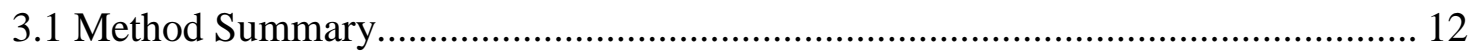

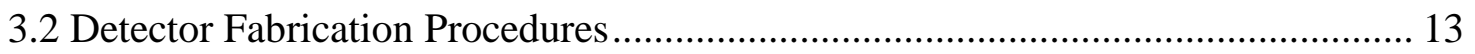

3.2.1 Chemical Cleaning Process.............................................................................. 13

3.2.2 Metallization Procedure ....................................................................... 14

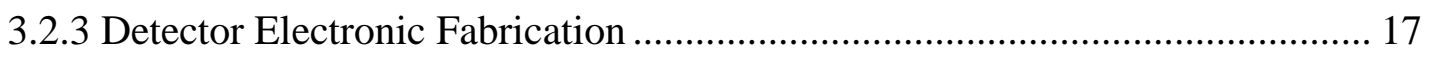

3.3 Electrical Characteristic of Diamond Detectors ……............................................. 18

3.3.1 Current-Voltage Characteristic ........................................................................ 18

3.3.2 Detector Calibration with Alpha Particles ......................................................... 19

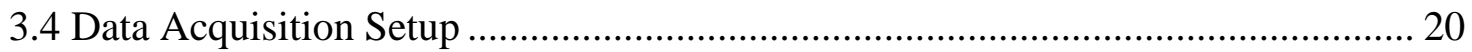

3.5 Gas Loading Experiment .................................................................................. 21 


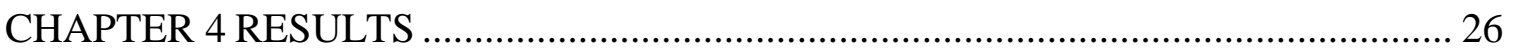

4.1 The CVD diamond detector characterization ……….......................................... 26

4.2 Current-Voltage Measurements ........................................................................... 28

4.3 Calibration with Alpha Particle Exposures................................................................ 31

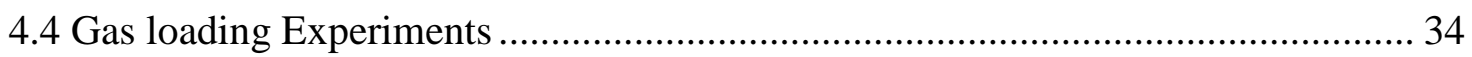

4.4.1 Experiment-1: Palladium-Deuterium (Ti/ $\mathrm{Pd}_{1-1}$ and $\left.\mathrm{Ti} / \mathrm{Pd}_{1-2}\right)$......................... 34

4.4.2 Experiment-2: Nickel-Hydrogen ................................................................ 38

4.4.3 Experiment-3: Nickel-Hydrogen ( $\mathrm{Ti} / \mathrm{Pt} / \mathrm{Au} / \mathrm{Ni}_{2-1}$ and $\left.\mathrm{Ti} / \mathrm{Pt} / \mathrm{Au} / \mathrm{Ni}_{2-2}\right)$............. 42

4.4.4 Experiment-4: Nickel-Hydrogen (Ti/Pt/Au/ $/ \mathrm{Ni}_{2-1}$ and $\left.\mathrm{Ti} / \mathrm{Pt} / \mathrm{Au} / \mathrm{Ni}_{2-2}\right)$............. 54

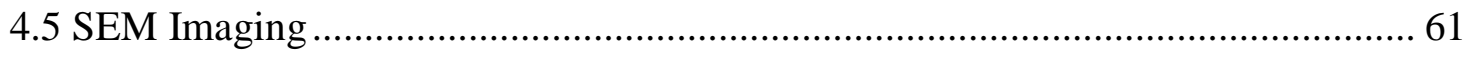

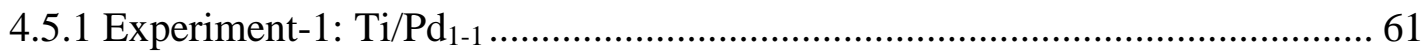

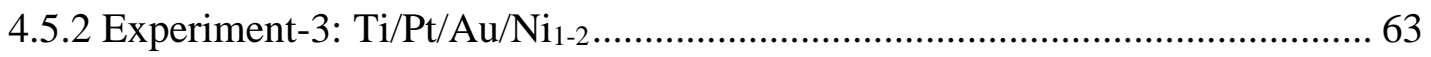

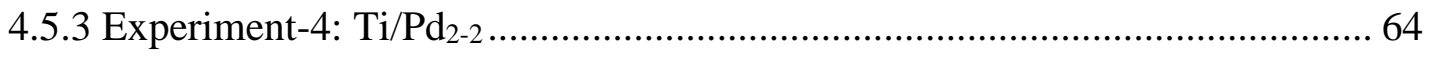

4.6 Detector Response to Radiations (Alpha and Beta)................................................. 65

4.6.1 Simulation with Alpha and Beta .................................................................. 65

4.6.2 Alpha exposure to CVD diamond detector ....................................................... 67

4.6.3 Beta exposure to CVD diamond detector ...................................................... 68

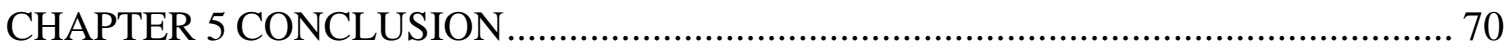

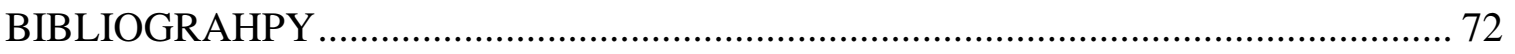

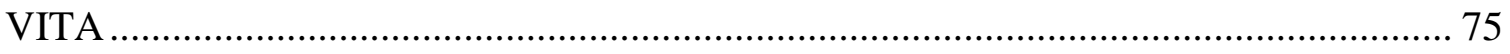




\section{LIST OF FIGURES}

Figure 1: The energy spectra from CVD diamond Ti/Pt/Au with $14.1 \mathrm{MeV}$ neutrons and 8.4 MeV alphas from ${ }^{12} \mathrm{C}\left(\mathrm{n}, \alpha_{0}\right){ }^{9} \mathrm{Be}$ reactions................................................................ 11

Figure 2: The energy spectrum from CVD diamond Ti/Pt/Au with a Pu/Be source........ 11

Figure 3: Electronic grade single crystal diamond samples............................................. 13

Figure 4: Electronic grade Diamond samples after metallization process.......................... 16

Figure 5: An illustration of radiation diamond detector. ............................................... 17

Figure 6: The diamond detector with thin film layers after mounting a CVD diamond packaged on a transistor header with aluminum wire bonding......................................... 18

Figure 7: Detector calibration with an alpha radiation source........................................... 20

Figure 8: Data acquisition diagram describing the electronics used in the diamond

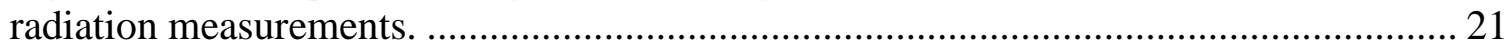

Figure 9: Gas loading chamber apparatus in Experiments 1-2......................................... 22

Figure 10: Gas loading chamber apparatus in Experiments 3-4...................................... 23

Figure 11: The diamond detector inside the six-cross chamber with viewports............... 23

Figure 12: The experimental setup: after the gas loading step where the chamber was placed inside the lead cave to eliminate noise from the surroundings............................... 24

Figure 13: The I-V curve of diamond detectors in Experiment-1. ................................... 28

Figure 14: The I-V curve of diamond detectors in Experiment-2. ................................... 29

Figure 15: The I-V curve of diamond detectors in Experiment-3. .................................. 29

Figure 16: The I-V curve of diamond detectors in Experiment-4. .................................. 30

Figure 17: The energy spectrum from the detector calibration in Experiment-1. ............. 32

Figure 18: The energy spectrum from the detector calibration in Experiment-2. ............ 32

Figure 19: The energy spectrum from the detector calibration in Experiment-3. ............ 33 
Figure 20: The energy spectrum from the detector calibration in Experiment-4.

Figure 21: Results from the $\mathrm{Ti} / \mathrm{Pd}_{1-1}$ detector during the first deuterium loading and continuous counting for 8 days a) the SCA count rate (counts/100ms) and b) the MCA energy spectrum.

Figure 22: Results from the $\mathrm{Ti} / \mathrm{Pd}_{1-1}$ detector during the second deuterium loading and continuous counting for five days a) the SCA count rate (counts/100ms) and b) the MCA energy spectrum (only 5-day data). 36

Figure 23: Results from the $\mathrm{Ti} / \mathrm{Pd}_{1-2}$ detector during the first deuterium loading and continuous counting for seven days a) the SCA count rate (counts/100ms) and b) the MCA energy spectrum.

Figure 24: Results from the Ti/Pt/Au/Ni $\mathrm{Ni}_{1-2}$ detector for the background, helium control gas, and hydrogen counting for 1 day a) the SCA count rate (counts/100ms) and b) the MCA energy spectrum.

Figure 25: The SCA count rate (counts/100ms) with hydrogen loading for 1 day (separated plot of Figure 24).

Figure 26: Results of $\mathrm{Ti} / \mathrm{Pt} / \mathrm{Au} / \mathrm{Ni}_{2-1}$ detector background, and first hydrogen loading for seven days a) the SCA count rate (counts/100ms) and b) the MCA energy spectrum..... 43

Figure 27: Results of $\mathrm{Ti} / \mathrm{Pt} / \mathrm{Au} / \mathrm{Ni}_{2-1}$ detector background, and second hydrogen loading for five days a) the SCA count rate (counts/100ms) and b) the MCA energy spectrum. . 46

Figure 28: Results of $\mathrm{Ti} / \mathrm{Pt} / \mathrm{Au} / \mathrm{Ni}_{2-1}$ background, and helium control gas loading for seven days a) the SCA count rate (counts/100ms) and b) the MCA energy spectrum..... 48

Figure 29: Results of $\mathrm{Ti} / \mathrm{Pt} / \mathrm{Au} / \mathrm{Ni}_{2-2}$ detector background, and hydrogen loading for seven days a) the SCA count rate (counts/100ms) and b) the MCA energy spectrum. 51

Figure 30: Results of $\mathrm{Ti} / \mathrm{Pt} / \mathrm{Au} / \mathrm{Ni}_{2-2}$ detector background, and deuterium loading for seven days a) the SCA count rate (counts/100ms) and b) the MCA energy spectrum..... 53

Figure 31: Results of $\mathrm{Ti} / \mathrm{Pd}_{2-2}$ detector background, and second deuterium loading for seven days a) the SCA count rate (counts/100ms) and b) the MCA energy spectrum..... 55

Figure 32: Results of $\mathrm{Ti} / \mathrm{Pd}_{2-2}$ detector background, and third deuterium loading for seven days a) the SCA count rate (counts/100ms) and b) the MCA energy spectrum............... 56

Figure 33:Results of $\mathrm{Ti} / \mathrm{Pd}_{2-2}$ detector background, and fourth deuterium loading for seven days a) the SCA count rate (counts/100ms) and b) the MCA energy spectrum..... 57 
Figure 34:Results of $\mathrm{Ti} / \mathrm{Pd}_{2-2}$ detector background, and helium control gas loading for seven days a) the SCA count rate (counts/100ms) and b) the MCA energy spectrum..... 58

Figure 35: SEM images of Ti/Pd $\mathrm{P}_{1-1}$ detector before and after gas loading in Experiment-1.

Figure 36: SEM images of $\mathrm{Ti} / \mathrm{Pd}_{1-1}$ detector using EDS to analyze the metal surface after deuterium gas loading in Experiment-1. 62

Figure 37: SEM images of Ti/Pt/Au/Ni1-2 detector before and after $\mathrm{He}, \mathrm{H} 2$, D2 gas loadings. 63

Figure 38: SEM images of Ti/Pd $2-2$ detector before and after $\mathrm{D} 2$ and He gas loadings. .. 64

Figure 39: The TRIM results of $\mathrm{Pu}-239$ alpha travel within a diamond plate. 65

Figure 40: The MCNP energy spectrum of alpha and beta particles interacting with carbon atoms in a diamond plate. 66

Figure 41: The energy spectra of Ti/Pd detector with Pu-239 with an applied voltage of 100-500V 67

Figure 42: The energy spectra of Ti/Pd detector with Am-241 with an applied voltage of 100-500V. 68

Figure 43: The energy spectra of Ti/Pd detector with Sr-90 at different applied voltages. 69

Figure 44: The energy spectra of Ti/Pd detector with Pm-147 at different source to detector distances. 69 


\section{LIST OF TABLES}

Table 1: Neutron interactions with natural carbon atoms .......................................... 10

Table 2: The metallization pattern on each CVD diamond size. .................................. 16

Table 3: CVD diamond plate dimensions and metallization layers used in this work. .... 27

Table 4: The leakage current of diamond detectors used in this work. .......................... 30

Table 5: The results of signal count rate of Experiment-1 (Ti/Pd detector-deuterium).... 38

Table 6: The results from SCA and MCA of Experiment-2 (Ti/Pt/Au/Ni detector-

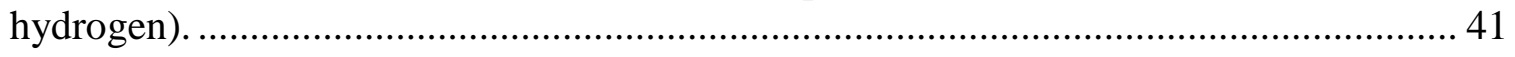

Table 7: The results of $\mathrm{Ti} / \mathrm{Pt} / \mathrm{Au} / \mathrm{Ni}_{2-1}$-first hydrogen loading from SCA and MCA. ...... 44

Table 8: The results of second hydrogen loading of Ti/Pt/Au/Ni $\mathrm{Ni}_{2-1}$ from SCA and MCA.

Table 9: The results of $\mathrm{Ti} / \mathrm{Pt} / \mathrm{Au} / \mathrm{Ni}_{2-2}$ helium control gas loading from SCA and MCA. 49

Table 10: The Ti/Pt/Au/Ni2-2 hydrogen loading results from SCA and MCA. ............... 52

Table 11: The results of $\mathrm{Ti} / \mathrm{Pd}_{2-2}$ Second deuterium loading from SCA and MCA. ........ 59

Table 12: The results of $\mathrm{Ti} / \mathrm{Pd}_{2-2}$ Third deuterium loading from SCA and MCA. ........... 60 


\begin{abstract}
In this work, the single crystal Chemical Vapor Deposition (CVD) diamond detectors were designed and fabricated to investigate and detect any possible charged particle and neutron emissions from gas-phase Low Energy Nuclear Reaction (LENR) experiments at room temperature. The diamond detectors were used in two experimental gas loading systems, palladium-deuterium, and nickel-hydrogen. Palladium and nickel were used as host materials. Thin film layers of $\mathrm{Ti} / \mathrm{Pd}$ and $\mathrm{Ti} / \mathrm{Pt} / \mathrm{Au} / \mathrm{Ni}$ were deposited on the CVD diamond plates by evaporation techniques to create an Ohmic contact. Electronic characterizations of the detectors were completed by current-voltage measurements and energy calibration with alpha particles. The simulation and experimental run of the diamond detector with alpha and beta radiations exposures were done to determine the response of the detector to charged particles.

The experimental results show that the diamond detectors observed and detected significant signal bursts from the gas loading experiments. The results from this work demonstrate that diamond detectors are suitable for alpha and beta radiation detection.
\end{abstract}




\section{CHAPTER 1}

\section{INTRODUCTION}

\subsection{Rationale and Background Research}

Nuclear energy is known as one of leading energy resources in the twentieth century. Nuclear energy provides about 10.9\% of world's electricity supply (2012 data) [1]. Both fission and fusion release energy by converting mass to energy, but they do in different ways. In theory, fusion reaction creates more energy per unit mass than fission but requires a very high temperature at the level of hundred million Kelvin [2]. Since there is a natural abundance of hydrogen isotopes for fusion reaction, and especially if it could occur at a lower temperature, fusion could be competitive with fission. In the 1990’s many studies claimed that fusion reactions could occur at low energies. These experiments and claims are part of the "Low Energy Nuclear Reaction" or LENR literature. There were many reports of results such as the production of excess heat, helium, charged particles, and very low levels of neutrons [3]. Several studies of in gasphase experiments were more encouraging than electrochemical techniques. The observations of the so called LENR effect have always suffered from consistency of results and the sensitivity of detectors used in the experiment to identify specific reaction products. In this study, the development of a highly sensitive radiation sensor was undertaken which could detect low production rates of ions, electrons or neutrons. Thus, if even low levels of particles were produced due the postulated LENR effect, the radiation sensor would be able to detect the particles. 
Many types of radiation detectors have been discovered for the detection of nuclear reaction products. Diamond is one of the most promising materials used to create nuclear radiation detectors. In the early 1920’s high-grade natural diamonds were selected to use as UV detectors. Later as technology advanced and the special characteristics of diamond improved, compared to other known materials, electronic grade diamonds was utilized in radiation, thermal, dielectric and optical applications [4, 5]. The unique properties of diamond which allows it to detect ions, electrons and neutrons at low levels, makes it a promising detector to identify the nature of the reaction(s) observed in LENR experiments.

\subsection{Objectives}

The purpose of this research is to develop rugged diamond radiation detectors to detect charged particles (light ions, heavy ions, electrons) and neutrons. This work demonstrated a development of new metallization formulas for diamond radiation detectors with reliable contacts with the highest sensitivity so that they can be used under a highpressure deuterium or hydrogen gas environment as a diagnostic for the reported gas-phase LENR phenomena which reportedly produces ionizing radiation emissions in experiments with hydrogen and deuterium gas loading used the host metals of palladium and nickel. Palladium and nickel have been used for some of the most prominent observations made in gas phase LENR experiments. These gas phase experiments occur at room temperature and at high pressures of deuterium for palladium and hydrogen for nickel. The diamond sensors built for these studies were so sensitive that extremely low levels of ions, electrons and neutrons production could be identified. Thus, if the gas phase LENR experiments 
produced any of these common emissions, which are characteristic of nuclear reactions, then the diamond sensor would be capable of providing the evidence for a nuclear basis for the LENR reaction. 


\section{CHAPTER 2}

\section{LITERATURE REVIEW}

\subsection{Low energy nuclear reaction (LENR)}

At present, nuclear energy is mainly used in the power industry as a producer of

electricity from fission reactions. Fission energy is produced by a nuclear fission reaction which splits a heavy nuclide into lighter nuclei. Fusion, in contrast, is a nuclear reaction that occurs when two or more light nuclei fuse together to form an element with a higher atomic number. Fusion is as well-known in that is the energy source for the sun and stars. In theory, a fusion reaction releases more energy per reaction than fission [6]. However, fusion energy only occurs at the extremely high temperature (>of $10 \mathrm{keV}$ ). Several wellknown nuclear fusion processes $[6,7]$ are shown below;

$$
\begin{aligned}
& \mathrm{D}+\mathrm{D} \rightarrow{ }^{3} \mathrm{He}(0.82 \mathrm{MeV})+\mathrm{n}(2.45 \mathrm{MeV}) \\
& \mathrm{D}+\mathrm{D} \rightarrow{ }^{3} \mathrm{H}(1.01 \mathrm{MeV})+\mathrm{p}(3.02 \mathrm{MeV}) \quad \text { (ratio 50\%) } \\
& \left.\mathrm{D}+\mathrm{D} \rightarrow{ }^{4} \mathrm{He}(73.7 \mathrm{keV})+\gamma(23.8 \mathrm{MeV}) \quad \text { (ratio } 10^{-6}\right) \\
& \mathrm{D}+\mathrm{T} \rightarrow{ }^{4} \mathrm{He}(3.5 \mathrm{MeV})+\mathrm{n}(14.1 \mathrm{MeV}) \\
& \mathrm{D}+{ }^{3} \mathrm{He} \rightarrow{ }^{4} \mathrm{He}(3.6 \mathrm{MeV})+\mathrm{n}(14.7 \mathrm{MeV})
\end{aligned}
$$

Where $\mathrm{D}$ represents deuterium atom and $\mathrm{T}$ is tritium atom.

In 1989, Martin Fleischmann and Stanley Pons [8] at the University of Utah reported unusual heat generation which they believed was due to significant energy release from the fusion of deuterium nuclei without application of high energy and they described this as “cold fusion.” In the same year, Jones et al. [9] at Brigham Young 
University reported a small but significant neutron flux during low voltage infusion of deuterium into gas loaded titanium.

Cold fusion received a great deal of criticism because the expected products of deuterium fusion (Equations 1 to 3) were not observed in the expected quantities. The observations of excess heat production from electrochemical-type cells (as used by Pons and Fleishman) and in gas phase loading experiments persisted throughout the years with the scientific community highly divided as to the validity of the observations. Eventually, the postulated reaction was call a "Low Energy Nuclear Reaction” or LENR since evidence of products from fusion reactions were not found in substantial quantities and could not justify this postulated phenomenon being called fusion. The definition of LENR is a reaction that occurs under certain conditions in specific solids and metal hydrides and produces excess heat (at power levels beyond the capability of chemical reactions), helium, charged particles, and occasionally very lows level of neutrons. Because the observed temperature rise (excess heat) was higher than could be accounted for by known chemical processes, it was postulated that nuclear reactions of some sort might explain the excess energy.

Several experiments reported evidence of low energy nuclear reaction mainly using electrochemical experiments. Additionally, the gas phase technique was developed, and a number of experimental results indicated that the gas loading technique appeared to be more promising than the electrochemical method because it had better reproducibility. Various host metals were studied to allow the postulated LENR reactions to occur such as titanium, nickel, palladium and some superconducting ceramics. Experiments have been 
performed to specifically determine what reaction is responsible for the postulated LENR phenomena.

In this review, interesting experimental results from gas phase LENR experiments, especially with palladium and nickel metal hosts, are summarized. Also, an advanced technology using a diamond-based detector is outlined as a diagnostic to help determine the mechanism(s) of the postulated LENR reaction has a nuclear basis.

In this work with deuterium gas loading, from Equations 1 to 3, if D-D fusion were the energy producing mechanism, the highest probability products would be neutrons, protons, tritium and helium-3. Moreover, the tritium product decays with a 12.4-year half-life to form ${ }^{3}$ He. For a nickel-hydrogen system, a D-D reaction is not possible. Rossi and Focardi [10-13] reported an exothermic reaction between hydrogen and nickel. Rossi claimed that nickel behaves like a catalyst and breaks the bi-atomic molecule of hydrogen $\left(\mathrm{H}_{2}\right)$ into a single atom. Then the hydrogen atoms diffuse into the nickel lattice, resulting in a nickel-hydrogen fusion that results in a probable transmutation of nickel nucleus into a copper nucleus. The process is shown in Equation 6 below. Focardi et al. claimed that "the two cells ran about 300 days and produced an excess energy of $600 \mathrm{MJ}$ and $900 \mathrm{MJ}$, respectively” [13]. However, many researchers believe that this reaction is impossible, and there is no evidence that can support this claim.

$$
{ }^{58} \mathrm{Ni}+\mathrm{p} \rightarrow{ }^{59} \mathrm{Cu}+\text { energy }
$$

Significant experimental results in gas phase LENR began in 1989 following the Pons and Fleischmann claim. Fralick et al. [14] at NASA published an investigation 
showing excess heat in a gas loading experiment. They simply loaded a hydrogen purifier consisting of a palladium tube heated to $370^{\circ} \mathrm{C}$ and loaded with deuterium and hydrogen (at 1.4 MPa or around $200 \mathrm{psi}$ ), separately. They observed a temperature rise for a deuterium gas load but no temperature change in the case of hydrogen. However, no significant neutrons were observed which is inconsistent with what is known about the DD fusion reaction.

In 1998, Iwamura et al. [15] performed a series of experiments which used a particular multi-layer chip of $\mathrm{Pd}-\mathrm{CaO}$ with a deposition of $0.1 \mathrm{~mm}$ thick palladium on the surface. They allowed deuterium gas to continuously permeate the target by gas loading at about atmospheric pressure on one side of the target and a high vacuum on the other side. They observed excess heat generation and x-ray emissions. In 2000, similar to many other researchers, Arata and Zhang [16] initially ran their experiments in an electrolytic cell with the so-called double structure palladium cathode. They ran two experiments with this unique using a loading of water $\left(\mathrm{H}_{2} \mathrm{O}\right)$ and heavy water $\left(\mathrm{D}_{2} \mathrm{O}\right)$. They reported the observation of excess heat and helium-4 production. They also published work on experimental results using deuterium gas loading into nano-sized palladium powder imbedded inside a $\mathrm{ZrO}_{2}$ matrix and reported excess heat and helium generated by a postulated deuterium-palladium reaction [17].

Prelas and his students reported intense neutron bursts after rapid temperature cycling of deuterated titanium chips from an experiment ran in 1991 [18]. It was believed that if the temperature of the titanium increased rapidly enough, a very high deuterium pressure could occur within defects of the titanium crystal lattice that could generate 
sufficient pressure and temperature to cause the deuterium to fuse before the atoms could diffuse out of the crystal.

\subsection{Diamond Radiation Detector}

Diamond has strong covalent chemical bonds of carbon atoms. It is the highest hardness material because of its face-centered cubic structure. Natural diamond characteristic interactions with ionizing radiation were studied in the early 1920's [4]. During the 1990's synthetic diamonds, with high purity electronic grade, were made by chemical vapor deposition (CVD) techniques for applications including in radiation detectors. Many studies reported that diamond radiation detectors could detect ionizing radiations in the energy range from $5.5 \mathrm{eV}$ to $\mathrm{GeV}$. In other words diamond can cover UV photons, x-rays, gammas, alphas, charged particles, neutrons and cosmic rays [19, 20]. Diamond has a wide energy band-gap at $5.5 \mathrm{eV}$ [21]. Therefore, it has negligible dark current noise at room temperature without cooling. Diamond has a high mobility of free charges that gives it fast response in signal collection and detection.

Diamond has a high radiation tolerance [22]. CVD diamond is damaged similarly to other semiconductor materials, but the effects of the damage are very different regarding the change in its electronic properties. There is, in fact, no significant effect that has been observed in the leakage current before and after irradiation exposure [23]. This radiation hardness property means that diamond devices would have longevity in high radiation environments. CVD diamond is reported as a suitable detector for intermediate and high-energy heavy-ion measurement [24, 25]. 
There are two types of electronic grade CVD diamond: single crystal and polycrystalline. The difference between them is that the polycrystalline is made from large single crystal grains, and it tends to exhibit poor electronic properties as compared to the single crystal [26]. Electronic grade single crystal diamond is a new and promising type of semiconductor radiation detector material, and it has been studied to investigate LENR. Its superior properties make it an ideal material to detect potential neutrons and charged particles if nuclear based reactions are indeed the mechanism for LENR.

Diamond can be used as a radiation detector due to its semiconducting properties. It is suitable for both charged particle and neutron detection. Regarding neutron detection, the interactions between neutrons and carbon atoms are shown in Table 1. Charged particles and photons can be detected by diamond through the mechanism of electron-hole pairs generated within its energy band structure as charged particles slow down inside it. The average electron-hole pair created per total energy deposition is 0.42 $\mathrm{eV}$ for a diamond. CVD diamond was tested with protons between 55-220 MeV and it showed a high efficiency of $96.8 \%$ at $200 \mathrm{MeV}$ and $99.9 \%$ at $55 \mathrm{MeV}$ [27]. It is suitable as a fast signal response charged particle detector [28]. 
Table 1: Neutron interactions with natural carbon atoms [29-31].

\begin{tabular}{|c|c|c|c|}
\hline $\begin{array}{l}\text { Reaction } \\
\text { number }\end{array}$ & Reaction & $\begin{array}{l}\text { Q-Value } \\
(\mathrm{MeV})\end{array}$ & $\begin{array}{c}\text { Threshold } \\
\text { Energy } \\
(\mathrm{MeV})\end{array}$ \\
\hline 1 & ${ }^{12} \mathrm{C}(\mathrm{n}, \gamma)^{13} \mathrm{C}$ & 4.946 & 0 \\
\hline 2 & ${ }^{12} \mathrm{C}(\mathrm{n}, \mathrm{el}){ }^{12} \mathrm{C}$ & 0 & 0 \\
\hline 3 & ${ }^{12} \mathrm{C}\left(\mathrm{n}, \mathrm{n}^{\prime}\right){ }^{12} \mathrm{C}^{*}$ & - & $4.450^{2}$ \\
\hline 4 & ${ }^{12} C\left(n, n^{\prime}\right)^{12} C^{*}(3 \alpha)$ & -7.275 & 7.886 \\
\hline 5 & ${ }^{12} \mathrm{C}\left(\mathrm{n}, \mathrm{n}^{\prime}\right){ }^{12} \mathrm{C}^{*}(3 \alpha)$ & - & $9.64^{2}$ \\
\hline 6 & ${ }^{12} \mathrm{C}\left(\mathrm{n}, \mathrm{n}^{\prime}\right){ }^{12} \mathrm{C}^{*}(3 \alpha)$ & - & $10.8^{2}$ \\
\hline 7 & ${ }^{12} C\left(n, n^{\prime}\right)^{12} C^{*}(3 \alpha)$ & - & $11.8^{2}$ \\
\hline 8 & ${ }^{12} \mathrm{C}\left(\mathrm{n}, \mathrm{\alpha}_{0}\right)^{9} \mathrm{Be}$ & -5.701 & 6.181 \\
\hline 9 & ${ }^{12} \mathrm{C}\left(\mathrm{n}, \alpha_{1}\right)^{9} \mathrm{Be}^{*}$ & -7.381 & 8.800 \\
\hline 10 & ${ }^{12} \mathrm{C}(\mathrm{n}, \mathrm{p})^{12} \mathrm{~B}$ & -12.59 & 13.64 \\
\hline 11 & ${ }^{12} \mathrm{C}(\mathrm{n}, \mathrm{d})^{11} \mathrm{~B}$ & -13.73 & 14.89 \\
\hline 12 & ${ }^{12} \mathrm{C}(\mathrm{n}, \mathrm{np}){ }^{11} \mathrm{~B}$ & -15.96 & 17.30 \\
\hline 13 & ${ }^{13} \mathrm{C}(\mathrm{n}, \gamma){ }^{14} \mathrm{C}$ & 8.176 & 0 \\
\hline 14 & ${ }^{13} \mathrm{C}(\mathrm{n}, \mathrm{el}){ }^{13} \mathrm{C}$ & 0 & 0 \\
\hline 15 & ${ }^{13} \mathrm{C}(\mathrm{n}, \alpha)^{10} \mathrm{Be}$ & -3.835 & 4.132 \\
\hline 16 & ${ }^{13} \mathrm{C}(\mathrm{n}, \mathrm{n} \alpha){ }^{9} \mathrm{Be}$ & -10.65 & 11.47 \\
\hline 17 & ${ }^{13} \mathrm{C}(\mathrm{n}, \mathrm{t})^{11} \mathrm{Be}$ & -12.42 & 13.39 \\
\hline 18 & ${ }^{13} \mathrm{C}(\mathrm{n}, \mathrm{p})^{13} \mathrm{~B}$ & -12.66 & 13.64 \\
\hline 19 & ${ }^{13} \mathrm{C}(\mathrm{n}, \mathrm{d})^{12} \mathrm{~B}$ & -15.31 & 16.50 \\
\hline 20 & ${ }^{13} \mathrm{C}(\mathrm{n}, \mathrm{np})^{12} \mathrm{~B}$ & -17.53 & 18.89 \\
\hline
\end{tabular}

Lukosi et al. [32] reported using Monte Carlo simulations of electronic grade CVD diamond (with Ti/Pt/Au metallization) with mono-energetic energy 14.1 MeV neutrons which induced the product of $8.4 \mathrm{MeV}$ alphas from neutron interaction with carbon- the ${ }^{12} \mathrm{C}\left(\mathrm{n}, \alpha_{0}\right){ }^{9} \mathrm{Be}$ reaction. The energy spectra are shown in Figure 1, and it can clearly distinguish between the broad energy spectrum of neutrons and a single peak from indirect alpha particle emission. They also presented experimental results of the expected 
pulse height spectrum with a single diamond plate using a plutonium/beryllium source $(\mathrm{Pu} / \mathrm{Be})$ as seen in Figure 2.

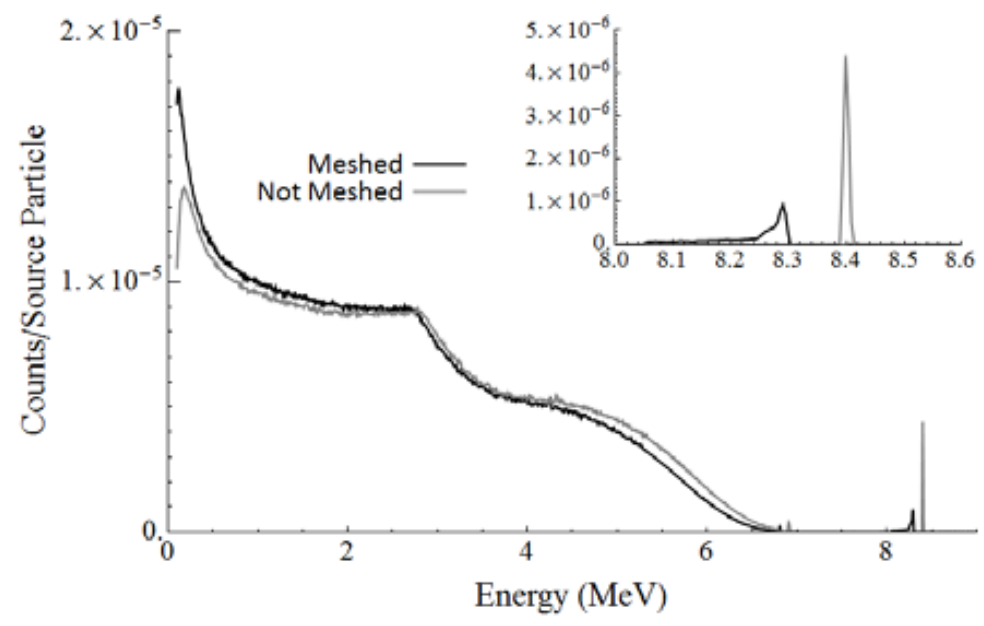

Figure 1: The energy spectra from CVD diamond Ti/Pt/Au with $14.1 \mathrm{MeV}$ neutrons and 8.4 MeV alphas from ${ }^{12} \mathrm{C}\left(\mathrm{n}, \alpha_{0}\right){ }^{9} \mathrm{Be}$ reactions.

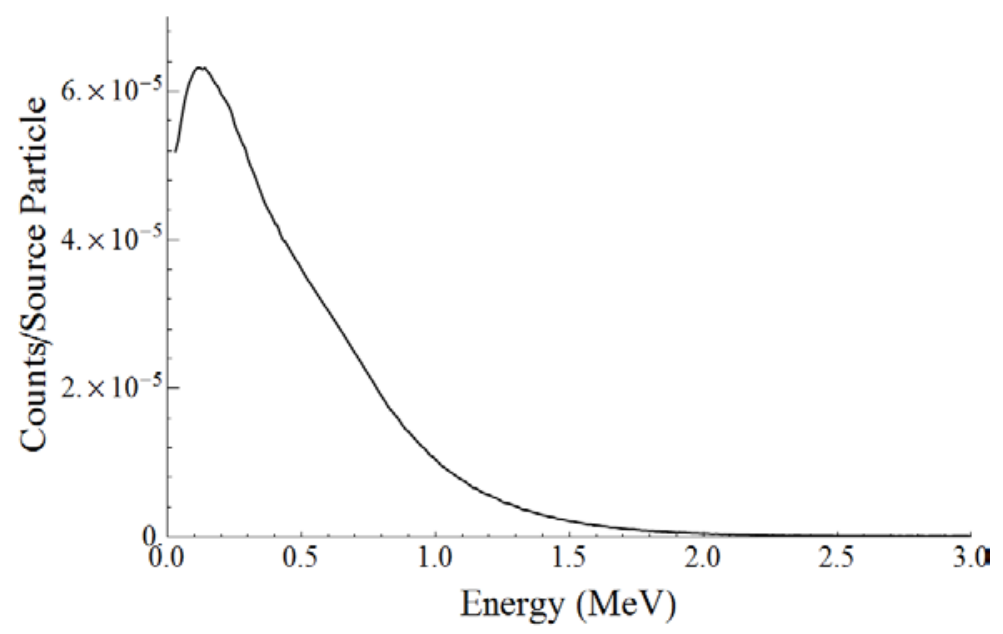

Figure 2: The energy spectrum from CVD diamond Ti/Pt/Au with a Pu/Be source. 


\section{CHAPTER 3}

\section{RESEARCH METHODOLOGY}

\subsection{Method Summary}

Each cleaned diamond chip was processed using metallization to deposit desired thin film layers on both sides of the chip to form a detector. The detector was imaged by a scanning electron microscope (SEM) to obtain before experiment images of the detector's metallization surface. The diamond then was mounted on a transistor head and turned into an electronic detector by wire bonding. A current-voltage characterization was done to determine an optimum voltage for operation of the ohmic contact. The diamond detector later was calibrated by alpha radiation exposure using alpha spectrometry and this experiment determined the optimum voltage that provided a complete charge collection. The experiment started by placing the diamond detector inside a sealed metal chamber using a BNC connection. First, the detector was connected to the counting system and a counting procedure was initiated for determining the background count under vacuum. Second, helium gas was loaded into the metal chamber as a control gas and the counting procedure was implements to generate counting data. Third, the detector was pumped down again to remove all residue gas before hydrogen or deuterium gas was loaded to initiate the gas phase LENR process. There are four experimental results presented in this work, two with palladium-deuterium loadings (Experiment-1 and 4) and two with nickel-hydrogen loadings (Experiment-2 and 3).

It is noted that a heat tape was required during the pumping down process to bake out the chamber. A thermocouple connected to an analog to digital converter and recorded 
using the Labview ${ }^{\mathrm{TM}}$ program was placed in the metal chamber for temperature measurement. A helium-3 neutron detector was placed close to the experiment in order to observe possible neutrons emission and partly as a safety measure.

\subsection{Detector Fabrication Procedures}

Electronic grade single crystal plates with the highest purity crystals commercially available were acquired from Element Six with lateral dimensions of 3x3x0.5 mm, 4x4x0.5 mm, 4.5x4.5x0.5 mm, (they are $50 \mu \mathrm{m}$ thick as seen in Figure 3). The specific chemical process used to confirm that all diamond samples were cleaned is given below.

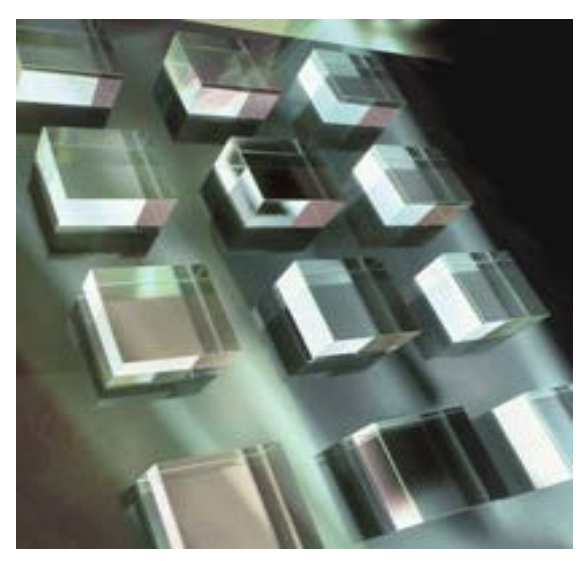

Figure 3: Electronic grade single crystal diamond samples.

\subsubsection{Chemical Cleaning Process}

1. To remove metals from the sample surface: boil in Aqua Regia (HCL: $\mathrm{HNO}_{3}$ at ratio $3: 1$ ) for thirty minutes at $100^{\circ} \mathrm{C}$. Rinse with deionized (DI) water. 
2. To remove particles and organic contamination from the sample surface: boil in Base Piranha $\left(\mathrm{NH}_{4} \mathrm{OH}: \mathrm{H}_{2} \mathrm{O}_{2}: \mathrm{H}_{2} \mathrm{O}\right.$ at ratio 1:1:5) for thirty minutes at $100^{\circ} \mathrm{C}$. Rinse with deionized (DI) water.

3. To remove graphitic top layers and partially oxygenate the sample surface: boil in Piranha $\left(\mathrm{H}_{2} \mathrm{SO}_{4}: \mathrm{H}_{2} \mathrm{O}_{2}\right.$ at ratio $\left.4: 1\right)$ for thirty minutes at $120^{\circ} \mathrm{C}$. Rinse with deionized (DI) water.

4. To additionally oxygenate the sample surface: Boil in $\mathrm{HNO}_{3}: \mathrm{H}_{2} \mathrm{SO}_{4}: \mathrm{HCLO}_{4}$ (1:1:1) for thirty minutes at $150^{\circ} \mathrm{C}$. Rinse with deionized (DI) water.

5. Store in a dry, clean and sealed metal chamber.

\subsubsection{Metallization Procedure}

It is noted that a clean sample surface created by the above chemical procedure will provide for high surface resistivity and a good adhesion of the thin metal layers. In addition, each electronic grade CVD diamond sample was also cleaned by plasma cleaner before performing a metallization to reassure that the sample was uncontaminated. After the cleaning procedure, the samples were transferred to the metallization chamber or the evaporator which was operated in high vacuum and located inside a class 100 clean room. The evaporator was pumped down for 24 hours at a level below one mtorr before beginning the metallization process. Regarding the metallization procedure, the first electrode layer of titanium attached to the diamond surface was deposited by a thermal sputtering technique to create a good adhesive contact with the diamond [6]. To avoid frequently unloading and loading sample to the metallization chamber, which would 
increase the risk of surface contamination, the rest of metal layers were deposited over the titanium layer by thermal evaporation.

Two stainless steel plates were used as masks along with Kapton tape to fix the diamond chips position in place inside the evaporator. The thickness monitor probe model SQM-160 was placed inside the metallization chamber for thickness measurement during the metal deposition process. The sputtering evaporation was conducted using a Kurt J Lesker 2 inch Torus RF sputtering gun which was mounted inside the evaporator. It required a straight-line direction from the gun to the sample holder. In thermal evaporation, the materials were separately put in tungsten boats and heated until the metal boiled and evaporated to form thin film layers on the diamond surface. A sample holder rotated with an optimum rotation speed during evaporation to achieve a good homogeneity of the material deposition. It is noted that in general the thickness monitor should be placed close to the sample holder. However, due to this metallization pattern which required both sputtering and thermal evaporation in the evaporator, the sample holder position was manipulated to reach an optimum position for both techniques. After metallization of the first side was finished, the diamond samples were removed from the evaporator, then the diamond chips were flipped over and re-masked for the second side metallization. Figure 4 shows the samples after metallization process.

For the palladium-deuterium experiment, the thin film layers of titanium, and palladium were deposited on both sides of the diamond chip. The first metal layer acts as an electrode contact on the diamond surface, and the palladium layer, which is on top of the titanium layer, is a metal host for palladium formation. The nickel-hydrogen 
experiment needed more metallization layers due to a prevention of titanium and nickel metal diffusion, therefore, diffusion barriers of gold and platinum were added in this experiment. The function of gold is to avoid oxidation while the platinum prevents interdiffusion between titanium and gold [7]. The nickel, which is used as a metal host in the gas loading experiment was formed as the top layer over the platinum and gold layers. The thin layer electrical contacts were between 2 to $3.5 \mathrm{~mm}$ in diameter depending on the diamond plate size as given in Table 2. The final metal metallization thickness was 50/150 nm of Ti/Pd and 50/5/20/150 nm of Ti/Pt/Au/Ni.

Table 2: The metallization pattern on each CVD diamond size.

\begin{tabular}{|c|c|}
\hline Sample area $\left(\mathrm{mm}^{2}\right)$ & Metal diameter $(\mathrm{mm})$ \\
\hline $3 \times 3$ & 2 \\
\hline $4 \times 4$ & 3 \\
\hline $4.5 \times 4.5$ & 3.5 \\
\hline
\end{tabular}

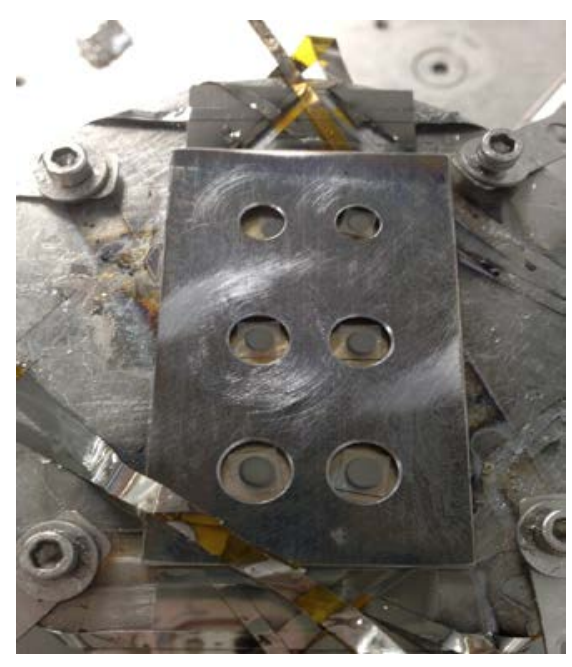

Figure 4: Electronic grade Diamond samples after metallization process. 


\subsubsection{Detector Electronic Fabrication}

Each metallized diamond sample was cleaned with DI water and was completely dried at room temperature. The diamond was then mounted by using silver paste on a transistor head outline header with two pins which pass through the metal plate and a glass seal. It turned into an electronic CVD diamond detector by wire bonding with a 25 $\mu \mathrm{m}$ diameter aluminum (1\% silicon) wire as shown in Figure 5 and 6 . The diamond detector had two aluminum wire bonds. One was a ground bond that was connected the transistor head pin to the ground; the other bond was a signal bond that was connected from the exposed palladium surface of the diamond detector to the high voltage pin.

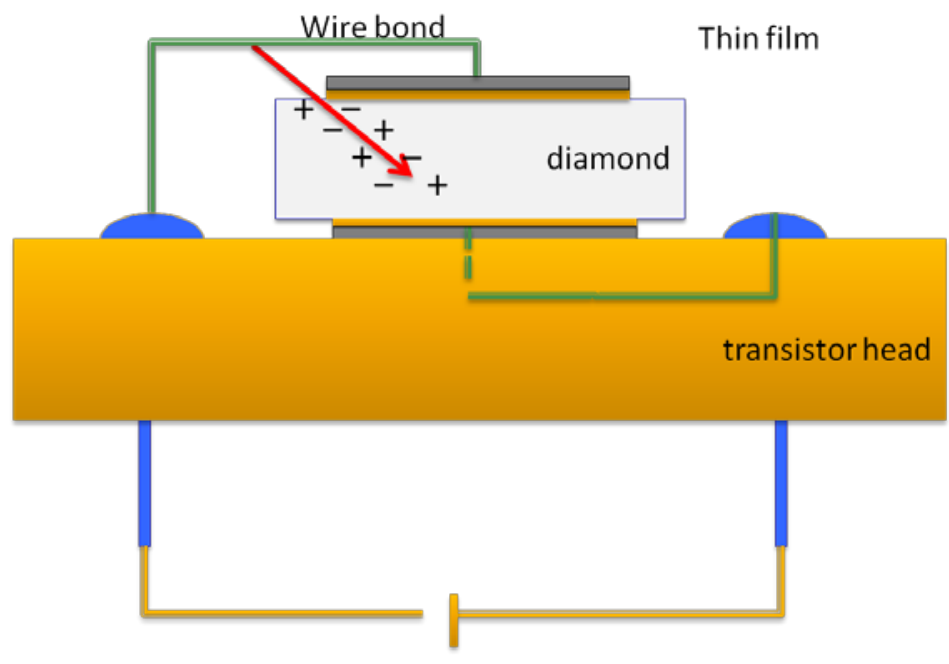

Figure 5: An illustration of radiation diamond detector. 


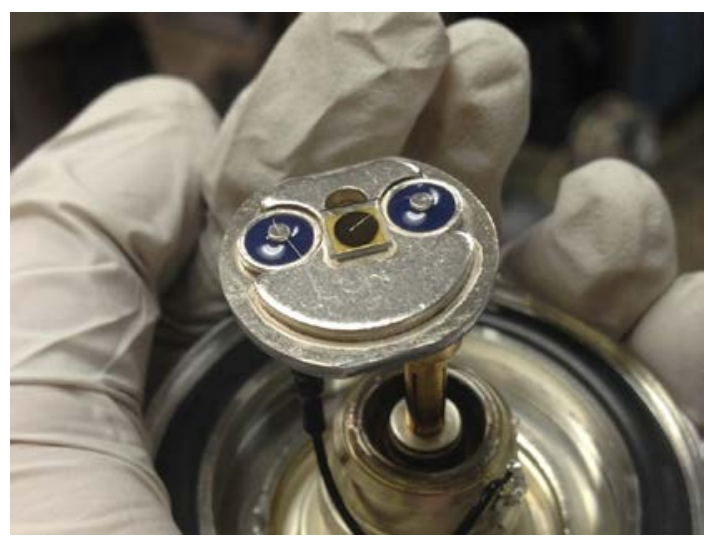

Figure 6: The diamond detector with thin film layers after mounting a CVD diamond packaged on a transistor header with aluminum wire bonding.

\subsection{Electrical Characteristic of Diamond Detectors}

\subsubsection{Current-Voltage Characteristic}

An I-V measurement needed to be done on each diamond detector to characterize its electrical properties such as its linearity, resistance and leakage current. This step also estimates noise from the detector, which therefore indicates the lower limit of detection of the diamond detector system. After wire bonding the detector, a current-voltage characterization using Keithley model 6487 picoammeter was done to determine an optimal operational voltage region for the Ohmic contact. Voltages between minus $500 \mathrm{~V}$ to plus $500 \mathrm{~V}$ with a step voltage at $25 \mathrm{~V}$ were supplied through the detector. To eliminate noise from the surrounding, the detector was put in a metal box while performing an I-V test. The plot data between output current and applied voltage provided the optimum voltage that should apply on the detector. 


\subsubsection{Detector Calibration with Alpha Particles}

Diamond detector calibration was done to test the performance of charged particle detection and obtain an energy calibration. The calibration was conducted by exposing the detector to alpha radiation using a $5.245 \mathrm{MeV}$ plutonium-239 disk source with around 363,000 cpm activity inside an alpha spectrometer under a vacuum environment. As mentioned previously regarding Table1, promising interactions of neutrons with carbon atoms can be ascertained measurements of alpha particle emission. This procedure was also used to determine the selected voltage that provides a complete charge collection, and it avoids the polarization effect [8].

The detector was mounted through a BNC-SHV feed through inside a Canberra quad alpha spectrometer model 7404 under high vacuum to prevent energy loss due to particle collisions with air and to eliminate noise from the surroundings. The detector was connected to the counting system of an Ortec 142PC preamplifier, Canberra 2026 spectroscopy amplifier, Ortec 459 bias supply and Genie 2000 for data acquisition. The detector was grounded by contacting the wall inside the alpha spectroscopy housing as seen in Figure 7. The Pu-239 source was placed near the detector at approximately $5 \mathrm{~mm}$. The detector counted alpha charged particles with varying voltages between 100-500 V at the same counting settings. 


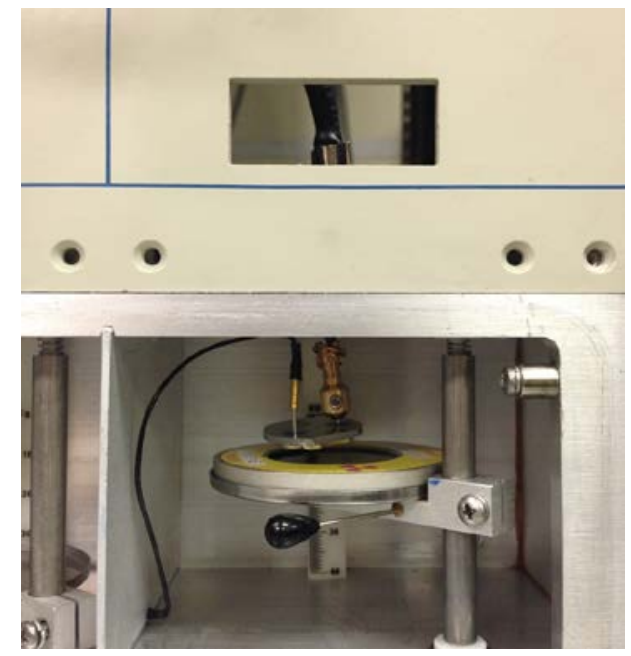

Figure 7: Detector calibration with an alpha radiation source.

The detector calibration was also done to observe a complete charge collection by acquiring the differing alpha spectrums versus different applied. The results from the current-voltage characteristic curve and the energy spectrum utilized an optimum selected voltage to run the detector in the experiment.

\subsection{Data Acquisition Setup}

The counting system consists of count rate data collected from a single channel analysis (SCA) and an energy spectrum from a multichannel analysis (MCA) as shown in Figure 8. Again, the detector was connected to the counting system of an Ortec 142PC preamplifier, Canberra 2026 spectroscopy amplifier, Ortec 459 bias supply. The voltage applied to the detector was between +200 and $+300 \mathrm{~V}$ during experimental runs. The signals from the diamond detector were amplified, shaped and then were split to the SCA and MCA. The count rate output to the SCA was sent to LabVIEW via a model 6602 
counting card while the output to the MCA was sent to Canberra's Genie 2000

acquisition software. This configuration allowed us the capability to define both the counting rate versus time and the collected energy spectrum to determine if large count rate spikes were observed or were a result of electronic noise.

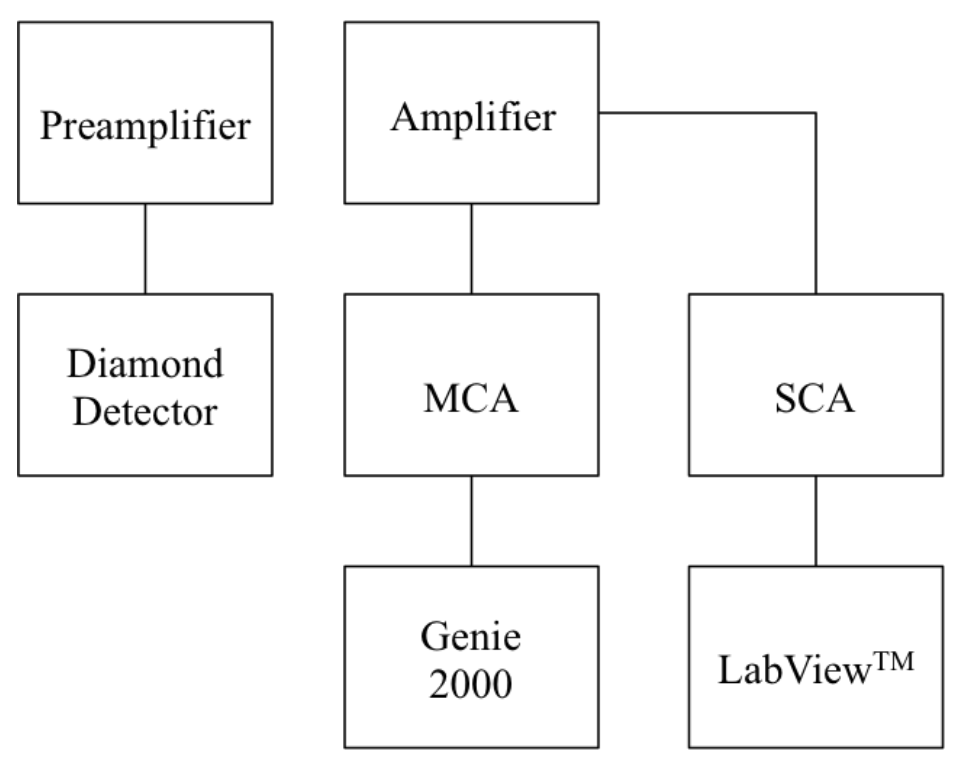

Figure 8: Data acquisition diagram describing the electronics used in the diamond radiation measurements.

\subsection{Gas Loading Experiment}

In Experiment-1 and 2, each detector was mounted through an SHV feed through connected to a sealed stainless steel chamber with a gas inlet/outlet, a pressure gauge and a pressure reader that attached to a pump as shown in Figure 9. In Experiment-1 and 2, a diaphragm pump was used to pump down the chamber to an optimum vacuum level $10^{-3}$ torr before deuterium or hydrogen loading. The chamber can handle up to 200 psi. A thermocouple was placed outside the chamber if needed. After all parts and the detector 
had been connected, the chamber was placed inside a three-inch thick wall lead cave for noise elimination. The chamber was pumped down for at least one day before hydrogen or deuterium gas loading. Then, hydrogen or deuterium was load into the chamber, which was under vacuum, and was pressurized for 15 minutes before disconnected the gas tank.

It is noted that the remaining oxygen or any other gases inside the loading chamber will interrupt or block hydrogen or deuterium atoms to diffuse into the host lattice and effect the gas-loading ratio. Therefore, in Experiment-3 and 4, the experimental setup was improved with a new vacuum system as shown in Figure 10. A diffusion pump which can reach up to $10^{-5}$ torr was introduced to efficiently remove any gas residues before loading hydrogen or deuterium. In addition, a six-cross stainless steel chamber with a glass viewport window was added to allow convenient observations of the detector while it was inside the chamber as seen in Figure 11. The experimental setup is shown in Figure 12.

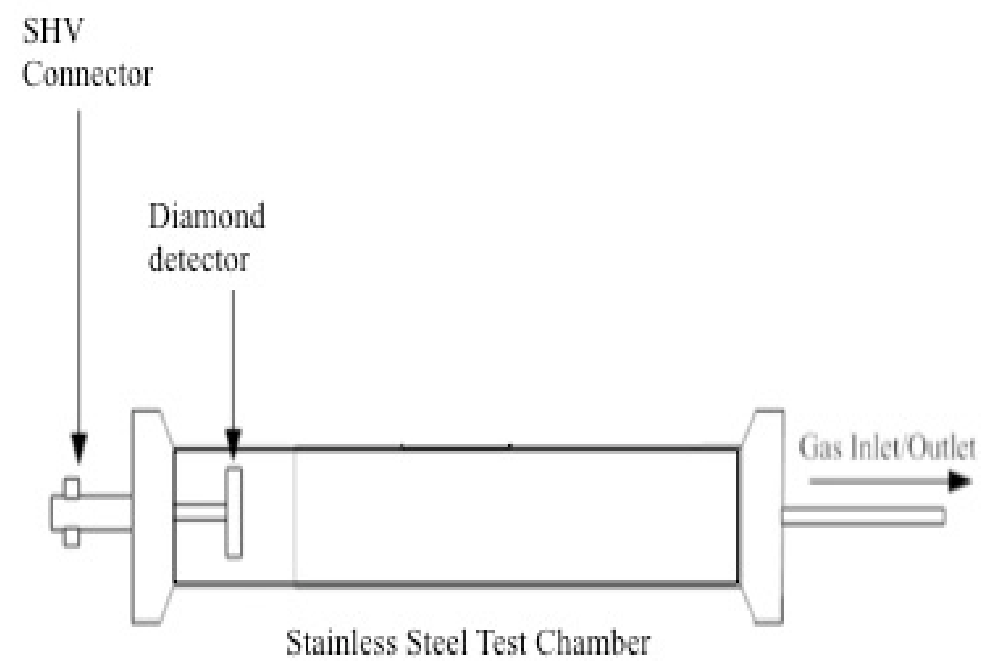

Figure 9: Gas loading chamber apparatus in Experiments 1-2. 


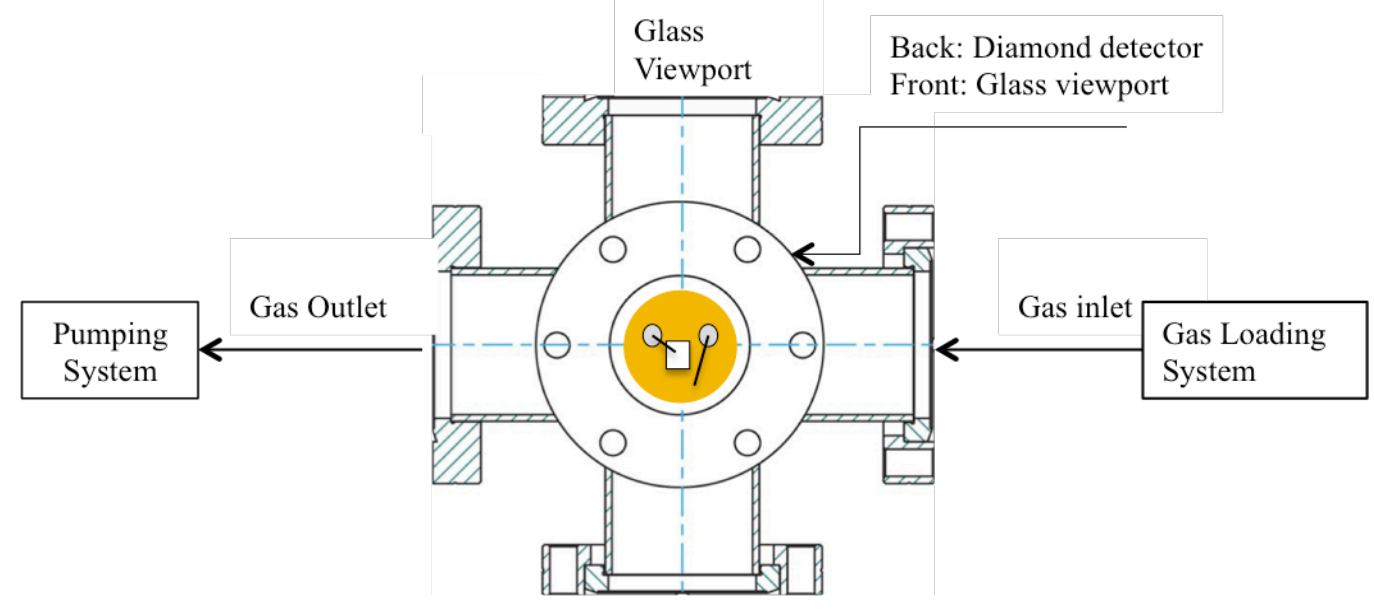

Figure 10: Gas loading chamber apparatus in Experiments 3-4.

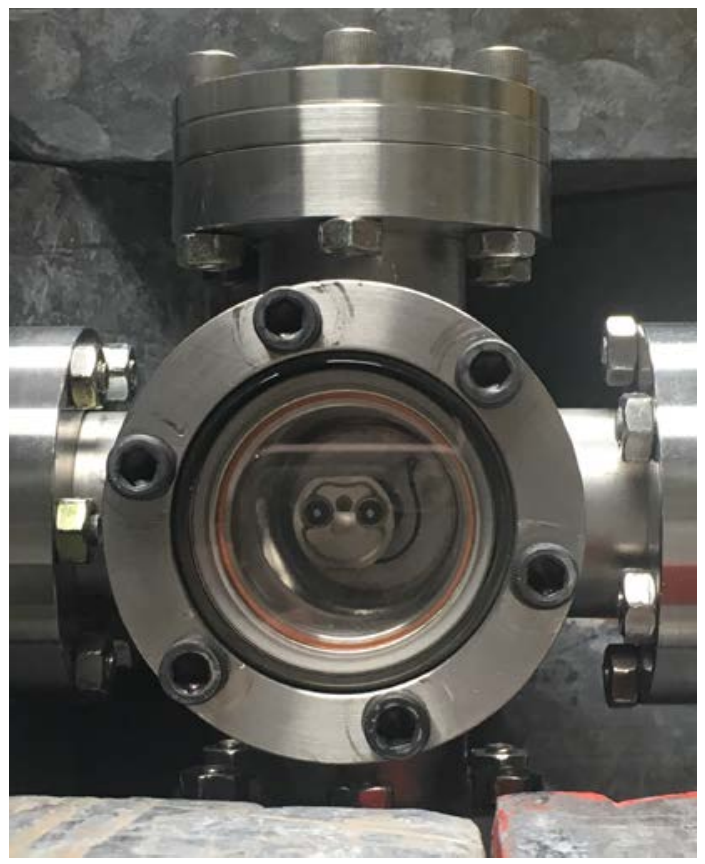

Figure 11: The diamond detector inside the six-cross chamber with viewports. 


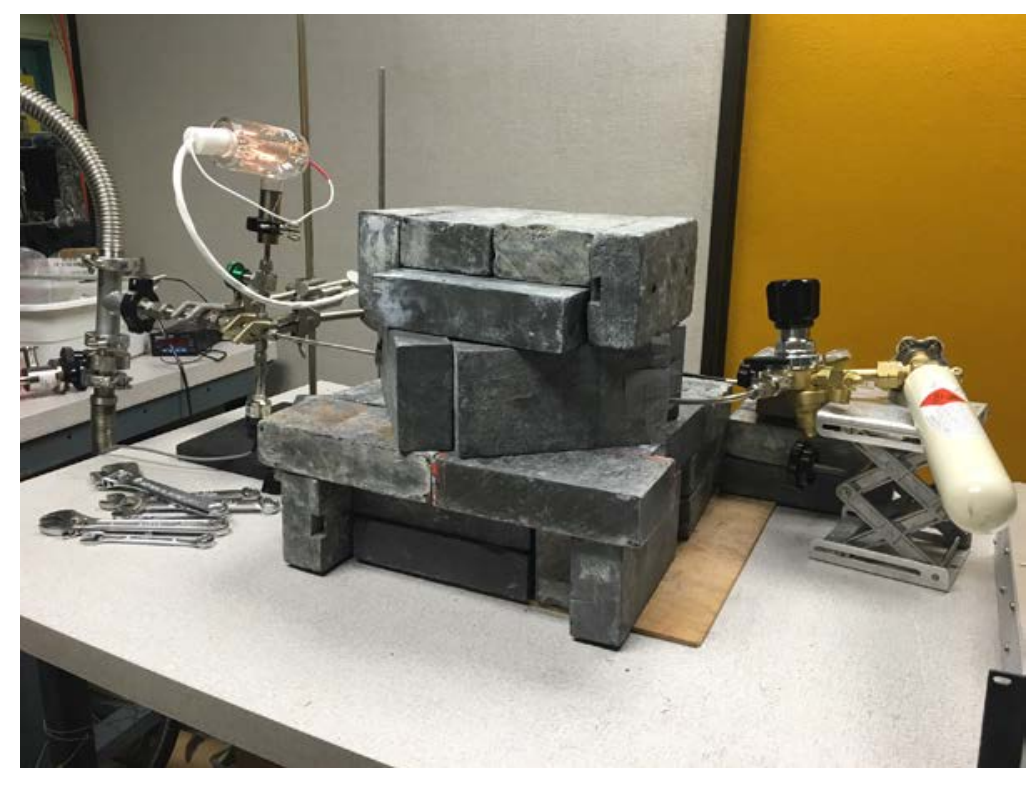

Figure 12: The experimental setup: after the gas loading step where the chamber was placed inside the lead cave to eliminate noise from the surroundings.

After the chamber was pumped down and background counted, the control gas loading was loaded at 5200 torr (about 100 psi) and ran for seven days. Next, the system was pumped down once more time before deuterium or hydrogen was loaded at about 100 psi. The experiment with hydrogen or deuterium ran continuously for seven days while the data were collect over 24 hours. A data comparison of background, control gas, and hydrogen or deuterium loading was done to determine any differences in the count rates and energy spectrum. These steps were repeated several times to investigate any possible count rate and signal bursts from each experiment. Before gas reloading, checking the diamond detector, the metallization surface and also the wire bonds needed to be done as often as leak checking the system. 
Next, the diamond detector was imaged by a Scanning Electron Microscope (SEM) to see if any differences in the metallization layers has occurred. Energy dispersive spectroscopy (EDS) analysis on the SEM which allows identifying particular elements in their relative proportions of atomic percentage on the sample was also performed to examine any elements created or found from the gas loading experiment. 


\section{CHAPTER 4}

\section{RESULTS}

This chapter reports experimental results that are presented in four parts; two of palladium-deuterium experiments and two of nickel-hydrogen experiments. The count rate data and the energy spectrum analysis from background count, control gas loading and deuterium or hydrogen loading were included in this chapter. The results of currentvoltage characteristic and energy calibration of each diamond detector are presented. The SEM images before and after running experiment are provided to observe any differences on the metallization surface. Also, a detector response to charged particle radiations such as beta and alpha was tested to study any potential changes in the diamond detector.

\subsection{The CVD diamond detector characterization}

This work consisted of four experiments with available electronic grade CVD diamond plates. The plates were initially available only in 3x3x0.5 mm dimension and then the larger sizes, $4 \times 4 \times 0.5 \mathrm{~mm}$ and $4.5 \times 4.5 \times 0.5 \mathrm{~mm}$, were obtained later. Table 3 shows the diamond plate sizes, metallization layers, and thicknesses used in the gas loading experiments. The specific detector will be identified by its metallization layer in future discussions.

In Experiment-1, three diamond detectors were fabricated for palladiumdeuterium gas loading. After a long and tedious optimization process, the metallization layer patterns used were based on 50/50/100 nm of Ti/Au/Pd and two were based on $50 / 150 \mathrm{~nm}$ of $\mathrm{Ti} / \mathrm{Pd}$ (The detectors will be referred to from here on as $\mathrm{Ti} / \mathrm{Pd}_{1-1}$ and $\mathrm{Ti} / \mathrm{Pd}_{1-}$ 
2). The gold layer was used as a diffusion barrier to avoid Ti-Pd interactions. However, this diamond detector with Ti/Au/Pd metallization pattern peeled off easily after few times use, then, the gold layer was not used in the future fabrication of diamond detectors.

In Experiment-2, two diamond detectors were fabricated with a metallization layer pattern of 50/5/20/150 nm of Ti/Pt/Au/Ni. As mentioned previously, to prevent titanium and nickel metal diffusion, the layers of gold and platinum were added between titanium and nickel layers.

Table 3: CVD diamond plate dimensions and metallization layers used in this work.

\begin{tabular}{|c|c|c|c|}
\hline Experiment & & Ietallization layer & \\
\hline $\begin{array}{l}\text { EXP.1 Pd-D } 2 \\
(\text { size } 3 \times 3 \times 0.5 \mathrm{~mm})\end{array}$ & $\begin{array}{c}\mathrm{Ti} / \mathrm{Au} / \mathrm{Pd} \\
50 / 50 / 100 \mathrm{~nm}\end{array}$ & $\begin{array}{c}\mathrm{Ti} / \mathrm{Pd}_{1-1} \\
50 / 150 \mathrm{~nm}\end{array}$ & $\begin{array}{l}\mathrm{Ti} / \mathrm{Pd}_{1-2} \\
50 / 150 \mathrm{~nm}\end{array}$ \\
\hline $\begin{array}{l}\text { EXP.2 Ni-H } 2 \\
(\text { size } 4 \times 4 \times 0.5 \mathrm{~mm})\end{array}$ & $\begin{array}{l}\mathrm{Ti} / \mathrm{Pt} / \mathrm{Au} / \mathrm{Ni}_{1-1} \\
50 / 5 / 20 / 150 \mathrm{~nm}\end{array}$ & $\begin{array}{l}\mathrm{Ti} / \mathrm{Pt} / \mathrm{Au} / \mathrm{Ni}_{1-2} \\
50 / 5 / 20 / 150 \mathrm{~nm}\end{array}$ & \\
\hline EXP.3 Ni-H 2 & $\begin{array}{c}\mathrm{Ti} / \mathrm{Pt} / \mathrm{Au} / \mathrm{Ni}_{2-1} \\
50 / 5 / 20 / 150 \mathrm{~nm} \\
(4.5 \times 4.5 \times 0.5 \mathrm{~mm})\end{array}$ & $\begin{array}{l}\mathrm{Ti} / \mathrm{Pt} / \mathrm{Au} / \mathrm{Ni}_{2-2} \\
50 / 5 / 20 / 150 \mathrm{~nm} \\
(4 \times 4 \times 0.5 \mathrm{~mm})\end{array}$ & \\
\hline $\begin{array}{l}\text { EXP.4 Pd-D } \\
(\text { size } 4.5 \times 4.5 \times 0.5 \mathrm{~mm})\end{array}$ & $\begin{array}{c}\mathrm{Ti} / \mathrm{Pd}_{2-1} \\
50 / 150 \mathrm{~nm}\end{array}$ & $\begin{array}{c}\mathrm{Ti} / \mathrm{Pd}_{2-2} \\
50 / 150 \mathrm{~nm}\end{array}$ & \\
\hline
\end{tabular}




\subsection{Current-Voltage Measurements}

The I-V measurement was done on each diamond detector by applying voltages between -500 to $500 \mathrm{~V}$ with a step voltage at $25 \mathrm{~V}$. The I-V characteristic curve of each detector as seen as Figure 13 to 16. Most of the diamond detectors showed an ohmic contact behavior when the applied bias was between minus $300 \mathrm{~V}$ and plus $300 \mathrm{~V}$. Most of the slope of the I-V curves plotted are relatively linear for all diamond detectors in a low to moderate applied voltage ranges. At high voltage, the I-V curve begins to display nonlinear behavior. Therefore, to achieve a complete charged collection efficiency of the detectors, the selected applied voltages were between 200 to $300 \mathrm{~V}$ as seen in Table 4. The leakage current (A) at zero voltage of each detector is in a range of 10E-14 and 10E11 as shown in Table 4.

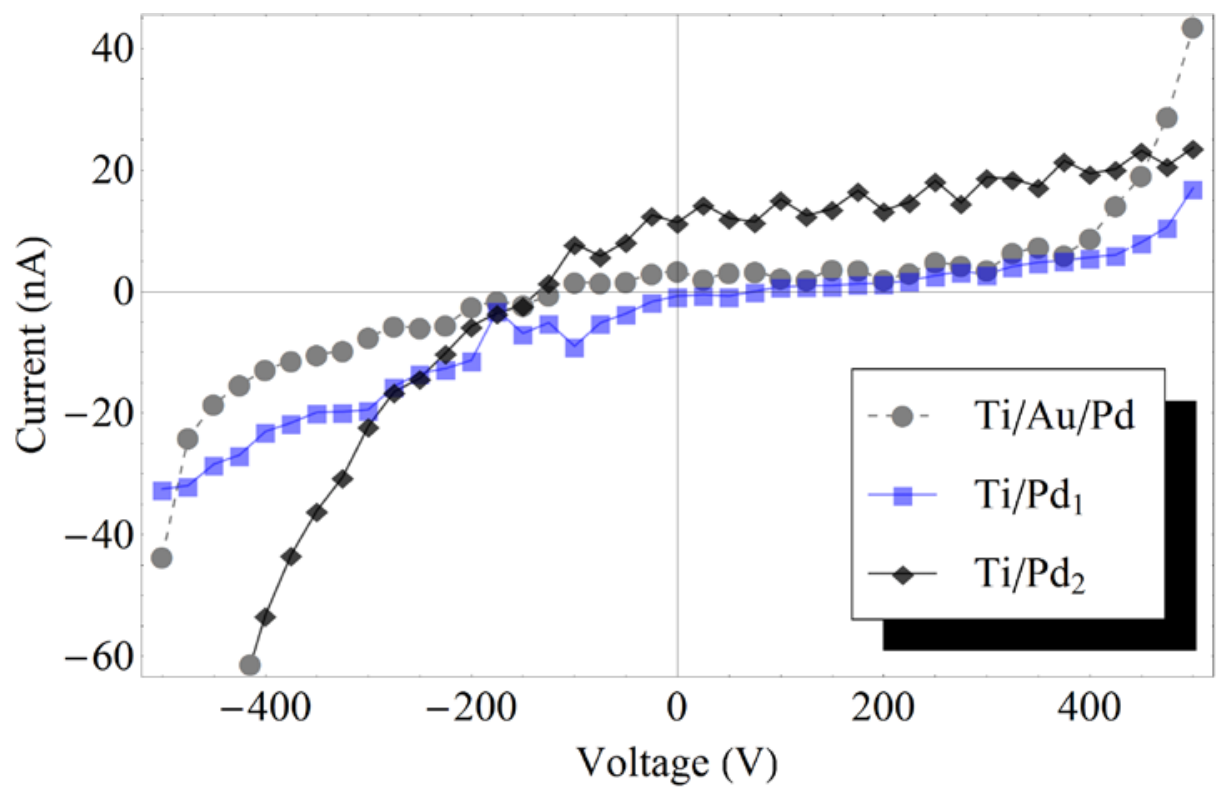

Figure 13: The I-V curve of diamond detectors in Experiment-1. 


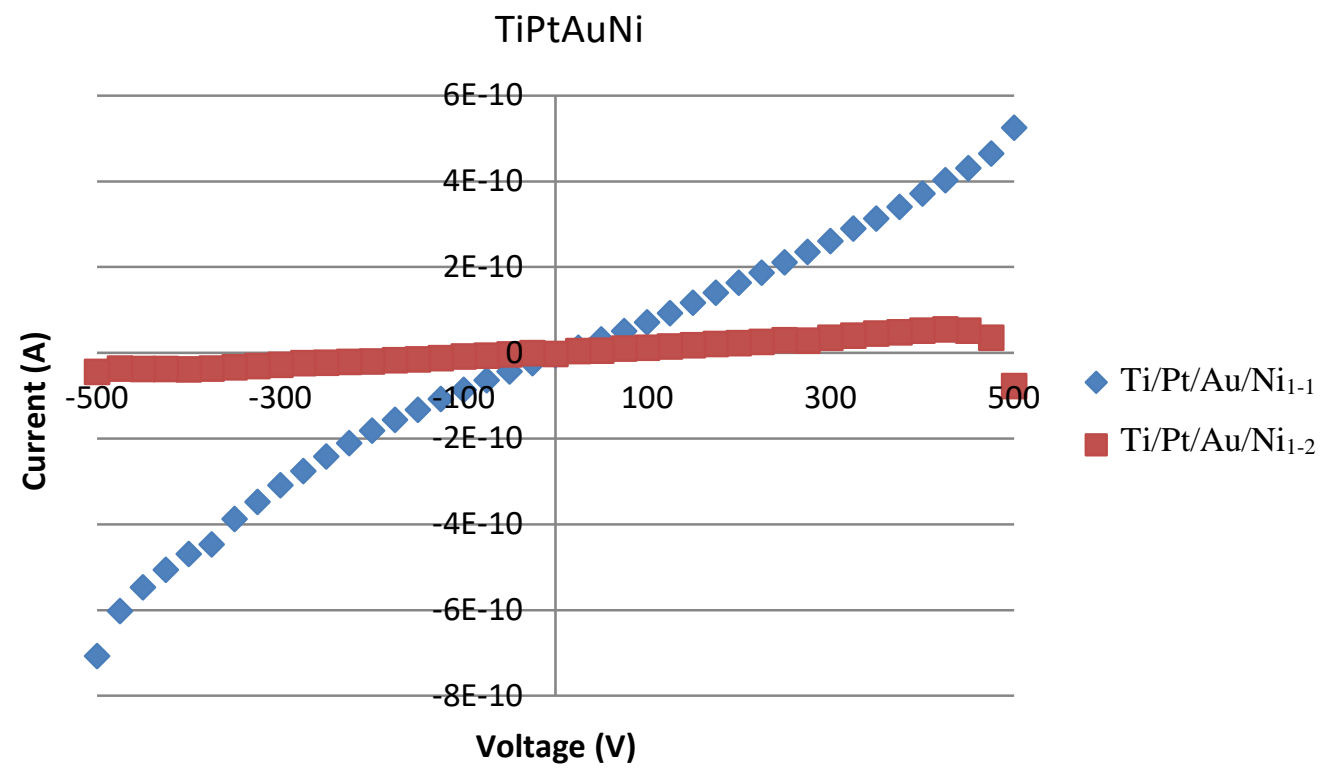

Figure 14: The I-V curve of diamond detectors in Experiment-2.

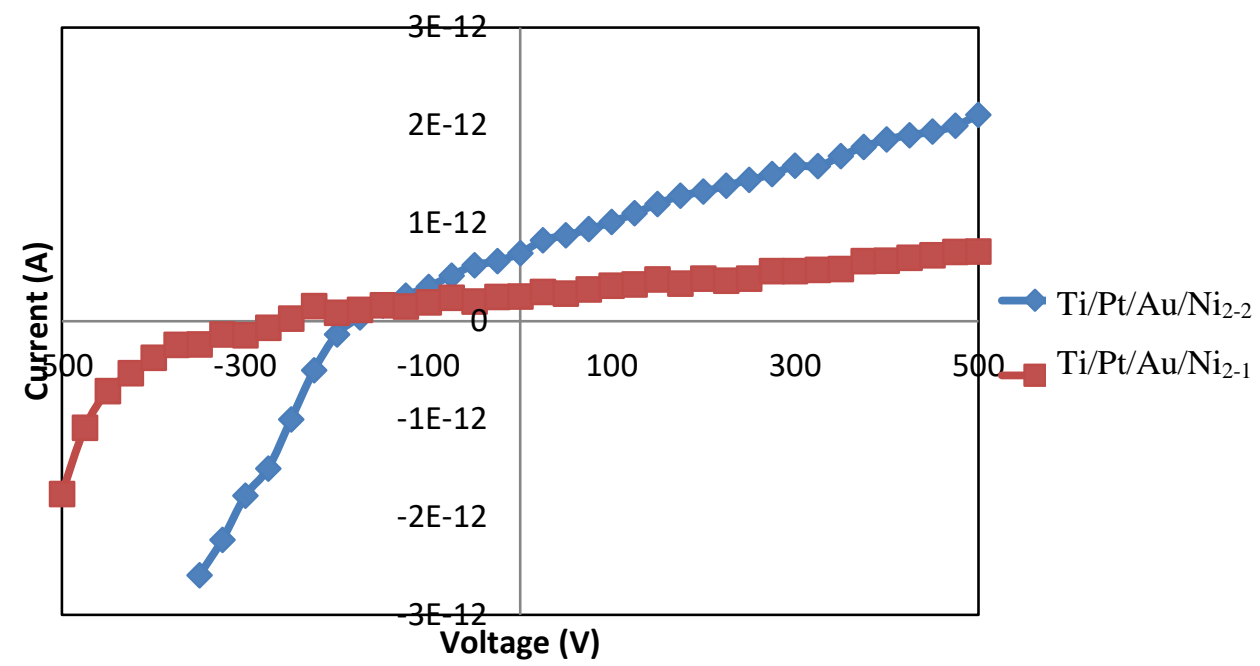

Figure 15: The I-V curve of diamond detectors in Experiment-3. 


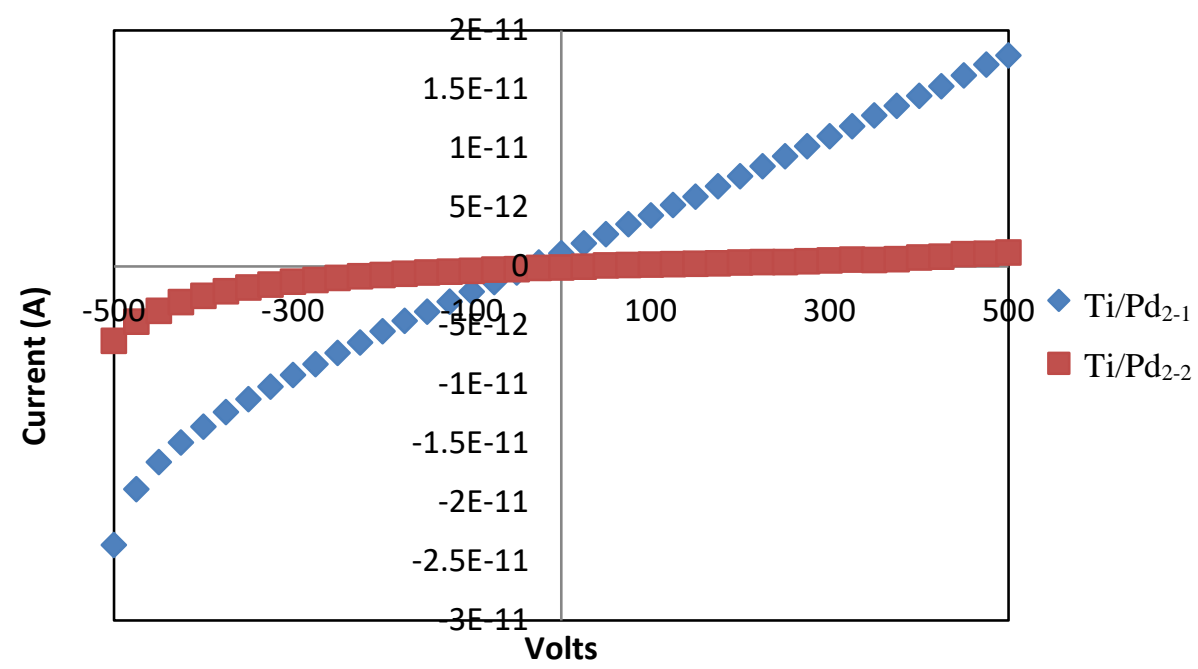

Figure 16: The I-V curve of diamond detectors in Experiment-4.

Table 4: The leakage current of diamond detectors used in this work.

\begin{tabular}{|c|c|c|}
\hline Experiment & The leakage current (A) & $\begin{array}{c}\text { Experiment applied } \\
\text { voltage }\end{array}$ \\
\hline EXP.1 Pd-D 2 & $200 \mathrm{~V}$ \\
\hline $\mathrm{Ti} / \mathrm{Au} / \mathrm{Pd}$ & $3.40 \mathrm{E}-12$ & \\
\hline $\mathrm{Ti} / \mathrm{Pd}{ }_{1-1}$ & $-7.01 \mathrm{E}-13$ & \\
\hline $\mathrm{Ti} / \mathrm{Pd}{ }_{1-2}$ & $1.14 \mathrm{E}-11$ & $200 \mathrm{~V}$ \\
\hline $\mathrm{EXP} .2 \mathrm{Ni}-\mathrm{H}_{2}$ & & \\
\hline $\mathrm{Ti} / \mathrm{Pt} / \mathrm{Au} / \mathrm{Ni}_{1-1}$ & $-5.58 \times 10-12$ & \\
\hline $\mathrm{Ti} / \mathrm{Pt} / \mathrm{Au} / \mathrm{Ni}_{1-2}$ & $-2.43 \times 10-12$ & \\
\hline $\mathrm{EXP} .3 \mathrm{Pd}-\mathrm{D}_{2}$ & & \\
\hline $\mathrm{Ti} / \mathrm{Pd}{ }_{2-1}$ & $6.96 \mathrm{E}-13$ & \\
\hline $\mathrm{Ti} / \mathrm{Pd}{ }_{2-2}$ & $2.50 \mathrm{E}-13$ & \\
\hline $\mathrm{EXP} .4 \mathrm{Ni}-\mathrm{H}_{2}$ & & \\
\hline $\mathrm{Ti} / \mathrm{Pt} / \mathrm{Au} / \mathrm{Ni}_{2-1}$ & $1.09 \mathrm{E}-12$ & \\
\hline $\mathrm{Ti} / \mathrm{Pt} / \mathrm{Au} / \mathrm{Ni}_{2-2}$ & $-8.48 \mathrm{E}-14$ & \\
\hline
\end{tabular}




\subsection{Calibration with Alpha Particle Exposures}

The detector calibration was done for electronic characterization of the diamond detectors with alpha radiation exposure from Pu-239 source. This step furthermore provided the optimum supplied voltage where the complete charged collection efficiency is comparable to the I-V characterization data. At the same counting settings, varying voltages between 100 to $500 \mathrm{~V}$, each diamond detector responded to alpha particles as displayed in Figure 17 to 20. At $200 \mathrm{~V}$ applied bias, which showed the complete charged collection efficiency, the range of FWHM from energy calibration of all detectors was $100 \mathrm{keV}$ and $320 \mathrm{keV}$, and the energy resolution was 2-7\% at 5.24 MeV of Pu-239.

In Experiment-1, the $\mathrm{Ti} / \mathrm{Au} / \mathrm{Pd}$ energy calibration spectrum showed a high level of noise and counts compared to the two Ti/Pd detectors, believed to be a result of nonadhesive metallization of the Ti/Au/Pd. Therefore, after calibration the Ti/Au/Pd metallization was not used in the experimental run. In Experiment-2, during radiation response and calibration process, the $\mathrm{Ti} / \mathrm{Pt} / \mathrm{Au} / \mathrm{Ni}_{1-1}$ did not respond to $\mathrm{Pu}-239$ alpha radiation. It could not pick up the energy peak of alpha radiation. It was possibly due to a problem during detector preparation after the metallization stage. Therefore, only $\mathrm{Ti} / \mathrm{Pt} / \mathrm{Au} / \mathrm{Ni}_{1-2}$ was used in the experiments. In Experiment-3, the total count at the energy peak from calibration of $\mathrm{Ti} / \mathrm{Pt} / \mathrm{Au} / \mathrm{Ni}_{2-1}$ is higher than $\mathrm{Ti} / \mathrm{Pt} / \mathrm{Au} / \mathrm{Ni}_{2-2}$ due to its larger sized diamond plate. The larger area of diamond and metallization will result in higher counts. In Experiment-4, after the I-V test and energy calibration, $\mathrm{Ti} / \mathrm{Pd}_{2-2}$ was used to observe the radiation-exposure response with several alpha and beta sources. It was then made 
defective due to a broken wire bond, and it could not be repaired. Only one detector was run in Experiment-4.

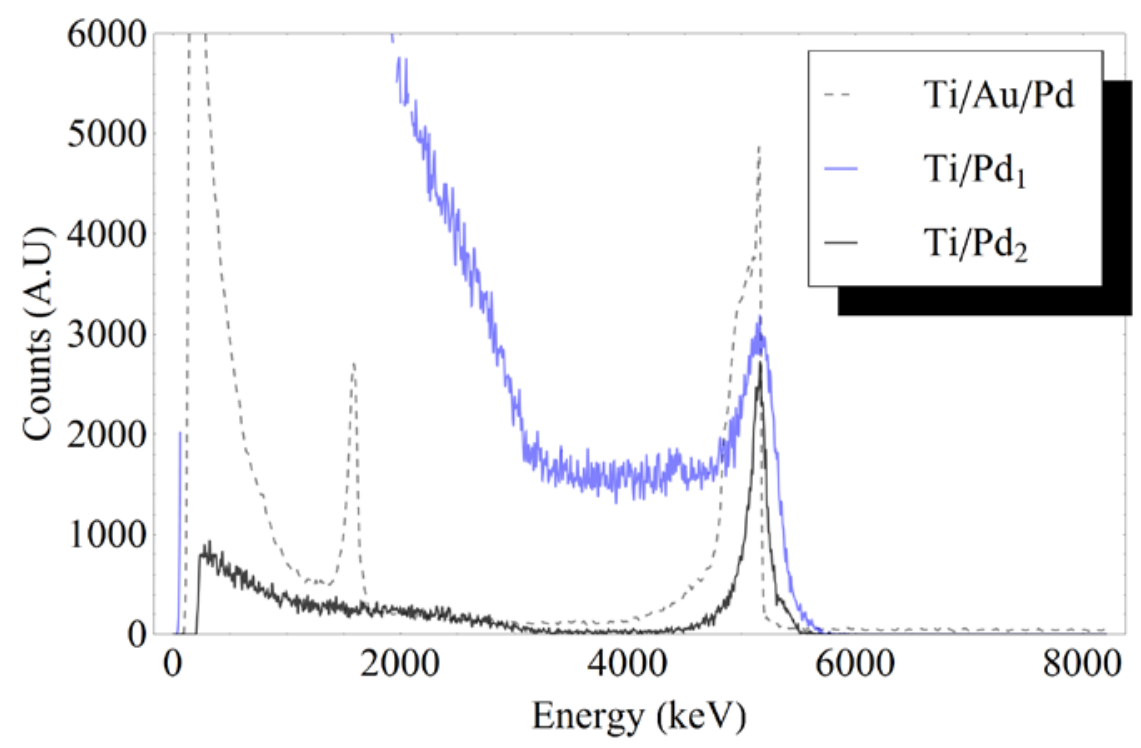

Figure 17: The energy spectrum from the detector calibration in Experiment-1.

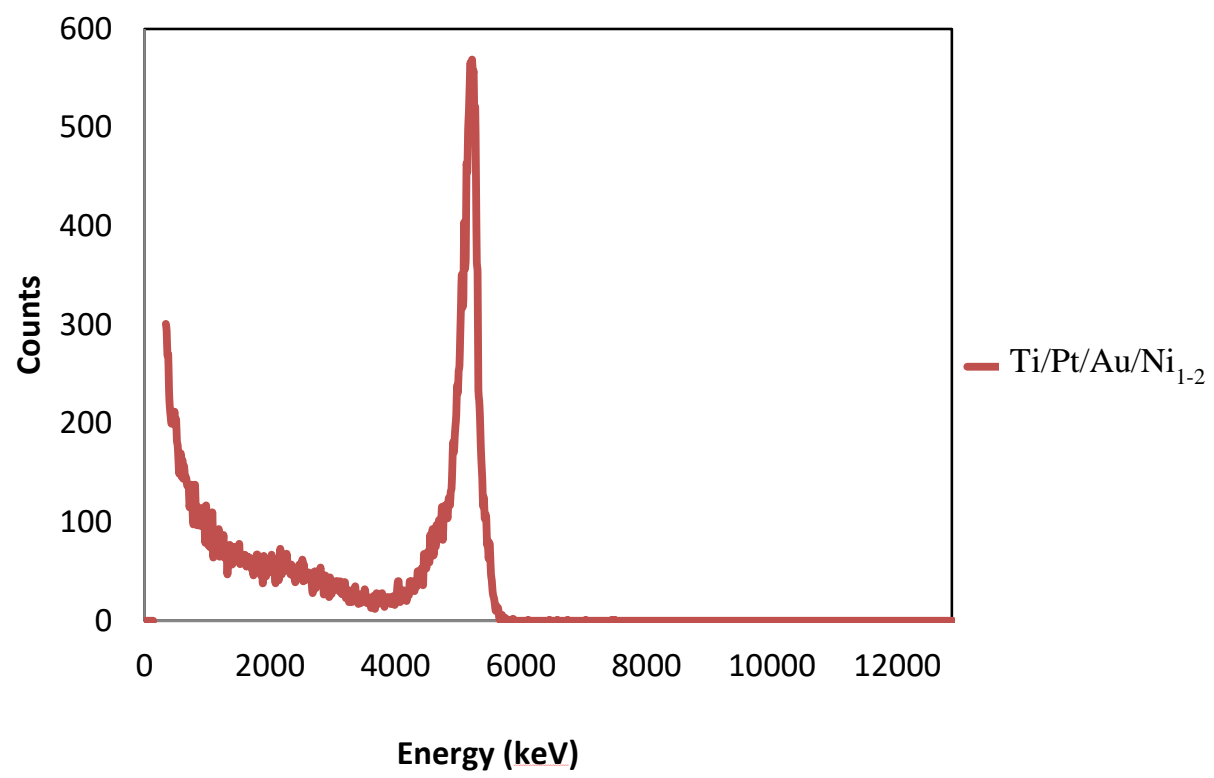

Figure 18: The energy spectrum from the detector calibration in Experiment-2. 


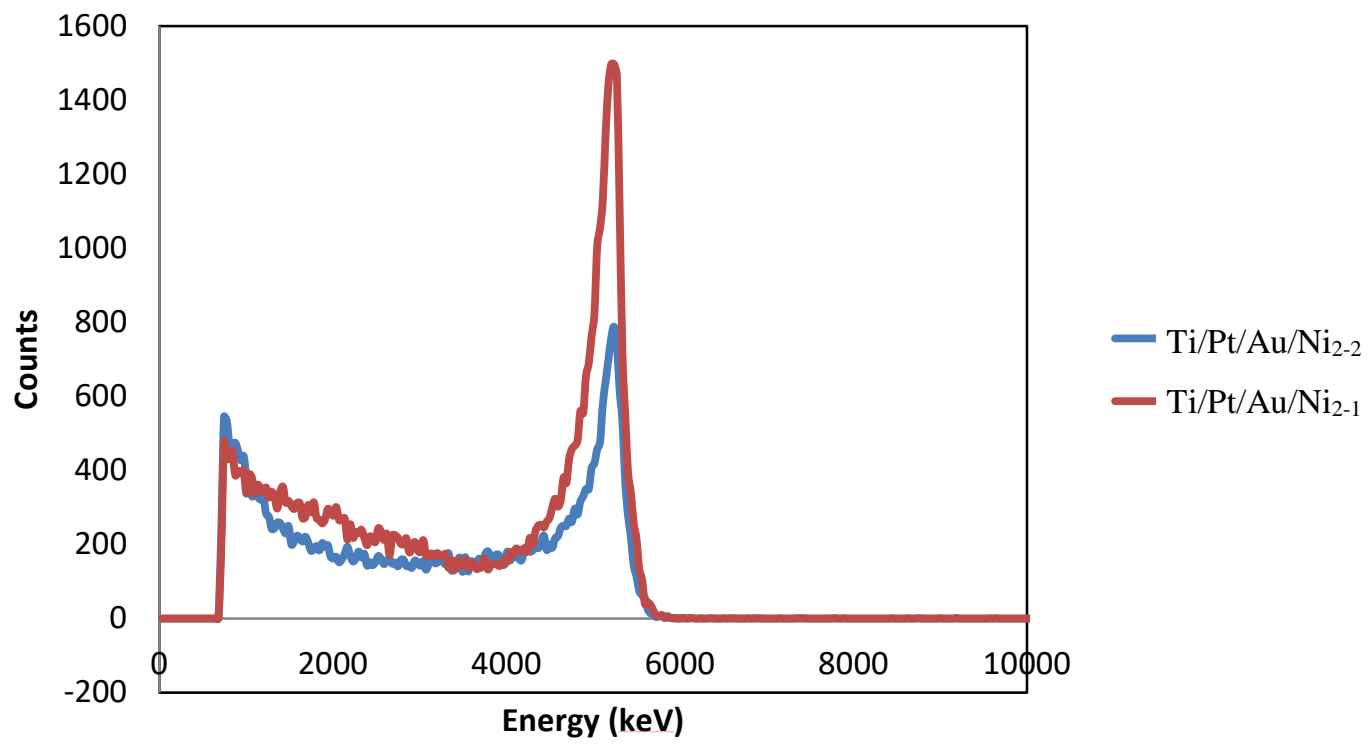

Figure 19: The energy spectrum from the detector calibration in Experiment-3.

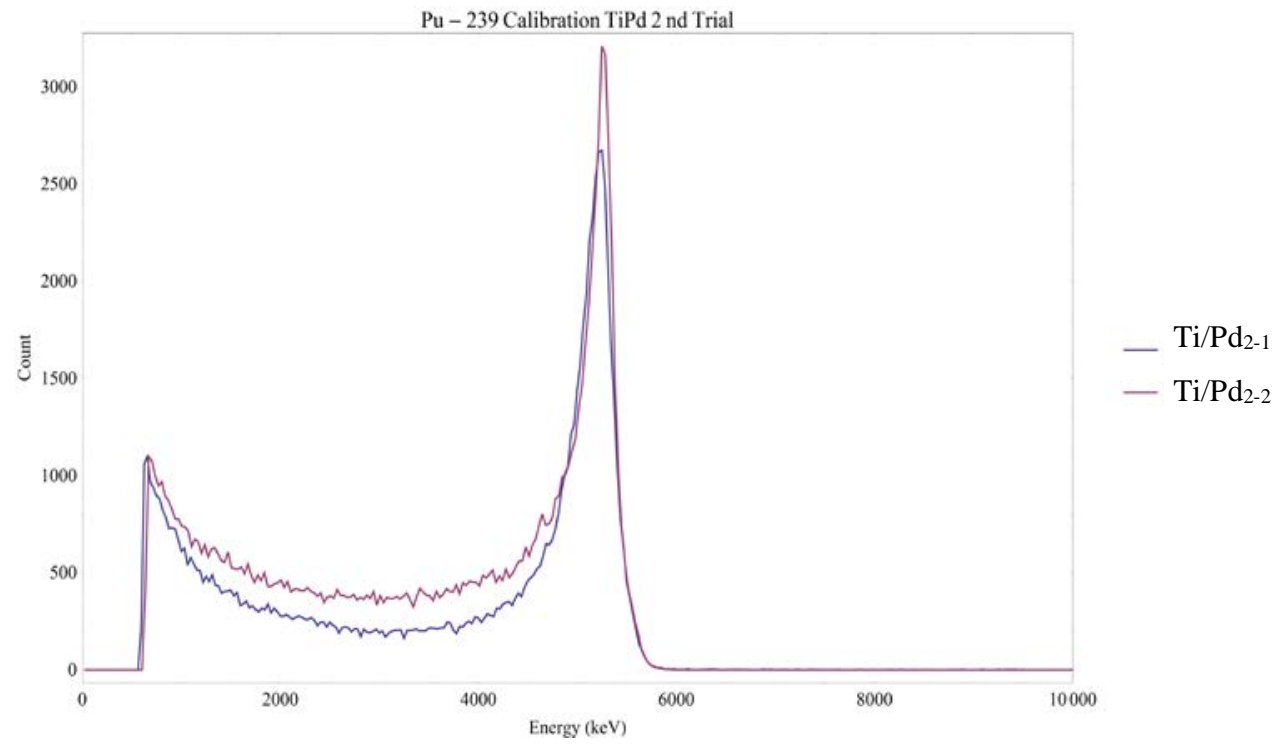

Figure 20: The energy spectrum from the detector calibration in Experiment-4. 


\subsection{Gas loading Experiments}

\subsubsection{Experiment-1: Palladium-Deuterium (Ti/Pd1-1 and Ti/Pd1-2)}

\section{Ti/Pd1-1}

Two trials of deuterium gas loading were done with the $\mathrm{Ti} / \mathrm{Pd}_{1-1}$ detector. The experiment started with a background counting using helium and hydrogen as a control gas loading. Since this was the first trial in this work, the data collection was not fully implemented. There were not adequate data presented for background and control gas loading, only a very low count rate at a level of $0-1$ counts/100ms and noise signals were observed from MCA energy spectrum.

After the background and control gas loading processes, the first deuterium trial of $\mathrm{Ti} / \mathrm{Pd}_{1-1}$ detector was done at $100 \mathrm{psi}$ and counted for eight days as shown in Figure 21. Then, the system was pumped down and reloaded deuterium to the chamber for the second trial at the same procedure and counted for seven days. Unfortunately, in the second trial, the MCA stopped running after Day-5 due to an instrument error. Only five days of data were collected from the MCA in the second trial of $\mathrm{Ti} / \mathrm{Pd}_{1-1}$ as shown in Figure 22. In the first trial, high signal bursts from the SCA were seen at Day-1and Day-2 in the data. The maximum count rates of Day-1 and Day-2 were 26 counts/100ms and 65 counts/100ms, respectively.

\section{Ti/Pd1-2}

Deuterium gas loading was done for seven days with the $\mathrm{Ti} / \mathrm{Pd}_{1-2}$ detector. The SCA and MCA data of the detector loaded with deuterium is shown in Figure 23. Only the SCA demonstrated a significant count rate of 11 counts/100 ms of Day-5 in this trial. 


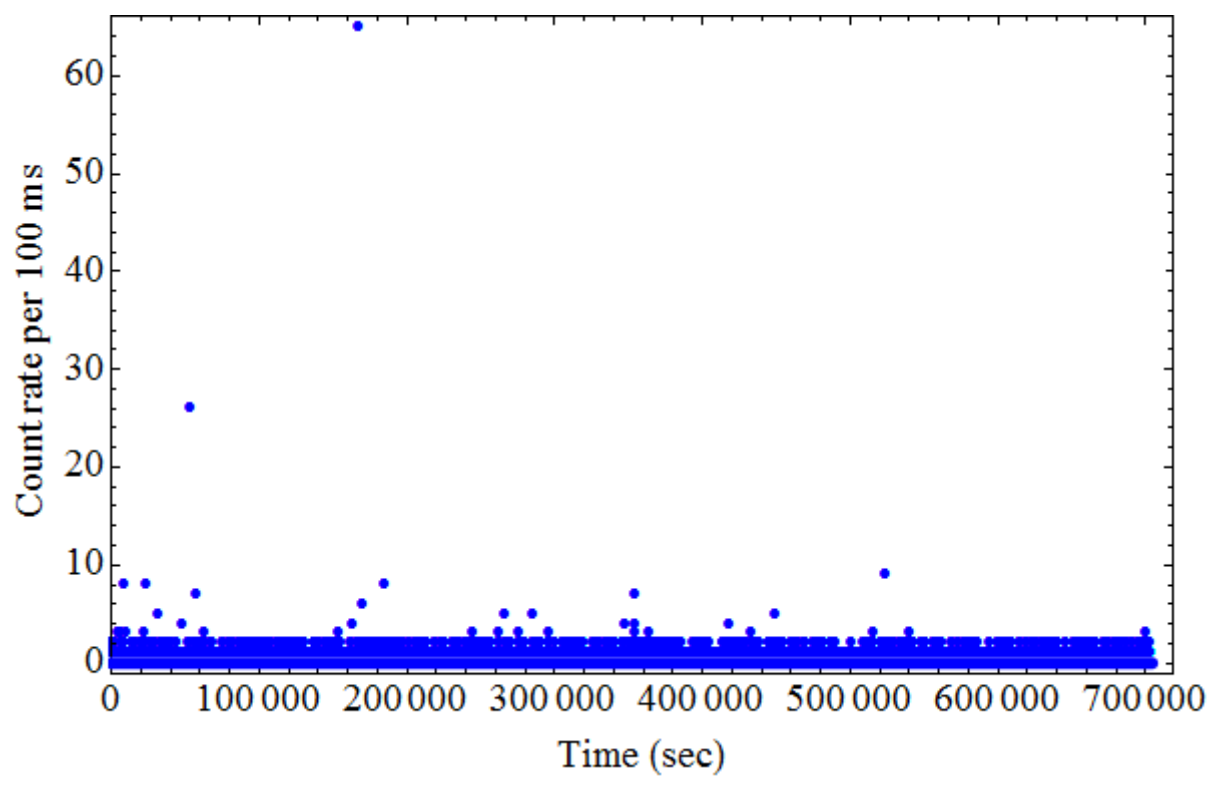

a)

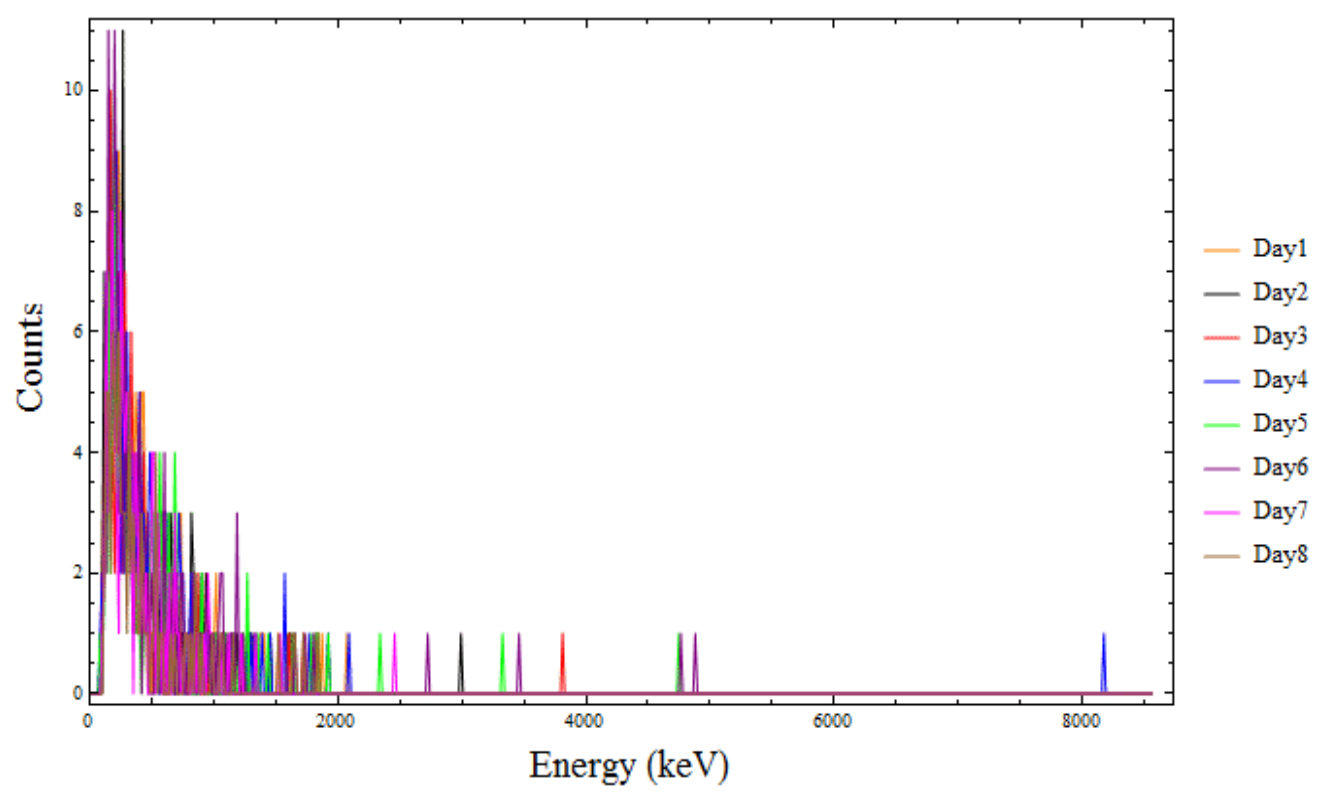

b)

Figure 21: Results from the $\mathrm{Ti} / \mathrm{Pd}_{1-1}$ detector during the first deuterium loading and continuous counting for 8 days a) the SCA count rate (counts/100ms) and b) the MCA energy spectrum. 


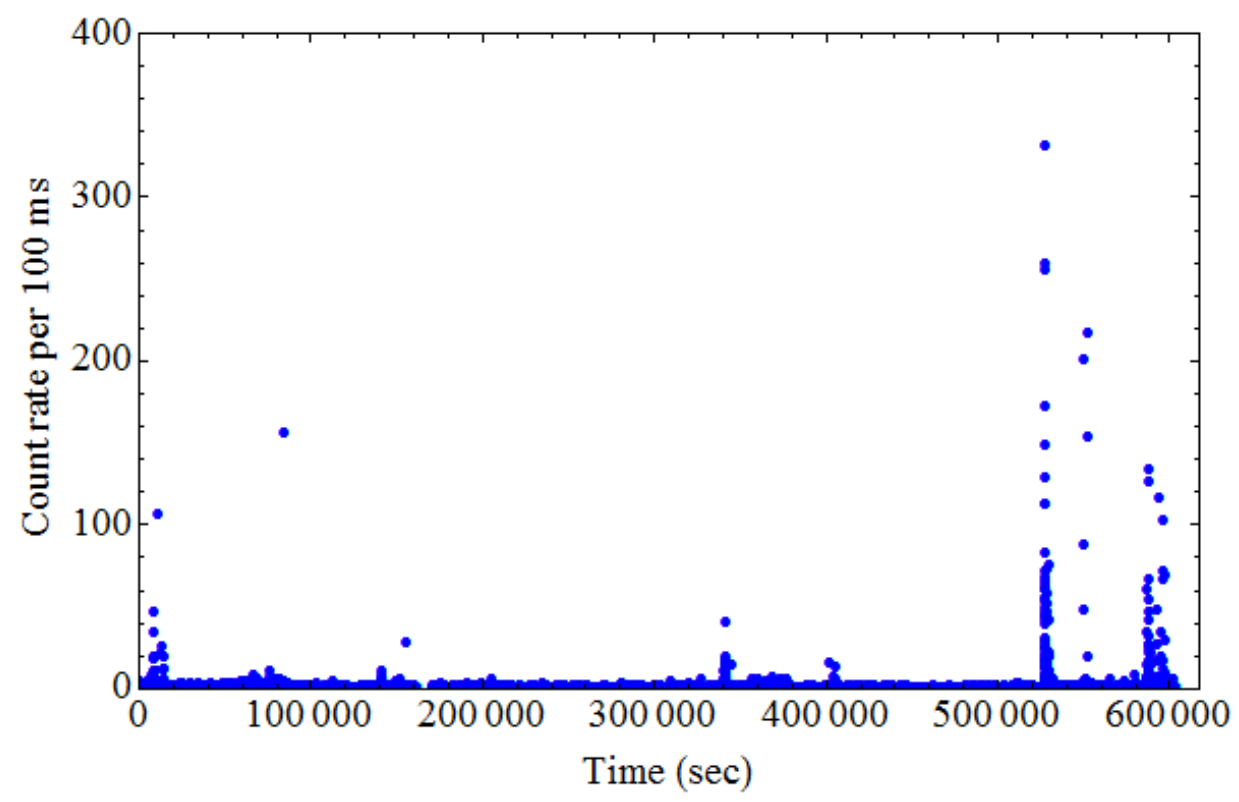

a)

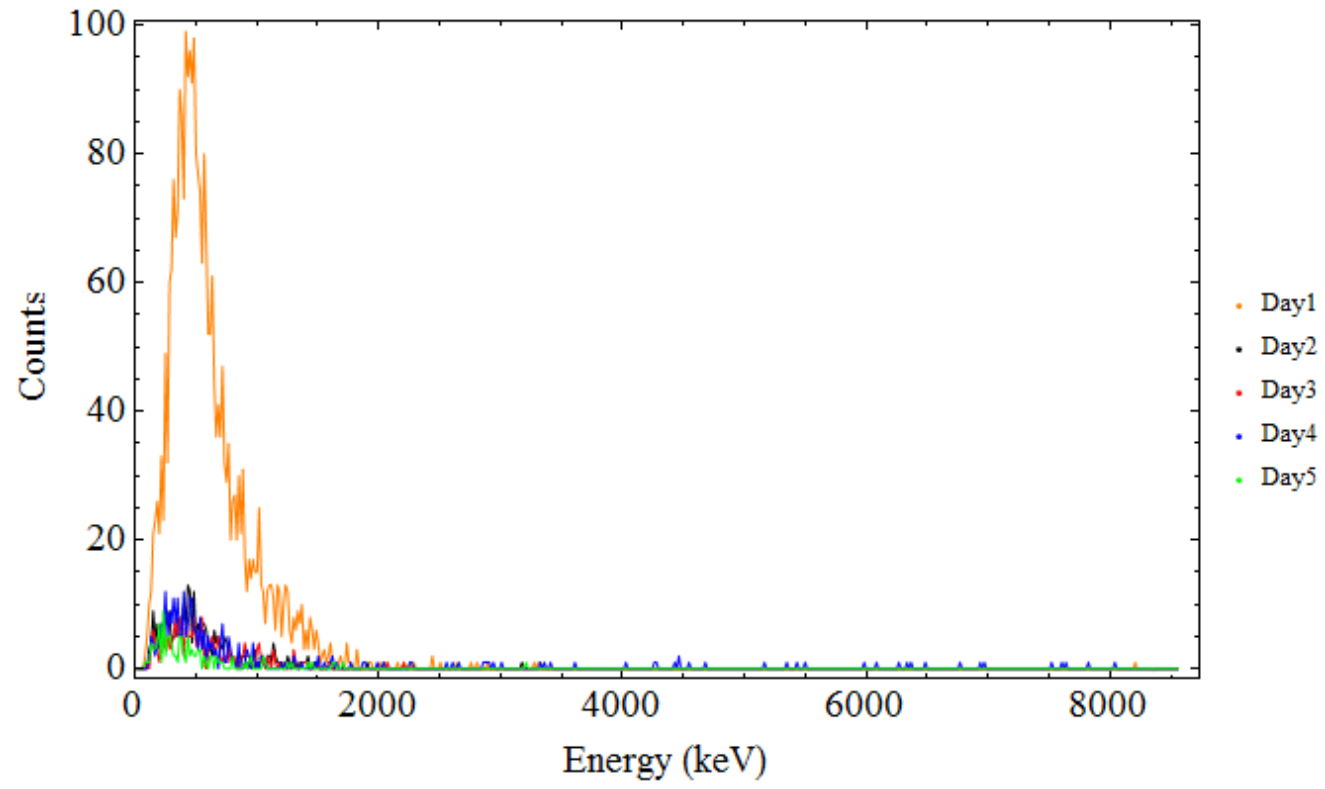

b)

Figure 22: Results from the $\mathrm{Ti} / \mathrm{Pd}_{1-1}$ detector during the second deuterium loading and continuous counting for five days a) the SCA count rate (counts/100ms) and b) the MCA energy spectrum (only 5-day data). 


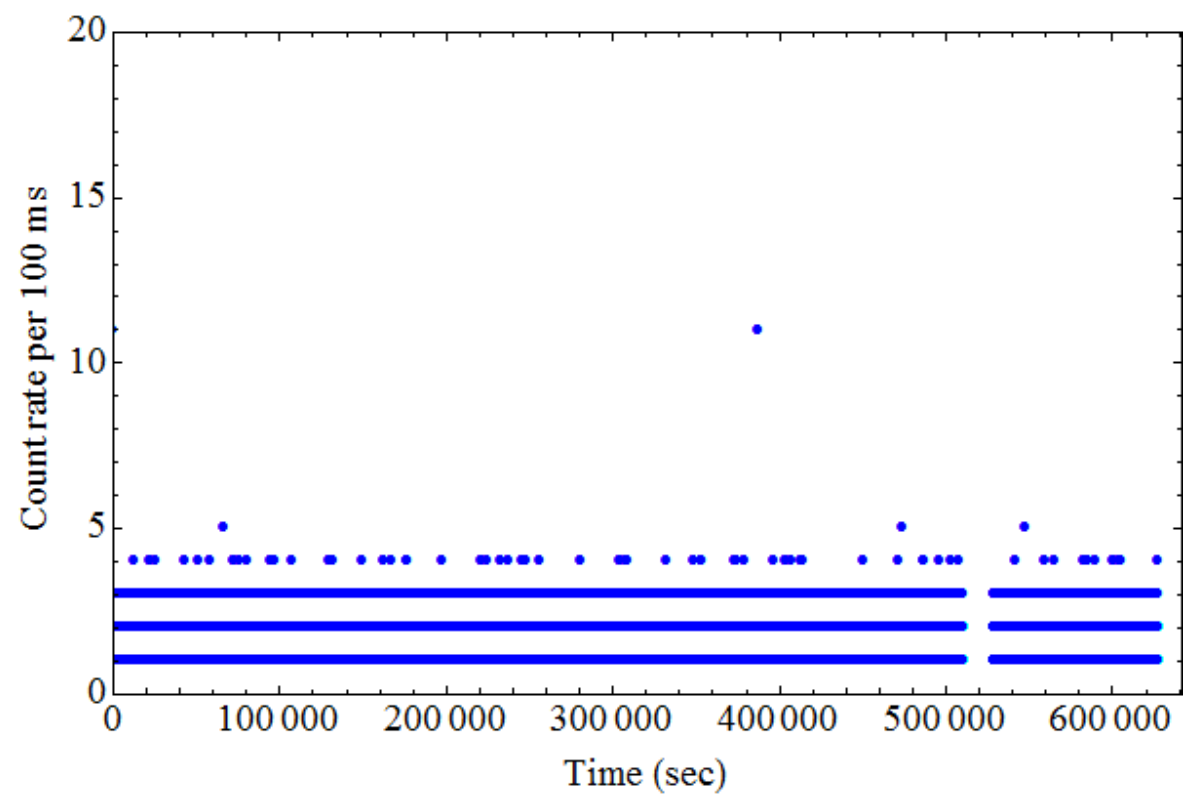

a)

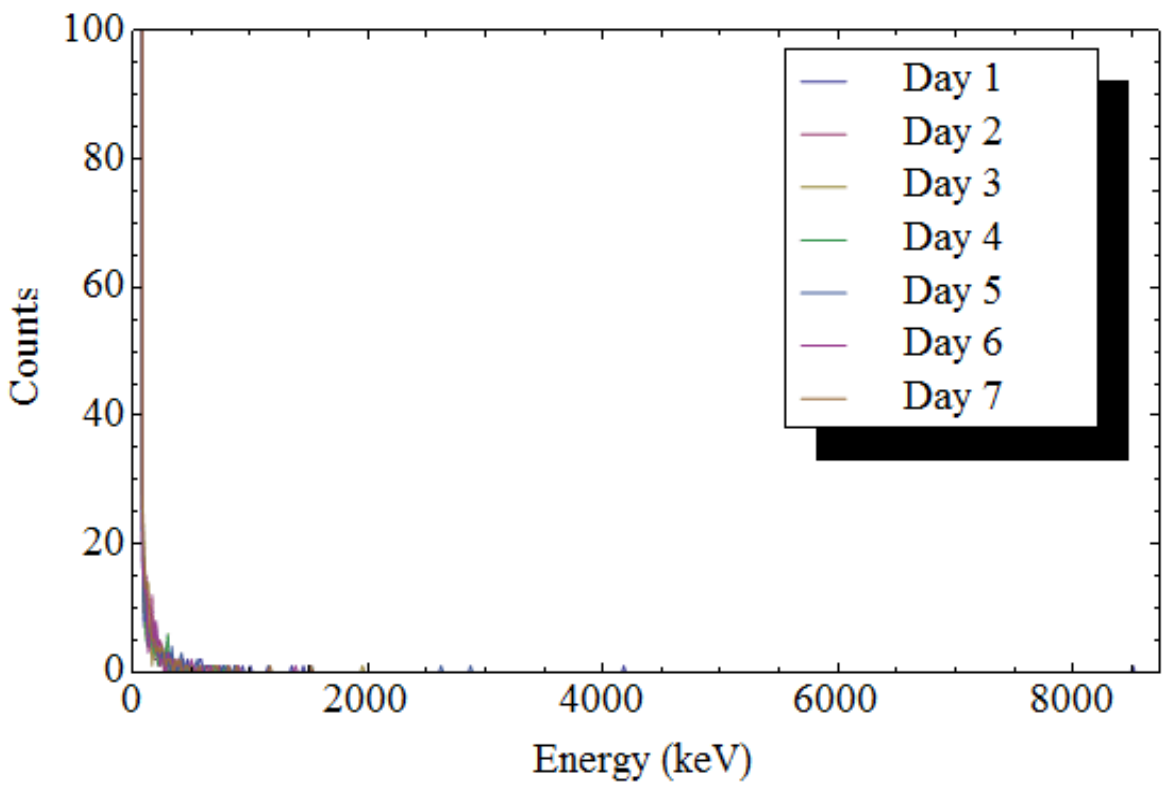

b)

Figure 23: Results from the $\mathrm{Ti} / \mathrm{Pd}_{1-2}$ detector during the first deuterium loading and continuous counting for seven days a) the SCA count rate (counts/100ms) and b) the MCA energy spectrum. 
Table 5: The results of signal count rate of Experiment-1 (Ti/Pd detector-deuterium).

\begin{tabular}{|c|c|c|}
\hline Sample & Day of gas loading & $\begin{array}{c}\text { SCA Max Counts Rate } \\
\text { (counts/100 ms) }\end{array}$ \\
\hline $\mathrm{Ti} / \mathrm{Pd}_{1-1}$ (D2 Load1) & Day 1 & 65 \\
\hline & Day 2 & 106 and 156 \\
\hline $\mathrm{Ti} / \mathrm{Pd}_{1-1}(\mathrm{D} 2$ Load2) & Day 1 & 40 \\
\hline & Day 4 & 331 \\
\hline $\mathrm{Ti} / \mathrm{Pd}_{1-2}(\mathrm{D} 2$ Load $)$ & Day 7 & 11 \\
\hline
\end{tabular}

According to the three cycles of deuterium loading in Experiment- 1 of Ti/Pd detectors, the count rate results can be summarized in Table 5. The second deuterium loading of $\mathrm{Ti} / \mathrm{Pd}_{1-1}$ showed the highest signal burst was 331 counts/100 ms on Day-7. There were no significant observed counts from the MCA. This experiment lacked the good background and control gas counting properties (using Hydrogen and Helium gas loading as the background counting gas). The experimental procedure was improved for the next experiments.

\subsubsection{Experiment-2: Nickel-Hydrogen}

In this experiment, the $\mathrm{Ti} / \mathrm{Pt} / \mathrm{Au} / \mathrm{Ni}_{1-2}$ detector was run with background counting under vacuum at a pressure level of one mtorr for 15 hours, then loaded with helium control gas and later loaded with hydrogen for 24 hours each run. Due to an electrical problem in the laboratory, only 24 hours of counting for the hydrogen loading was done 
for this experiment. It is noted that the detector chamber needed to pump down between each loading until the system pressure reached a level of one mtorr or less to remove gas residues.

Figure 24 to 25 show the plots of the SCA and MCA data for the background, helium control gas, and hydrogen loading experiment, respectively. The results summary is given in Table 6. The total for a 15-hour background count are 4159 counts from SCA and 6259 counts from MCA. The maximum count rate of SCA background is 5 counts/100ms. And the maximum energy from the MCA background is at $7.12 \mathrm{MeV}$, which is a high energy, but only one count appeared. For the helium results, the total count for SCA and MCA for 24 hours are 10366 and 14322 counts, respectively. The maximum count rate for the SCA He control gas is 8 counts/100ms, which is higher than the background. The maximum energy from the MCA for the He control gas is at 7.53 $\mathrm{MeV}$, which is quite close to that from the background count.

For hydrogen loading, the total count for the SCA and MCA for 24 hours are 57 and 403 counts, respectively. The high energies from the hydrogen control in the MCA spectrum is greater than background and the He control gas at 9.46 $\mathrm{MeV}$ and $12.18 \mathrm{MeV}$. The maximum count rate of SCA for hydrogen is 14 counts/100ms, which is higher than both background and the helium control gas. 


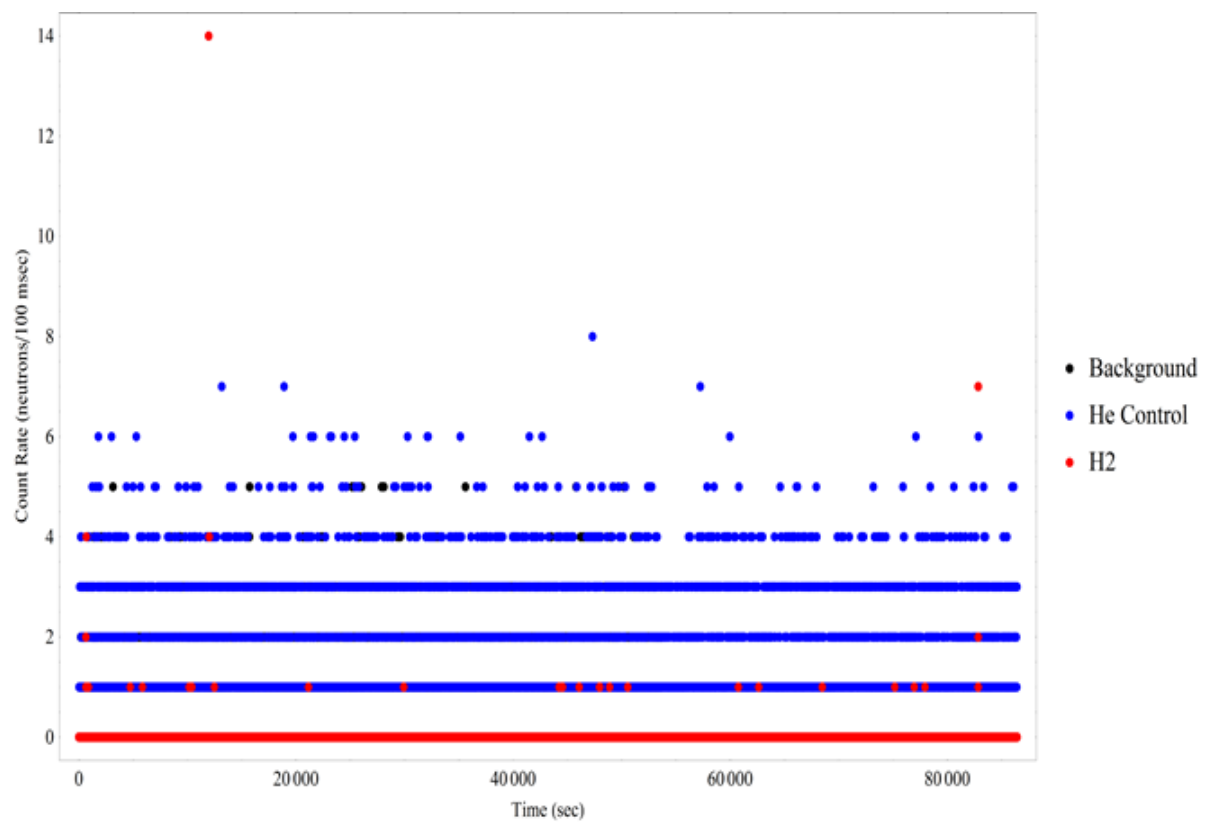

a)

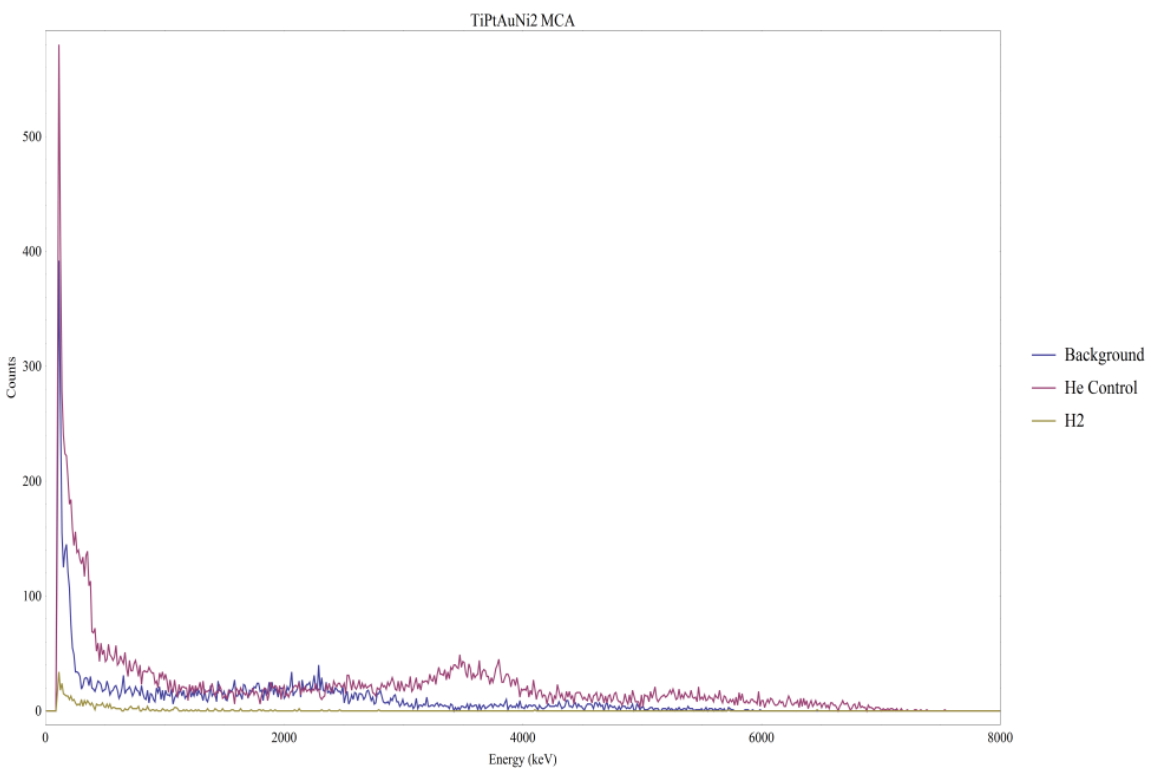

b)

Figure 24: Results from the $\mathrm{Ti} / \mathrm{Pt} / \mathrm{Au} / \mathrm{Ni}_{1-2}$ detector for the background, helium control gas, and hydrogen counting for 1 day a) the SCA count rate (counts/100ms) and b) the MCA energy spectrum. 


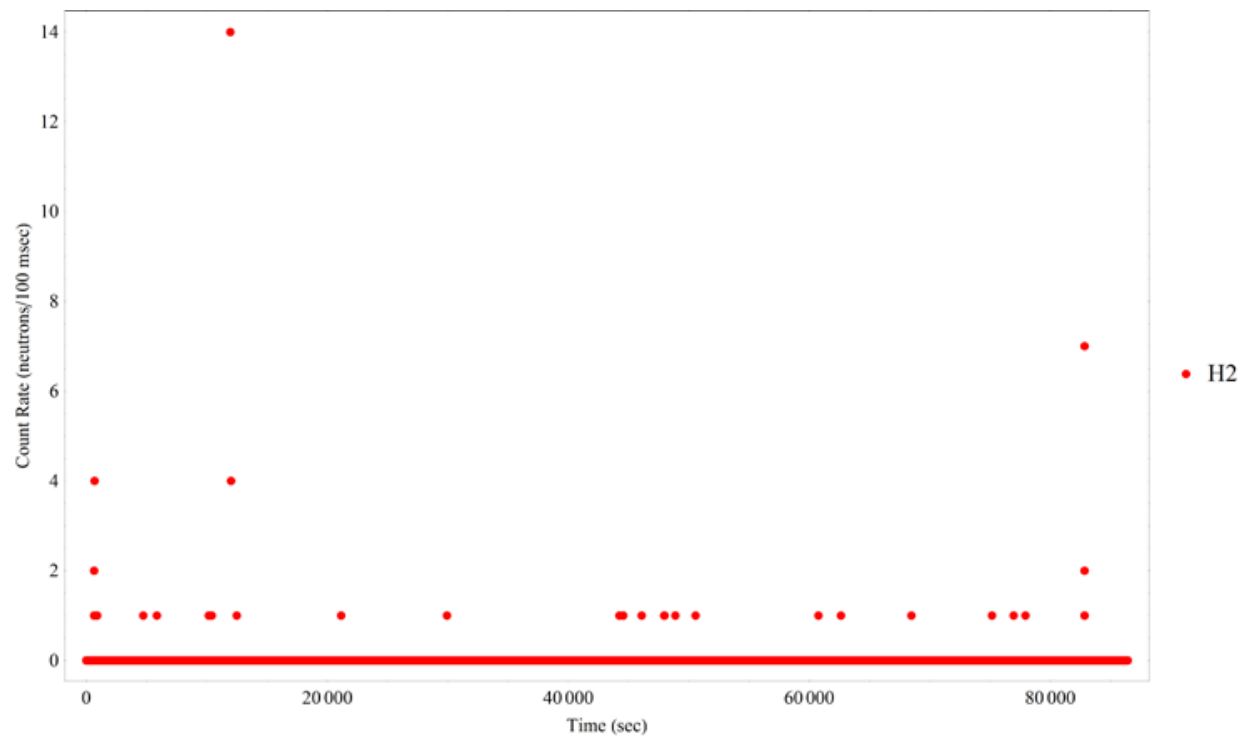

Figure 25: The SCA count rate (counts/100ms) with hydrogen loading for 1 day (separated plot of Figure 24).

Table 6: The results from SCA and MCA of Experiment-2 (Ti/Pt/Au/Ni detectorhydrogen).

\begin{tabular}{|c|c|c|c|c|}
\hline \multirow{2}{*}{ Gas Load } & \multicolumn{2}{|c|}{ SCA } & \multicolumn{2}{c|}{ MCA } \\
\hline & Total count & $\begin{array}{c}\text { Max Count } \\
\text { Rate } \\
\text { (count/100ms) }\end{array}$ & Total count & $\begin{array}{c}\text { Max Energy } \\
\text { (MeV) }\end{array}$ \\
\hline $\begin{array}{c}\text { Background } \\
\text { (15 hours) }\end{array}$ & 4159 & 5 & 6259 & 7.12 \\
\hline $\begin{array}{c}\text { Helium } \\
\text { Control }\end{array}$ & 10366 & 8 & 14322 & 7.53 \\
\hline Hydrogen & 57 & 14 & 423 & 9.46 \\
\hline & & & & 12.18 \\
\hline
\end{tabular}




\subsubsection{Experiment-3: Nickel-Hydrogen ( $\mathrm{Ti} / \mathrm{Pt} / \mathrm{Au} / \mathrm{Ni} 2-1$ and $\left.\mathrm{Ti} / \mathrm{Pt} / \mathrm{Au} / \mathrm{Ni}_{2-2}\right)$}

This second experiment of $\mathrm{Ti} / \mathrm{Pt} / \mathrm{Au} / \mathrm{Ni}$-hydrogen was done with two $\mathrm{Ti} / \mathrm{Pt} / \mathrm{Au} / \mathrm{Ni}$ detectors. The detectors were run for background counting under vacuum by using a diffusion pump at $10^{-5}$ torr for 24 hours. The $\mathrm{Ti} / \mathrm{Pt} / \mathrm{Au} / \mathrm{Ni}_{2-1}$ ran with two hydrogen loadings. Hydrogen gas was introduced into the detector chamber at 100 psi.

\section{Ti/Pt/Au/Ni2-1 - First Hydrogen Load}

For the first hydrogen loading, the detector was load with hydrogen and left for seven days. Figure 26 shows the plots of SCA and MCA data for a 1-day background and seven days with a hydrogen loading experiment, respectively. The results summary is provided in Table 7 . The total count of 24-hour background is 764 counts from SCA and 825 counts from the MCA. The maximum count rate of SCA background is 13 counts/100ms. And the maximum energy of MCA background is at $10.9 \mathrm{MeV}$. There was no helium control gas loading in this experiment. This was done so as to save the available lattice spaces in the host metal (nickel) for hydrogen atoms to diffuse into.

From the first hydrogen loading, the total count from the SCA and MCA for seven days are summarized in Table 7. The average total count of SCA 7-day hydrogen is 302 counts which is lower than 764 counts of the SCA background. The average total count of MCA 7-day hydrogen is 267 counts which is lower than 825 counts of the MCA background. The difference of total count from background and hydrogen loading may be a result of different pressure, a better vacuum at $10^{-5}$ torr and 100 psi (5171 torr) loading. 


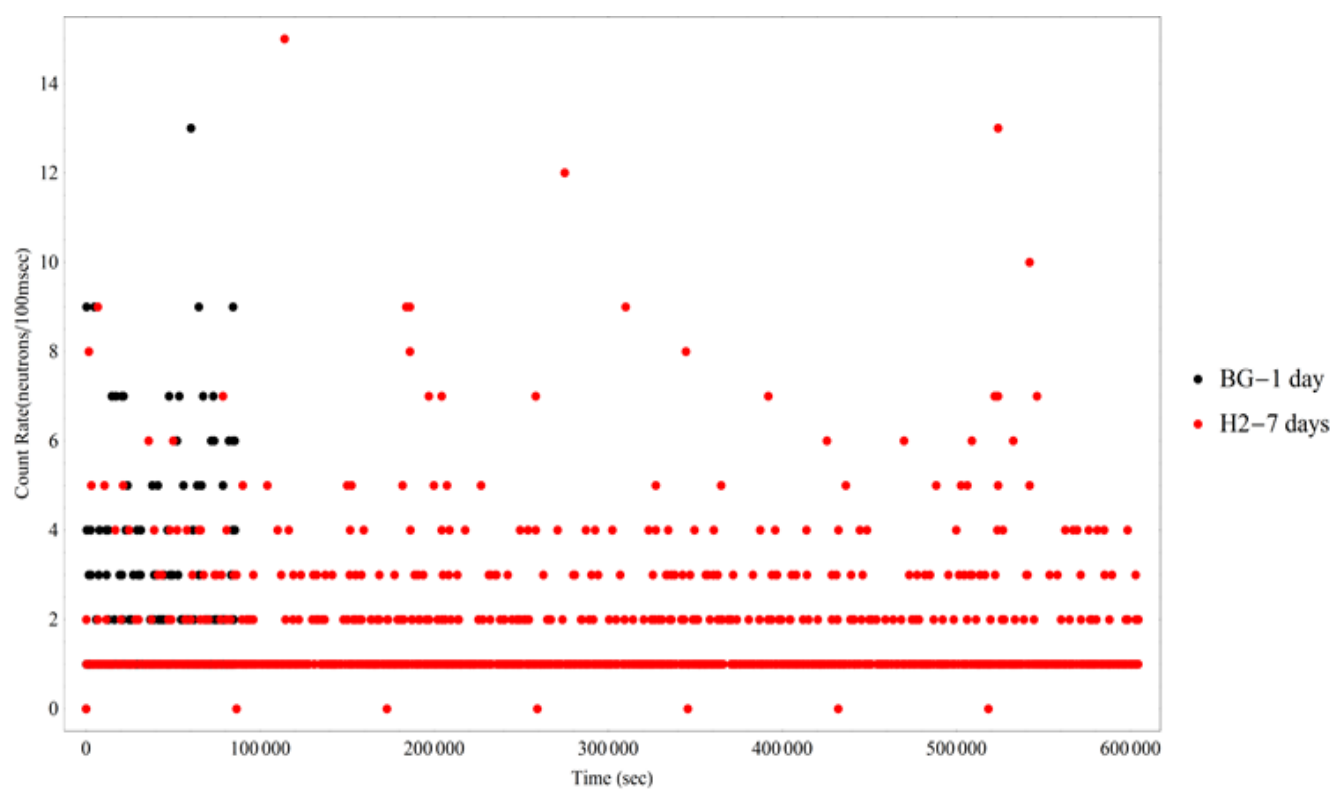

a)

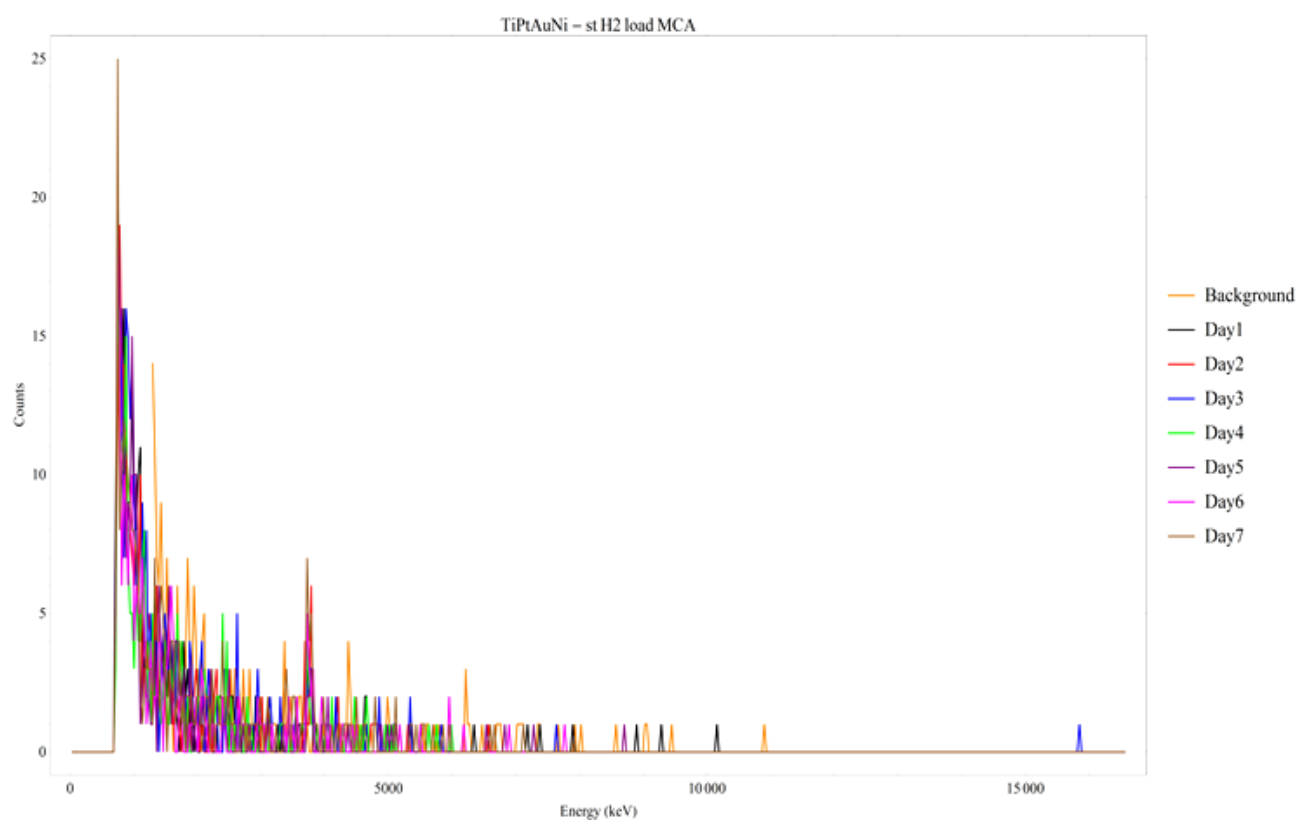

b)

Figure 26: Results of $\mathrm{Ti} / \mathrm{Pt} / \mathrm{Au} / \mathrm{Ni}_{2-1}$ detector background, and first hydrogen loading for seven days a) the SCA count rate (counts/100ms) and b) the MCA energy spectrum. 
The maximum count rates of 7-day SCA run were seen significantly high at Day2, Day-4 and Day-7 in a range of 12-15 counts/100ms. However, these SCA signal bursts are similar to the background burst at 13 counts/100ms.

Table 7: The results of Ti/Pt/Au/Ni2-1-first hydrogen loading from SCA and MCA.

\begin{tabular}{|c|c|c|}
\hline Load & $\begin{array}{c}\text { SCA } \\
\text { Total count } \\
\left(\text { Count rate }{ }_{\text {max }}\right)\end{array}$ & $\begin{array}{c}\text { MCA } \\
\text { Total count } \\
\left(\mathrm{E}_{\text {max }}\right)\end{array}$ \\
\hline $\begin{array}{c}764 \\
825 \\
(10.9 \mathrm{MeV})\end{array}$ \\
\hline $\begin{array}{c}\text { Hydrogen cts/100ms }) \\
\text { Day1 }\end{array}$ & 315 & 280 \\
\hline Day2 & $\begin{array}{c}287 \\
(15 \mathrm{cts} / 100 \mathrm{~ms})\end{array}$ & 253 \\
\hline Day3 & 363 & 310 \\
\hline Day4 & $\begin{array}{c}278 \\
(12 \mathrm{cts} / 100 \mathrm{~ms}\end{array}$ & $249.58 \mathrm{MeV})$ \\
\hline Day5 & 281 & 235 \\
\hline Day6 & 259 & 294 \\
\hline Day7 & $\begin{array}{c}331 \\
(13 \mathrm{cts} / 100 \mathrm{~ms})\end{array}$ & 302 \\
\hline Average 7-day count & 267 & 245 \\
\hline
\end{tabular}




\section{Ti/Pt/Au/Ni2-1 - Second Hydrogen Load}

For the second hydrogen loading of $\mathrm{Ti} / \mathrm{Pt} / \mathrm{Au} / \mathrm{Ni}_{2-1}$, the detector was loaded with hydrogen gas and left for five days. Figure 27 shows the plots of the SCA and MCA data for 1-day background and 5-day of hydrogen loading experiments, respectively. The results summary is shown in Table 8. The average total count of the SCA and MCA 7day hydrogen run are 428 and 405 counts, respectively. These average total counts are lower than the 748 and 712 counts of the SCA and MCA seen in the background respectively. The maximum count rates of SCA in the 5-day run were seen significantly higher at Day-2, Day-3 and Day-4 in a range of 15-26 counts/100ms. These SCA signal bursts are significantly higher than the background burst at 11 counts/100ms. 


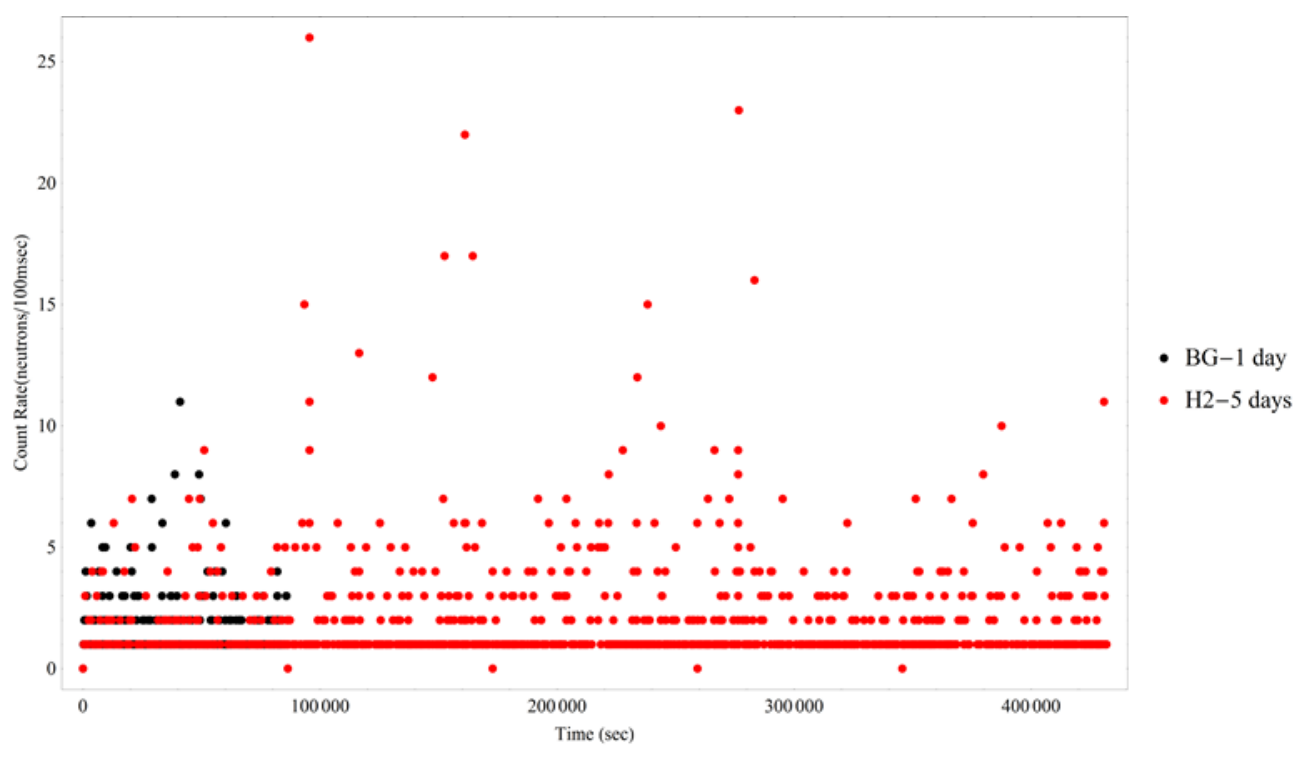

a)

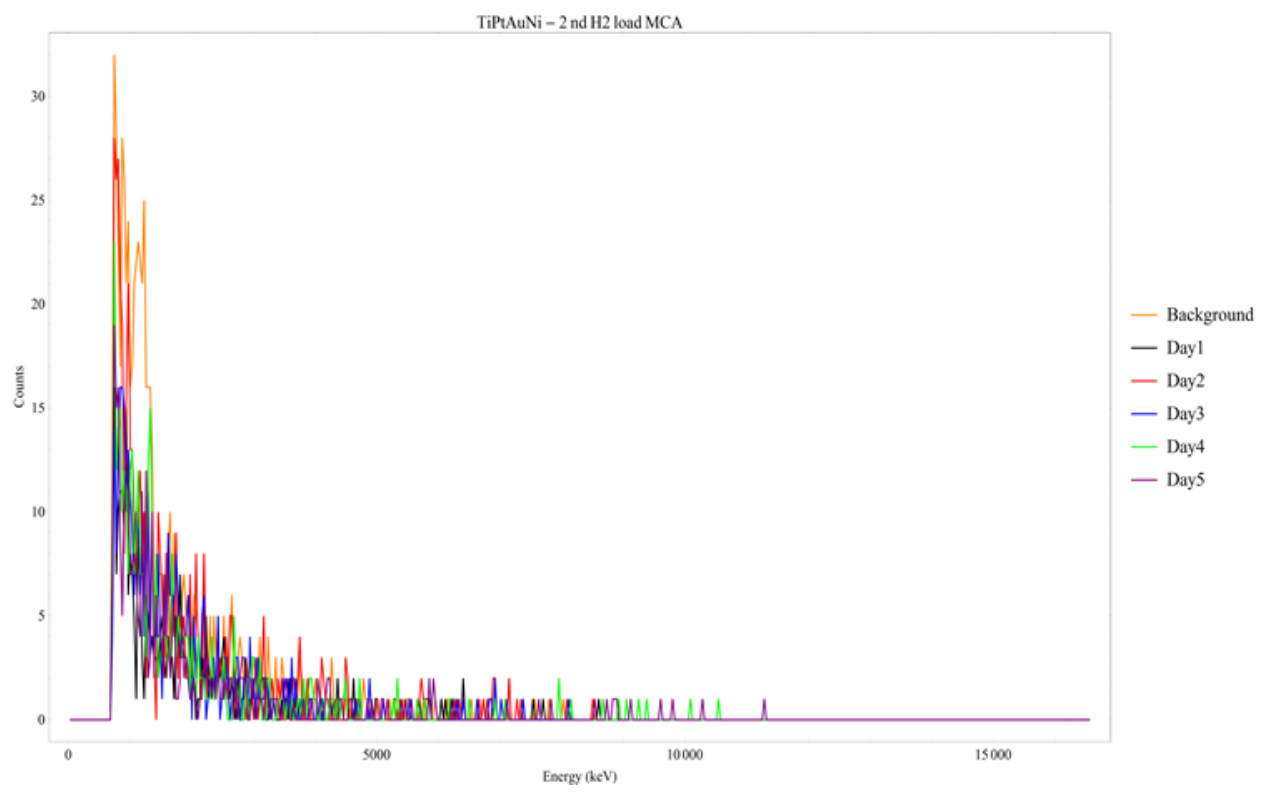

b)

Figure 27: Results of $\mathrm{Ti} / \mathrm{Pt} / \mathrm{Au} / \mathrm{Ni}_{2-1}$ detector background, and second hydrogen loading for five days a) the SCA count rate (counts/100ms) and b) the MCA energy spectrum. 
Table 8: The results of second hydrogen loading of Ti/Pt/Au/Ni2-1 from SCA and MCA.

\begin{tabular}{|c|c|c|}
\hline Load & $\left.\begin{array}{c}\text { SCA } \\
\text { Total count } \\
(\text { Count rate }\end{array}{ }_{\max }\right)$ & $\begin{array}{c}\text { MCA } \\
\text { Total count } \\
\left(\mathrm{E}_{\max }\right)\end{array}$ \\
\hline Background & $\begin{array}{c}748 \\
(11 \mathrm{cts} / 100 \mathrm{~ms})\end{array}$ & $\begin{array}{c}716 \\
(8.02 \mathrm{MeV})\end{array}$ \\
\hline $\begin{array}{c}\text { Hydrogen } \\
\text { Day1 }\end{array}$ & 328 & 303 \\
\hline Day2 & $\begin{array}{c}548 \\
(26 \mathrm{cts} / 100 \mathrm{~ms})\end{array}$ & 535 \\
\hline Day3 & $\begin{array}{c}428 \\
(15 \mathrm{cts} / 100 \mathrm{~ms})\end{array}$ & 410 \\
\hline Day4 & $\begin{array}{c}449 \\
(23 \mathrm{cts} / 100 \mathrm{~ms}\end{array}$ & $\begin{array}{c}422 \\
(10.54 \mathrm{MeV})\end{array}$ \\
\hline Day5 & 387 & $\begin{array}{c}357 \\
(11.23 \mathrm{MeV})\end{array}$ \\
\hline Average 5-day count & 428 & 405 \\
\hline
\end{tabular}

\section{Ti/Pt/Au/Ni2-2}

In this trial with $\mathrm{Ti} / \mathrm{Pt} / \mathrm{Au} / \mathrm{Ni}_{2-2}$, to see any different possible results from the results of $\mathrm{Ti} / \mathrm{Pt} / \mathrm{Au} / \mathrm{Ni}_{2-1}$, the helium control gas was loaded before hydrogen loading. In addition, deuterium gas loading was attempted to see any possible results of nickeldeuterium interaction.

\section{Ti/Pt/Au/Ni2-2 - Helium control gas}

Helium was loaded at 100 psi and left for seven days. Figure 28 shows the plots of SCA and MCA data for 1-day background and 7-day of helium control gas loading, respectively. The results summary is given in Table 9. In this trial, the noise from the previous run was determined; therefore, the lower limit discrimination of the amplifier was adjusted to lower the noise level. 


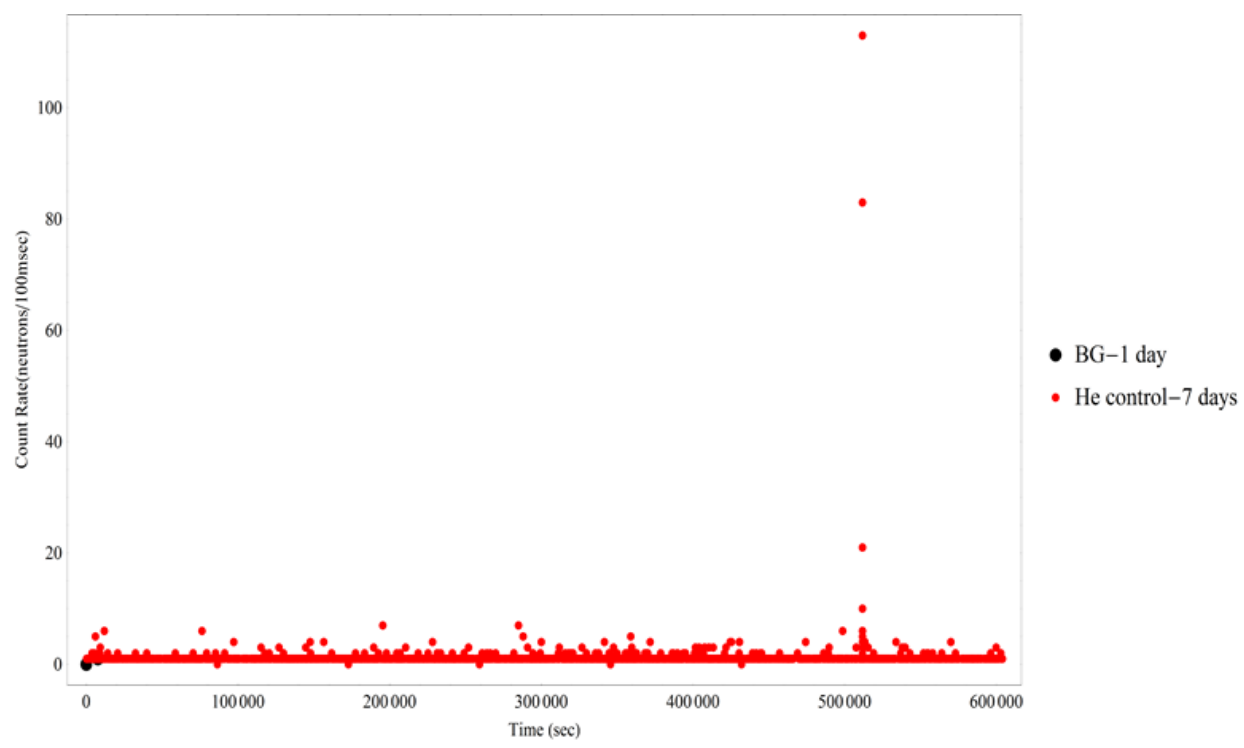

a)

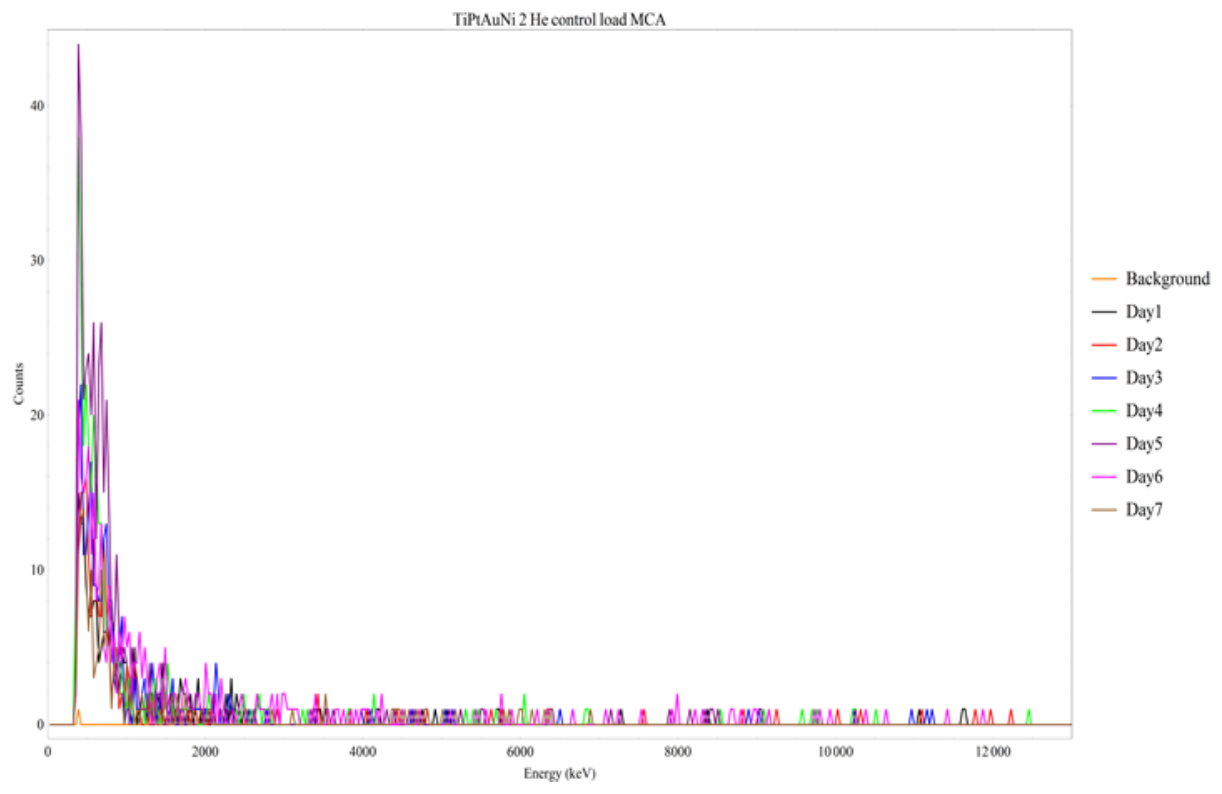

b)

Figure 28: Results of Ti/Pt/Au/Ni2-1 background, and helium control gas loading for seven days a) the SCA count rate (counts/100ms) and b) the MCA energy spectrum. 
The total count of the 1-day background is 1 count from both SCA and MCA. The maximum energy of the MCA background is at $390 \mathrm{keV}$. After noise adjustment, the background count was very low relatively.

Table 9: The results of $\mathrm{Ti} / \mathrm{Pt} / \mathrm{Au} / \mathrm{Ni}_{2-2}$ helium control gas loading from SCA and MCA.

\begin{tabular}{|c|c|c|}
\hline Load & $\begin{array}{c}\text { SCA } \\
\text { Total count } \\
\left(\text { Count rate }{ }_{\text {max }}\right)\end{array}$ & $\begin{array}{c}\text { MCA } \\
\text { Total count } \\
\left(\mathrm{E}_{\text {max }}\right)\end{array}$ \\
\hline $\begin{array}{c}1 \\
\text { Background }\end{array}$ & $\begin{array}{c}1 \\
(1 \mathrm{cts} / 100 \mathrm{~ms})\end{array}$ & 218 \\
\hline $\begin{array}{c}\text { Helium Control } \\
\text { Day1 }\end{array}$ & 213 & 205 \\
\hline Day2 & 204 & 258 \\
\hline Day3 & 330 & 337 \\
\hline Day4 & 414 & 313 \\
\hline Day5 & 433 & 166 \\
\hline Day6 & $(113$ cts/100ms $)$ & 278 \\
\hline Day7 & 165 & 352 \\
\hline Average 7-day count & 288 & 256 \\
\hline
\end{tabular}

In this helium control gas loading, the total count for SCA and MCA for seven days are summarized as in Table 9. The average total count of SCA and MCA 7-day helium run are 288 and 278 counts, respectively, that are both higher than 1 counts of the SCA and MCA background. 


\section{Ti/Pt/Au/Ni2-2 - Hydrogen gas loading}

After the helium load, the detector chamber was pumped down and prepared for the hydrogen loading experiment. Figure 29 shows the plots of SCA and MCA data for 1day background and 7-day of hydrogen loading experiment, respectively. The results summary is shown in Table 10.

The total count of 24-hour background from both SCA and MCA are the same as seen in the previous helium loading runs. The maximum count rate of SCA background is 1 count/100ms and the maximum energy of MCA background is at $390 \mathrm{keV}$.

As seen in Table 10, the average total count of SCA and MCA 7-day hydrogen run are 156 and 160 counts, respectively, higher than 1 counts from the SCA and MCA background. The maximum count rates from SCA run were seen significantly higher at Day-2 with 26 counts/100ms, which is about $185 \%$ different from the background. And, it is clearly seen that the maximum count from the MCA was at Day-2 was 214 counts. 


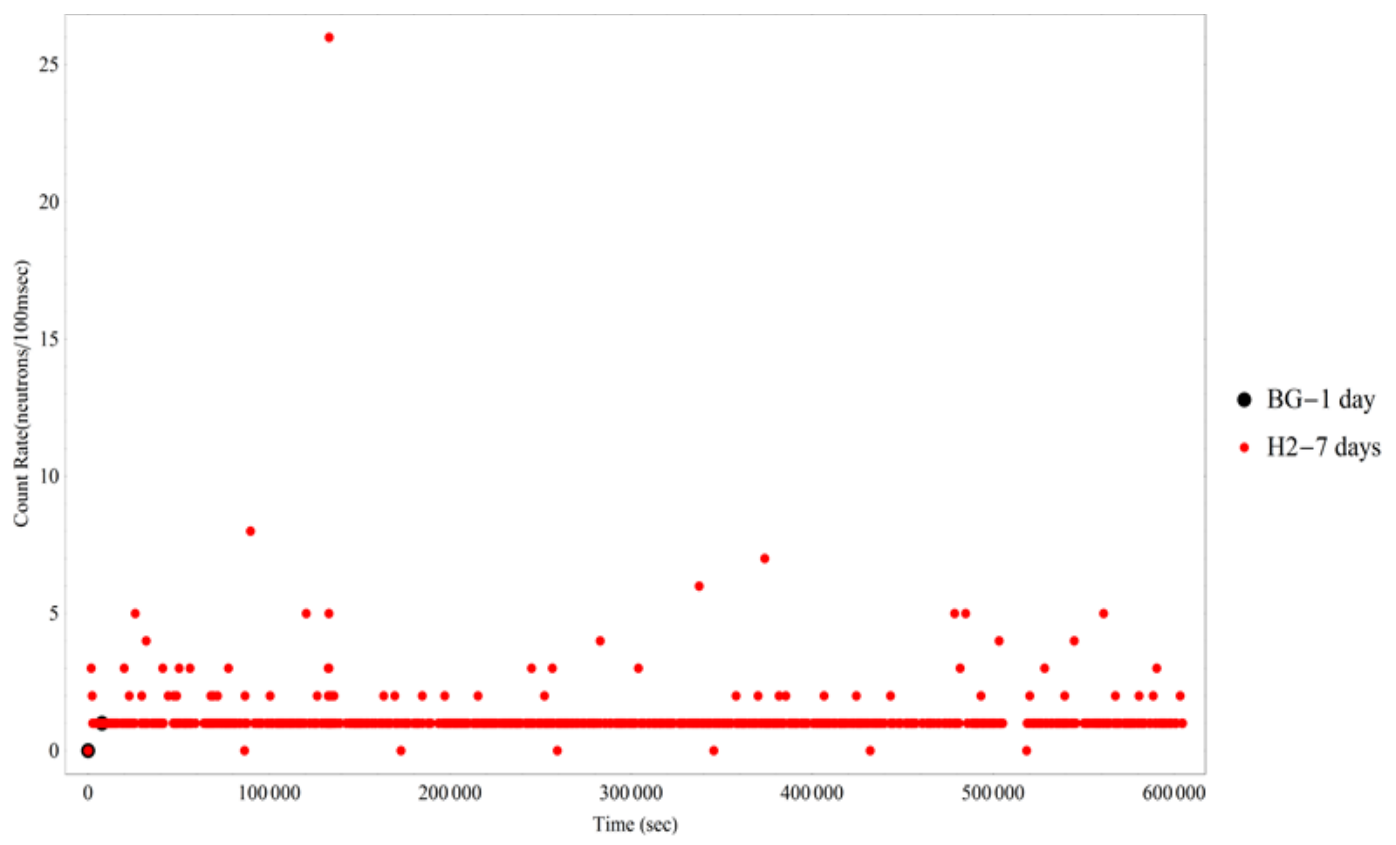

a)

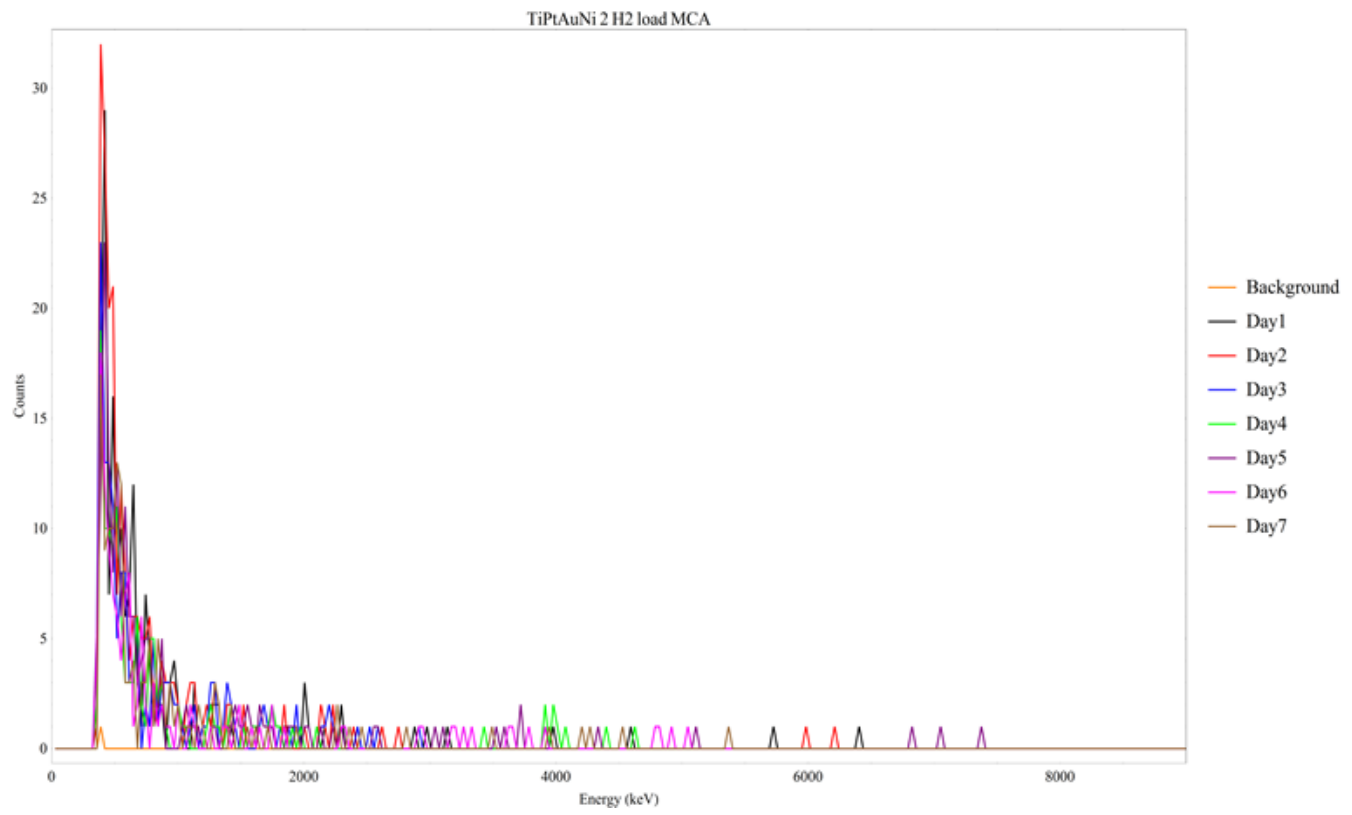

b)

Figure 29: Results of Ti/Pt/Au/Ni2-2 detector background, and hydrogen loading for seven days a) the SCA count rate (counts/100ms) and b) the MCA energy spectrum. 
Table 10: The Ti/Pt/Au/Ni 2-2 hydrogen loading results from SCA and MCA.

\begin{tabular}{|c|c|c|}
\hline Load & $\begin{array}{c}\text { SCA } \\
\text { Total count } \\
\text { (Count rate }_{\text {max }} \text { ) }\end{array}$ & $\begin{array}{c}\text { MCA } \\
\text { Total count } \\
\left(\mathrm{E}_{\max }\right)\end{array}$ \\
\hline Background & $\begin{array}{c}1 \\
(1 \mathrm{cts} / 100 \mathrm{~ms})\end{array}$ & $\begin{array}{c}1 \\
(0.390 \mathrm{MeV})\end{array}$ \\
\hline $\begin{array}{r}\text { Helium Control } \\
\text { Day1 } \\
\end{array}$ & 181 & 180 \\
\hline Day2 & $\begin{array}{c}217 \\
(26 \mathrm{cts} / 100 \mathrm{~ms}) \\
\end{array}$ & 214 \\
\hline Day3 & 154 & 158 \\
\hline Day4 & 134 & 136 \\
\hline Day5 & 167 & 170 \\
\hline Day6 & 98 & 128 \\
\hline Day7 & 138 & 135 \\
\hline Average 7-day count & 156 & 160 \\
\hline
\end{tabular}

\section{Ti/Pt/Au/Ni2-2 - Deuterium gas loading}

After the helium and hydrogen loadings, the detector chamber was pumped down and loaded with deuterium gas at 100 psi. As nickel-deuterium interaction was expected to be inconsequential, there was no expectation to see significant results. The plots of SCA and MCA of Ti/Pt/Au/ $\mathrm{Ni}_{2-2}$ - deuterium loaded for a 7-day run are shown in Figure 30. 


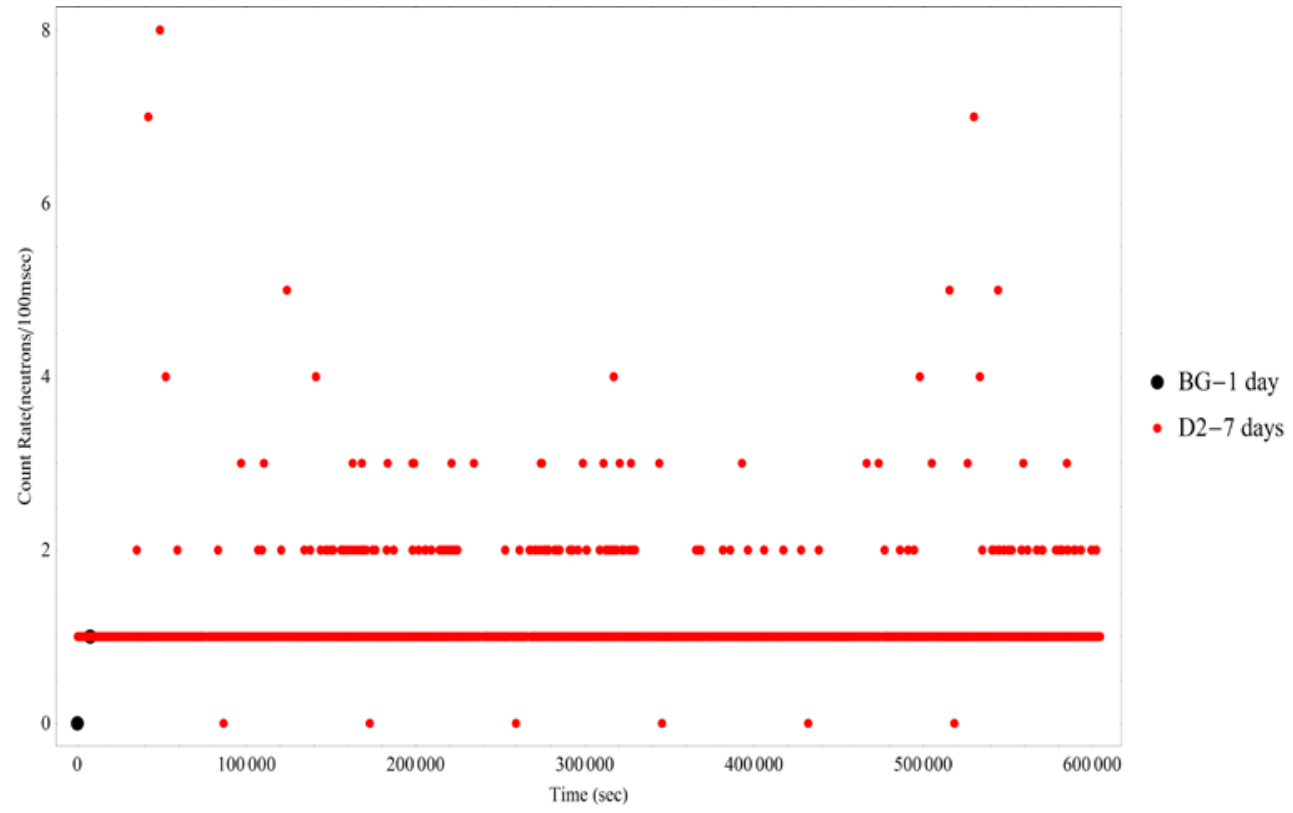

a)

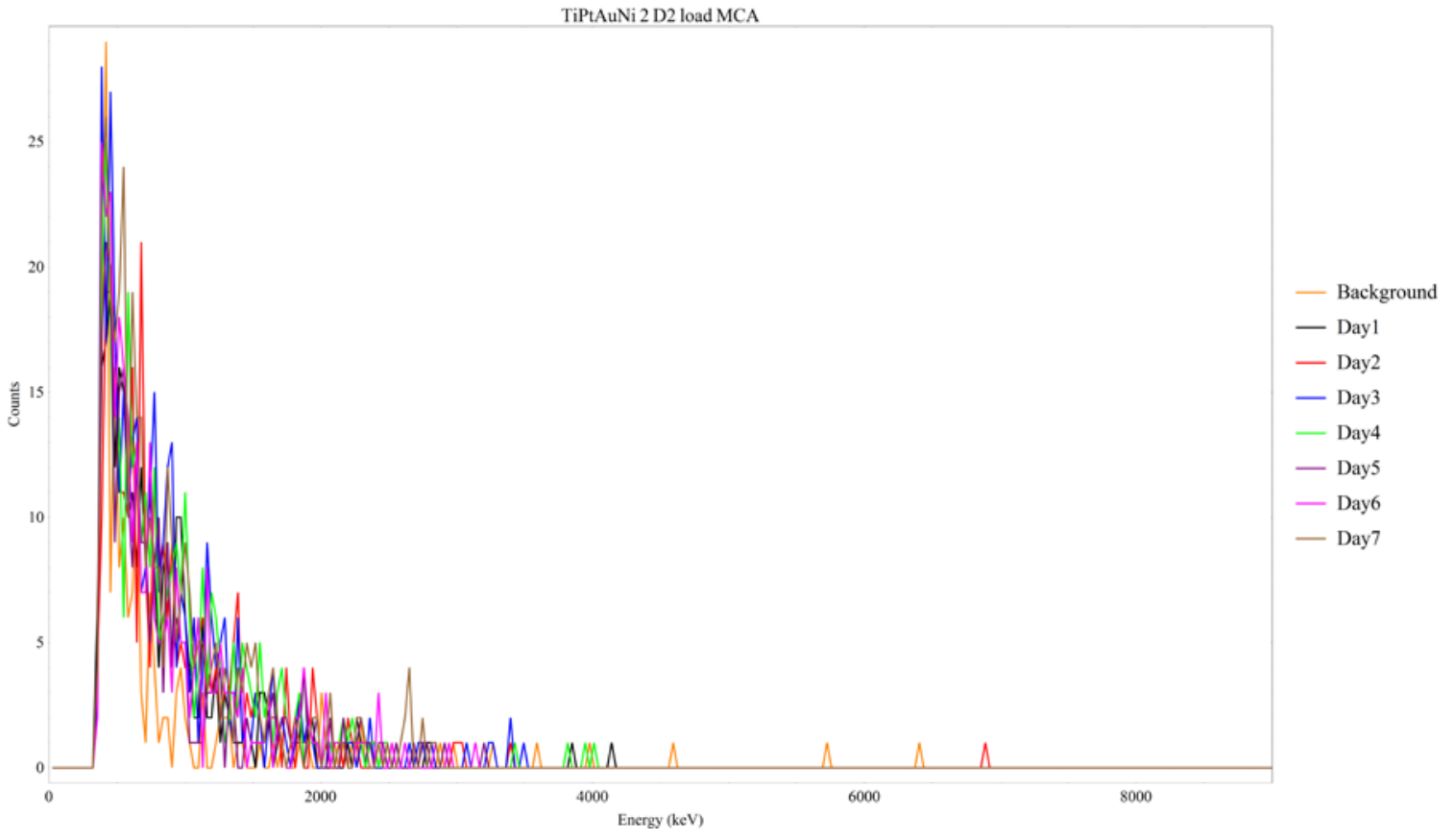

b)

Figure 30: Results of $\mathrm{Ti} / \mathrm{Pt} / \mathrm{Au} / \mathrm{Ni}_{2-2}$ detector background, and deuterium loading for seven days a) the SCA count rate (counts/100ms) and b) the MCA energy spectrum. 


\subsubsection{Experiment-4: Nickel-Hydrogen ( $\mathrm{Ti} / \mathrm{Pt} / \mathrm{Au} / \mathrm{Ni} 2-1$ and $\left.\mathrm{Ti} / \mathrm{Pt} / \mathrm{Au} / \mathrm{Ni}_{2-2}\right)$}

This last experiment, Ti/Pd detectors were fabricated. However, as mentioned before, $\mathrm{Ti} / \mathrm{Pd}_{2-1}$ had a broken wire bond and could not successfully be fixed. The $\mathrm{Ti} / \mathrm{Pd}_{2-2}$ detector used for background counts over one day under vacuum by a diffusion pump. Then, it was first loaded with deuterium; however, the maximum pressure only reached 85 psi due to the incomplete gas loading system connection. Therefore, after resolving the loading system, the $\mathrm{Ti} / \mathrm{Pd}_{2-2}$ was loaded at 100 psi for seven days. The detector was repeatedly loaded with deuterium gas three times and finally loaded with helium control gas. There were not significant results from these deuterium loadings as compared to the results from Experiment-1. The second, third and fourth deuterium loadings and helium control gas loading of $\mathrm{Ti} / \mathrm{Pd}_{2-2}$ are shown in Figure 31-34. The count rate SCA plots of the three deuterium loadings show that the count rate bursts are between 2-4 counts/100ms. While the last helium control gas loading showed a higher count rate at 6 counts/100ms. 


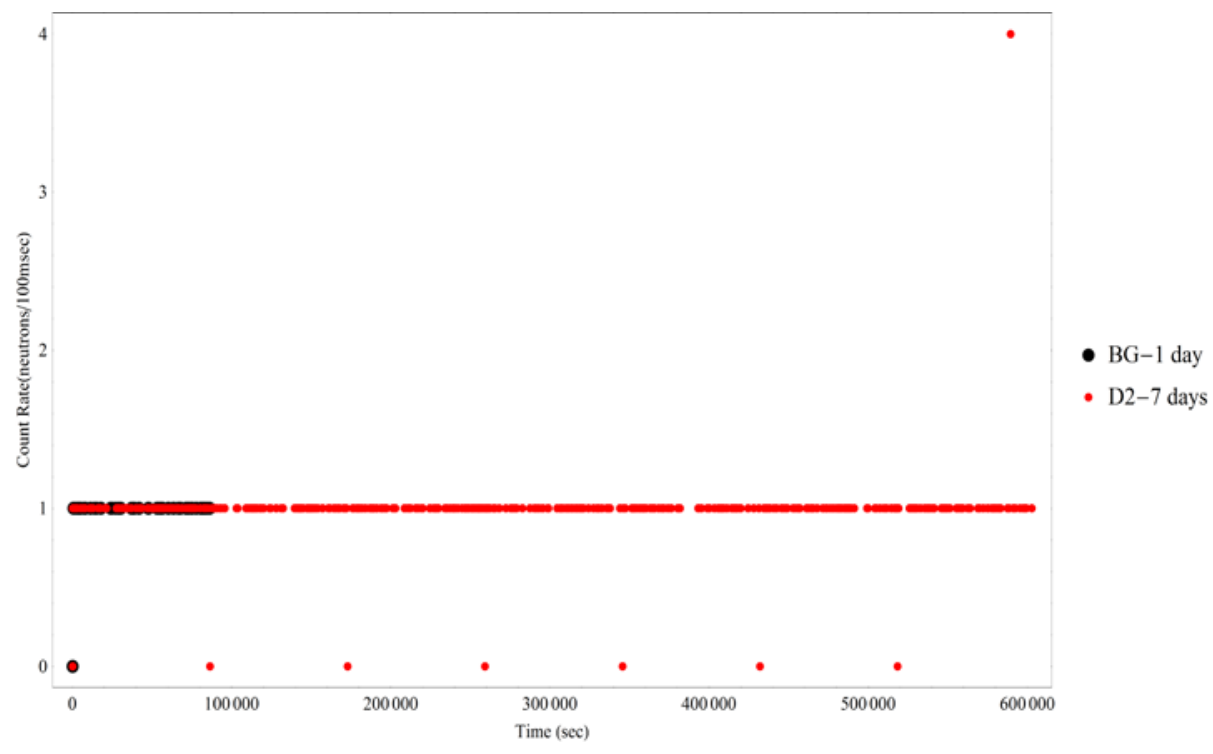

a)

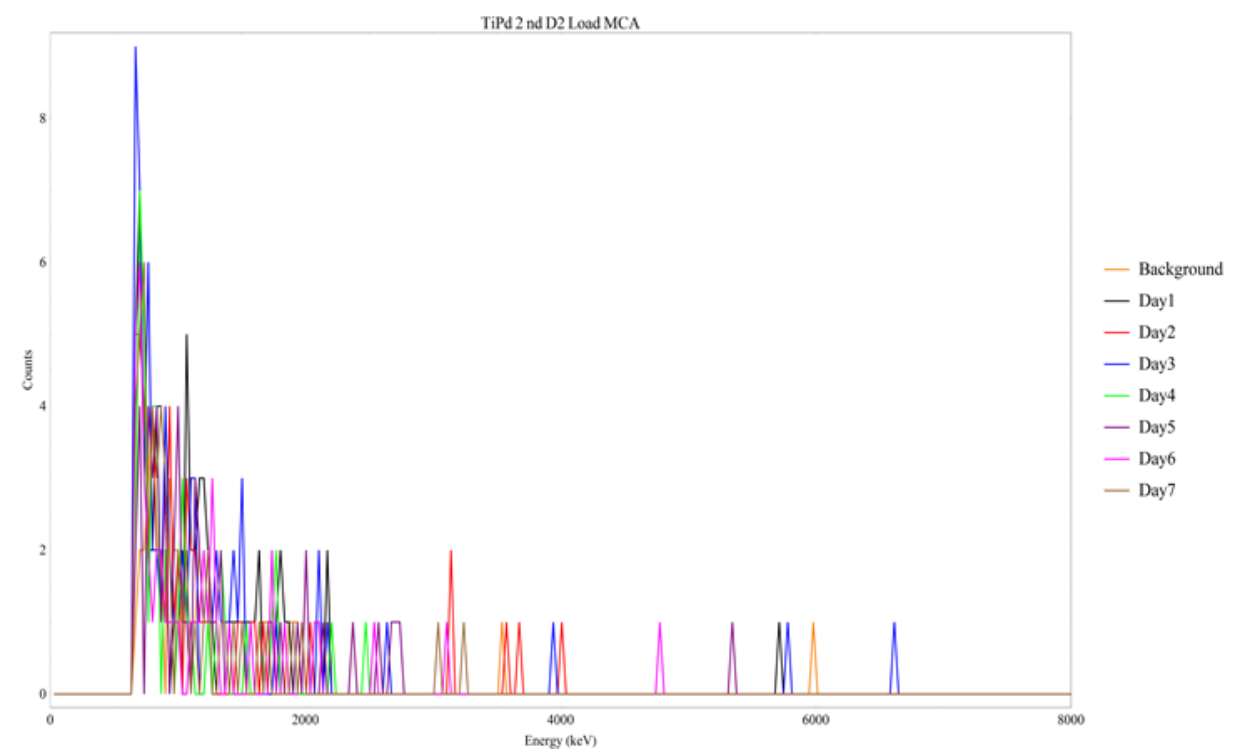

b)

Figure 31: Results of $\mathrm{Ti} / \mathrm{Pd}_{2-2}$ detector background, and second deuterium loading for seven days a) the SCA count rate (counts/100ms) and b) the MCA energy spectrum. 


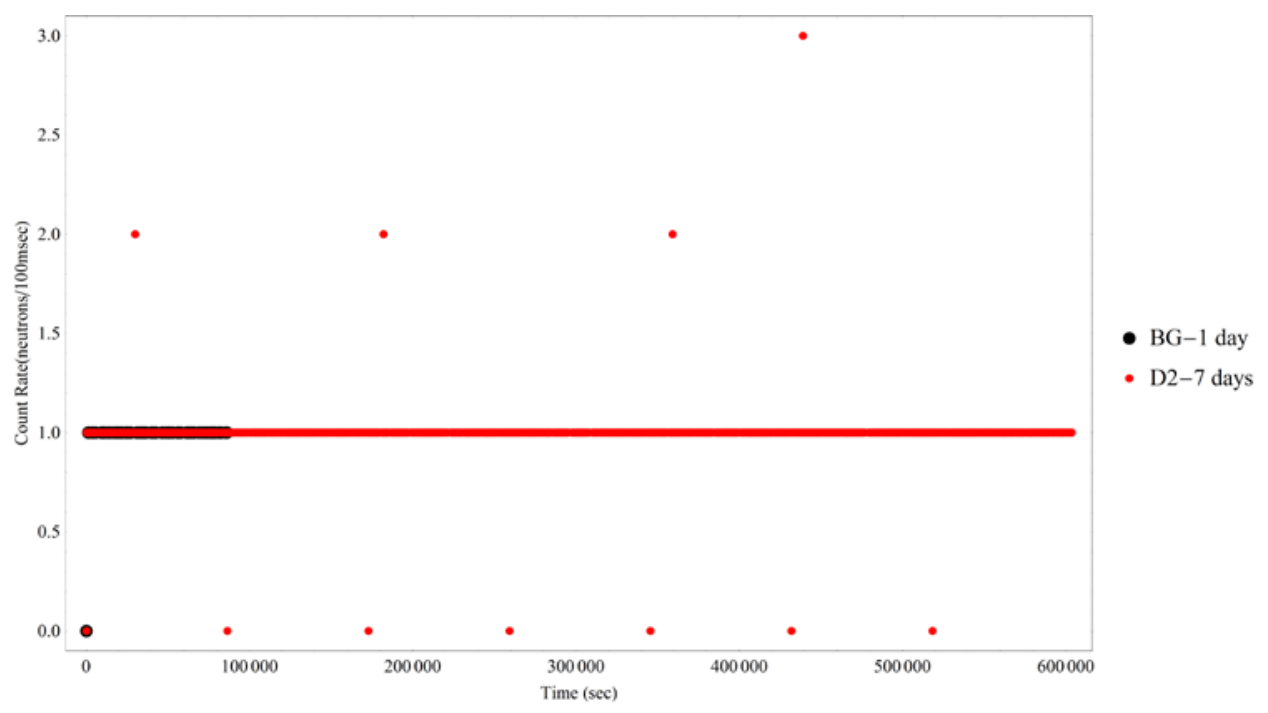

a)

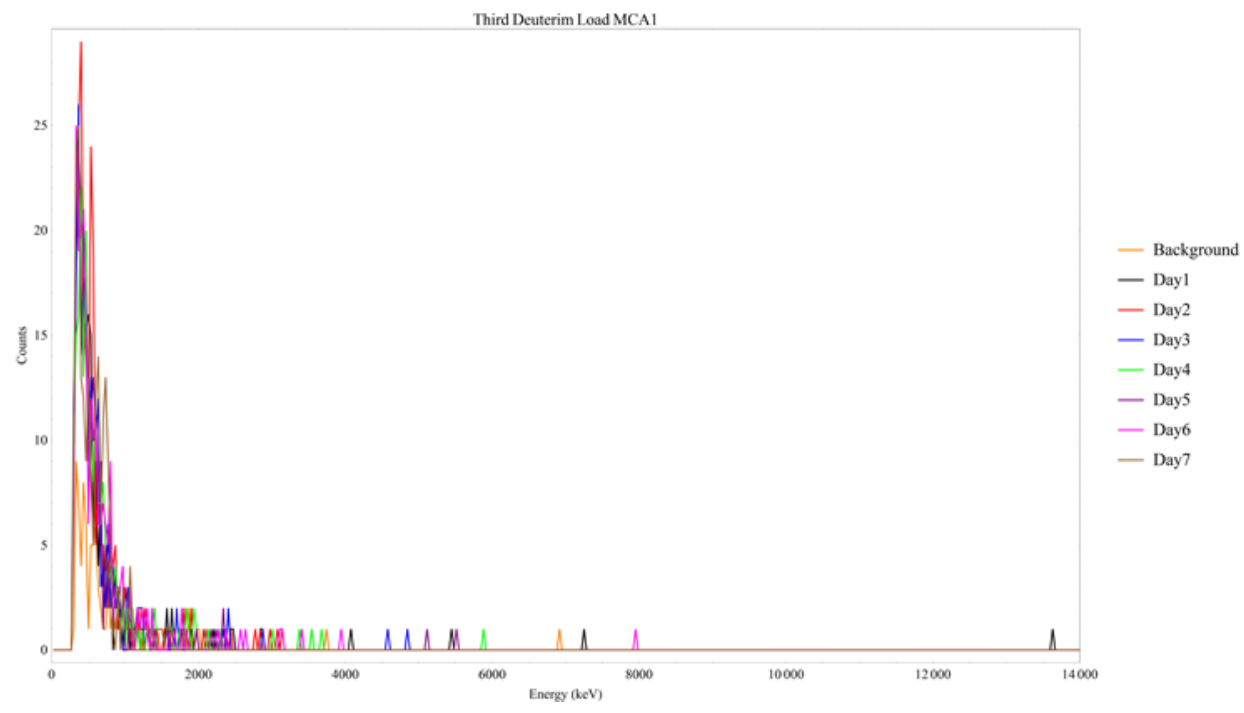

b)

Figure 32: Results of $\mathrm{Ti} / \mathrm{Pd}_{2-2}$ detector background, and third deuterium loading for seven days a) the SCA count rate (counts/100ms) and b) the MCA energy spectrum. 


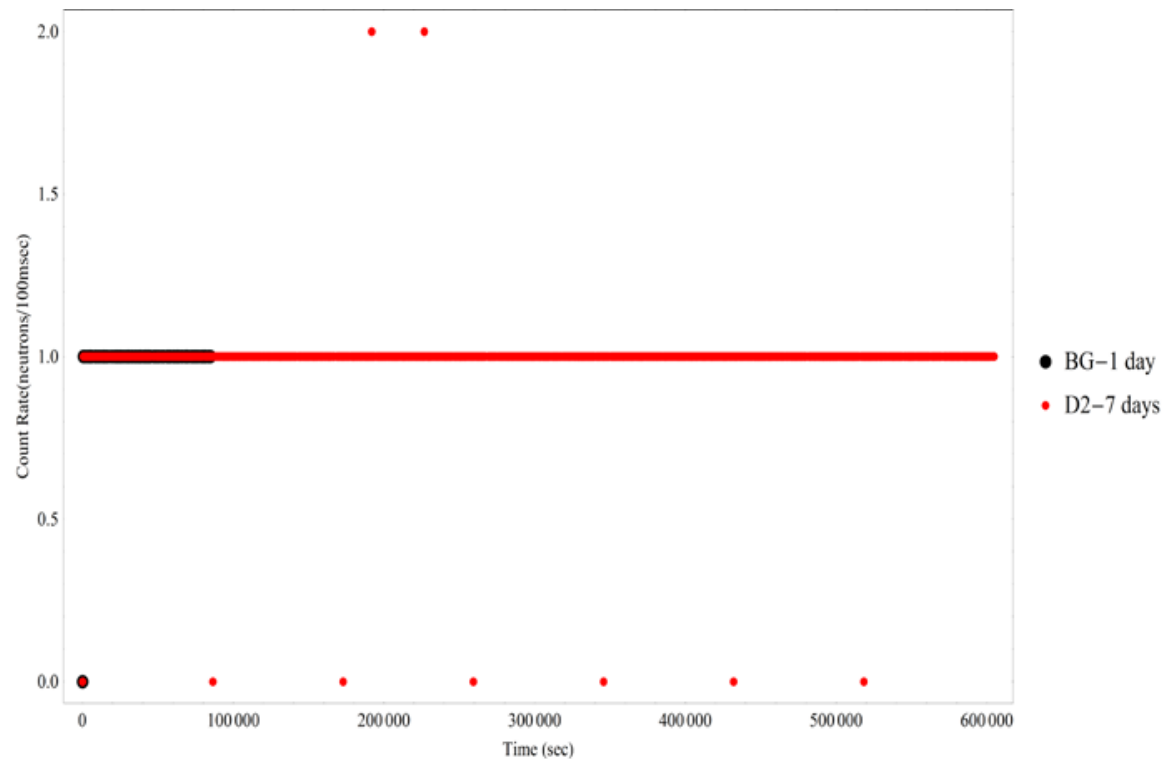

a)

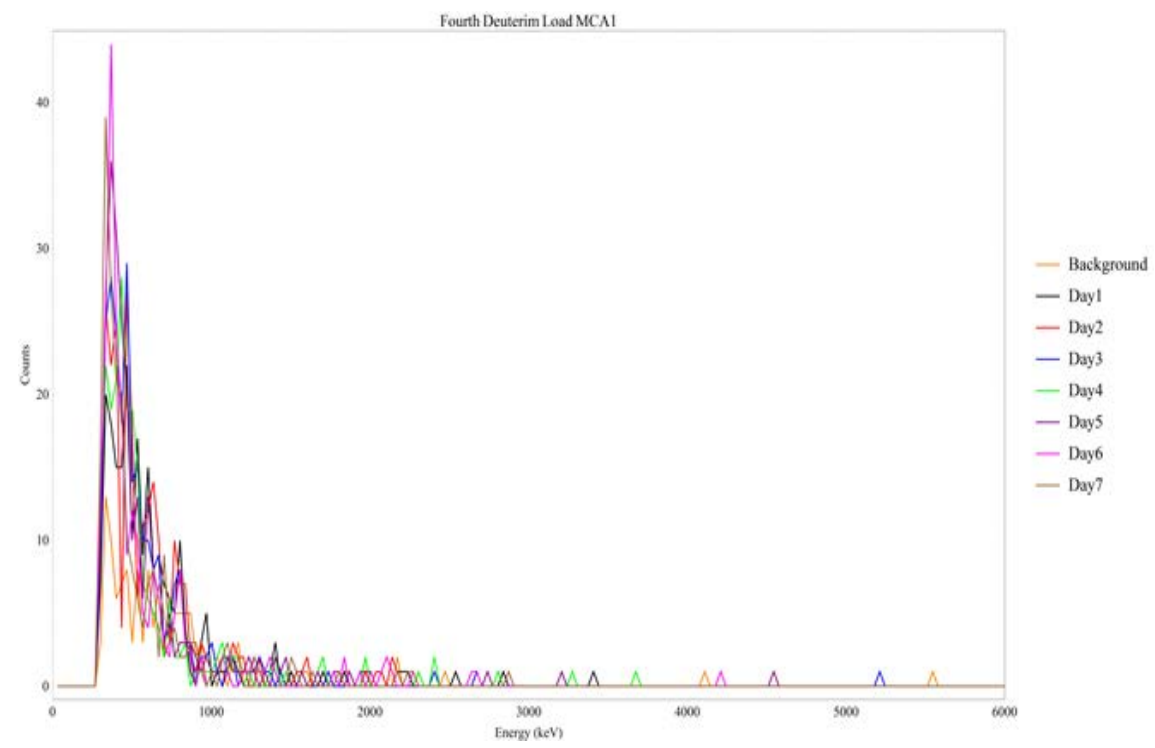

b)

Figure 33:Results of $\mathrm{Ti} / \mathrm{Pd}_{2-2}$ detector background, and fourth deuterium loading for seven days a) the SCA count rate (counts/100ms) and b) the MCA energy spectrum. 


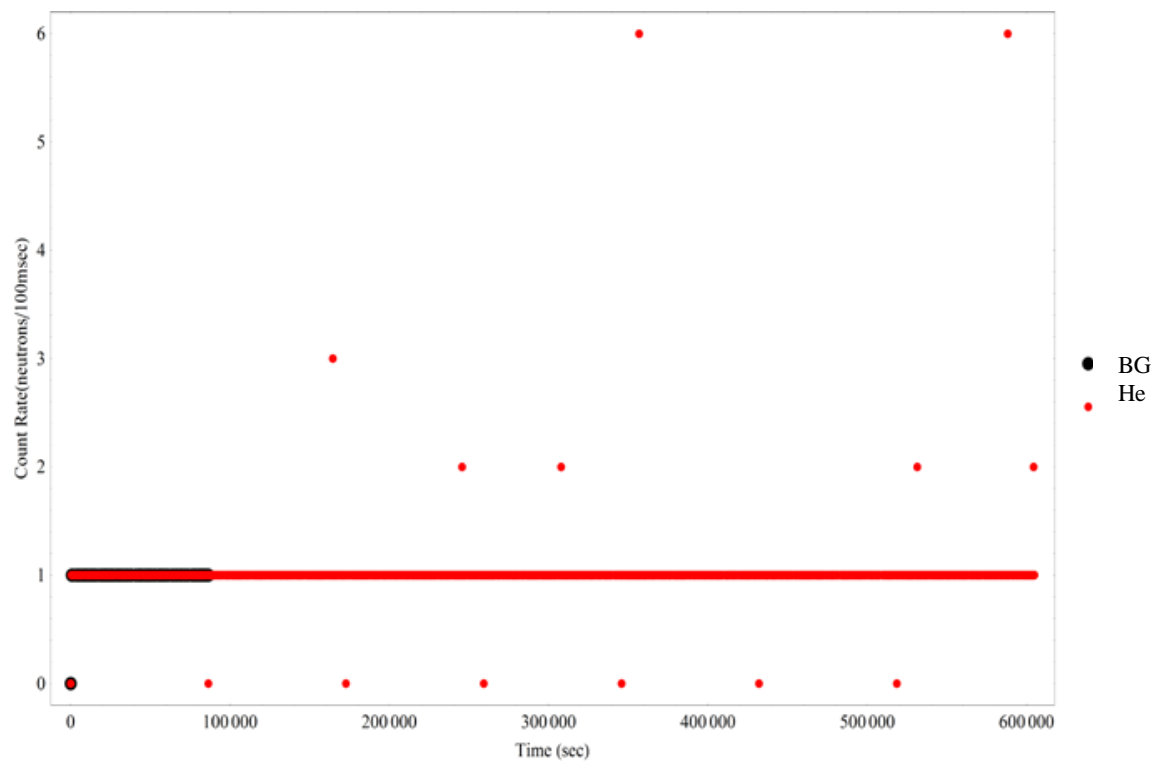

a)

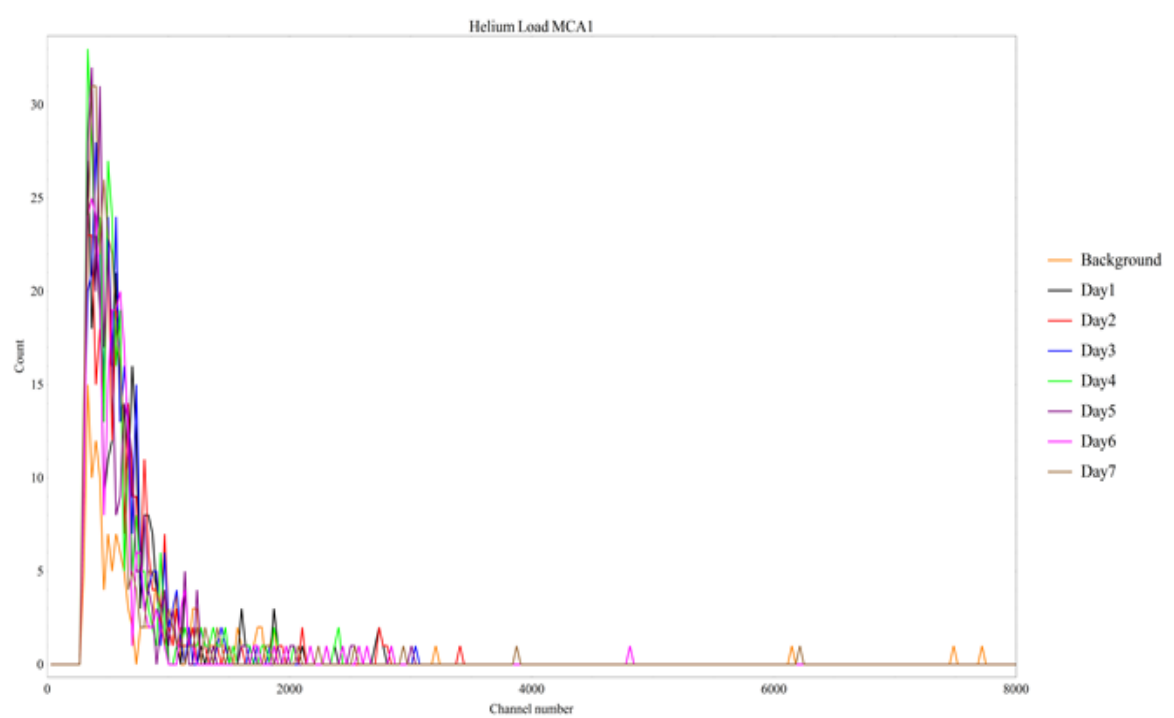

b)

Figure 34:Results of $\mathrm{Ti} / \mathrm{Pd}_{2-2}$ detector background, and helium control gas loading for seven days a) the SCA count rate (counts/100ms) and b) the MCA energy spectrum. 
Table 11: The results of $\mathrm{Ti} / \mathrm{Pd}_{2-2}$ Second deuterium loading from SCA and MCA.

\begin{tabular}{|c|c|c|}
\hline Load & $\left.\begin{array}{c}\text { SCA } \\
\text { Total count } \\
(\text { Count rate } \\
\text { max }\end{array}\right)$ & $\begin{array}{c}\text { MCA } \\
\text { Total count } \\
\left(\mathrm{E}_{\max }\right)\end{array}$ \\
\hline Background & $\begin{array}{c}46 \\
(1 \mathrm{cts} / 100 \mathrm{~ms})\end{array}$ & 42 \\
\hline $\begin{array}{c}\text { Deuterium } \\
\text { Day1 }\end{array}$ & 80 & 71 \\
\hline Day2 & 69 & 57 \\
\hline Day3 & 71 & 70 \\
\hline Day4 & 52 & 46 \\
\hline Day5 & 58 & 56 \\
\hline Day6 & 63 & 46 \\
\hline Day7 & 70 & 52 \\
\hline
\end{tabular}


Table 12: The results of $\mathrm{Ti} / \mathrm{Pd}_{2-2}$ Third deuterium loading from SCA and MCA.

\begin{tabular}{|c|c|c|}
\hline Load & $\begin{array}{c}\text { SCA } \\
\text { Total count } \\
\left(\text { Count rate }_{\text {max }}\right)\end{array}$ & $\begin{array}{c}\text { MCA } \\
\text { Total count } \\
\left(\mathrm{E}_{\text {max }}\right)\end{array}$ \\
\hline Background & $\begin{array}{c}83 \\
(6.92 \mathrm{MeV})\end{array}$ & $\begin{array}{c}230 \\
(1 \mathrm{cts} / 100 \mathrm{~ms})\end{array}$ \\
\hline $\begin{array}{c}\text { Deuterium } \\
\text { Day1 }\end{array}$ & $\begin{array}{c}211 \\
(13.6 \mathrm{MeV})\end{array}$ & 256 \\
\hline Day2 & 244 & 227 \\
\hline Day3 & 212 & 216 \\
\hline Day4 & 207 & 228 \\
\hline Day5 & 217 & 246 \\
\hline Day6 & $(7.9 \mathrm{MeV})$ & $(3 \mathrm{cts} / 100 \mathrm{~ms})$ \\
\hline Day7 & 212 & 221 \\
\hline
\end{tabular}




\subsection{SEM Imaging}

The Scanning Electron Microscope was used to investigate any possible related evidence correspondence to the gas loading experiment. The images of selected detectors were done before and after gas loading phase as shown below.

\subsubsection{Experiment-1: Ti/Pd1-1}

As seen in Figure 35, there were some scratch marks on the metal layers before deuterium loading. After deuterium loading, there were different surface patterns on the metal layers. It can be seen that several holes and tracks were observed on the top surface of metallization layers.

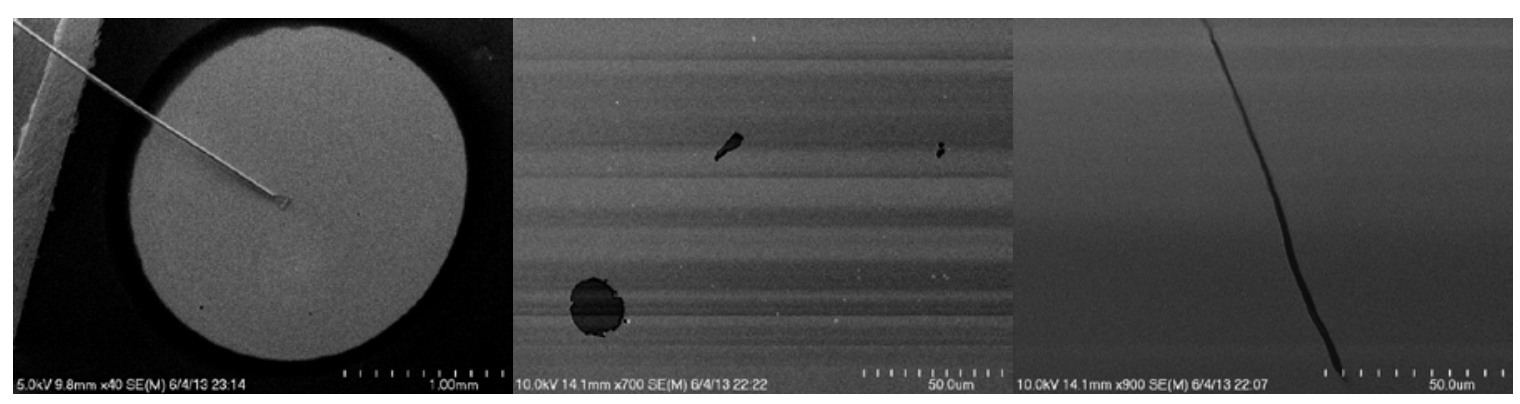

a) Before gas loading

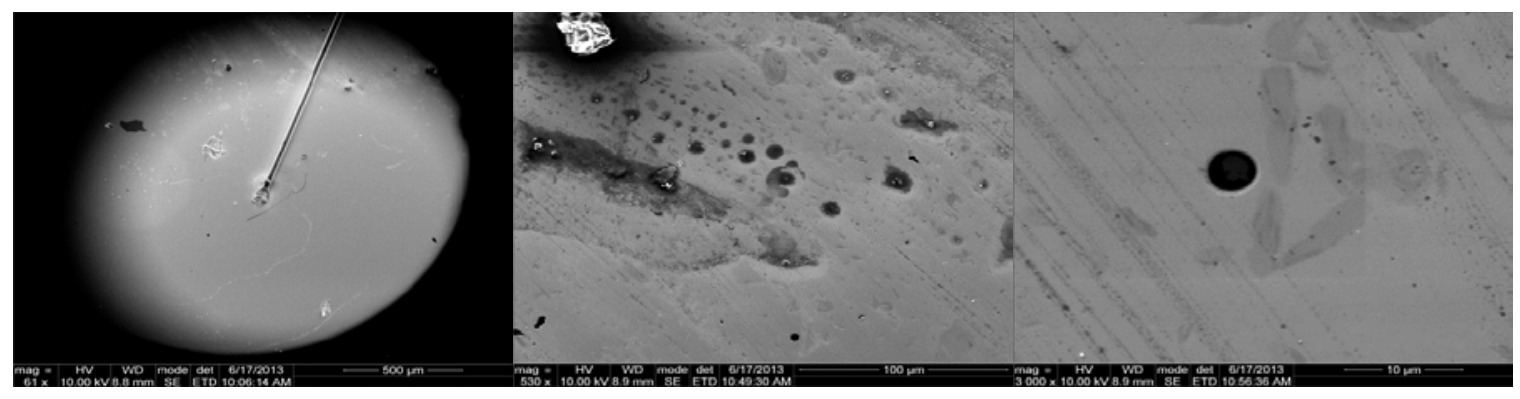

b) After deuterium gas loading

Figure 35: SEM images of $\mathrm{Ti} / \mathrm{Pd}_{1-1}$ detector before and after gas loading in Experiment-1. 
In addition, Energy Dispersive Spectroscopy (EDS) on the SEM showed that the holes created on the metal surface of the diamond detector in Experiment-1. As the EDS analysis of the position number 2 in Figure 36, it seemed to be a layer of titanium or the diamond plate itself. It can be concluded that the palladium layer was not observed in these holes.

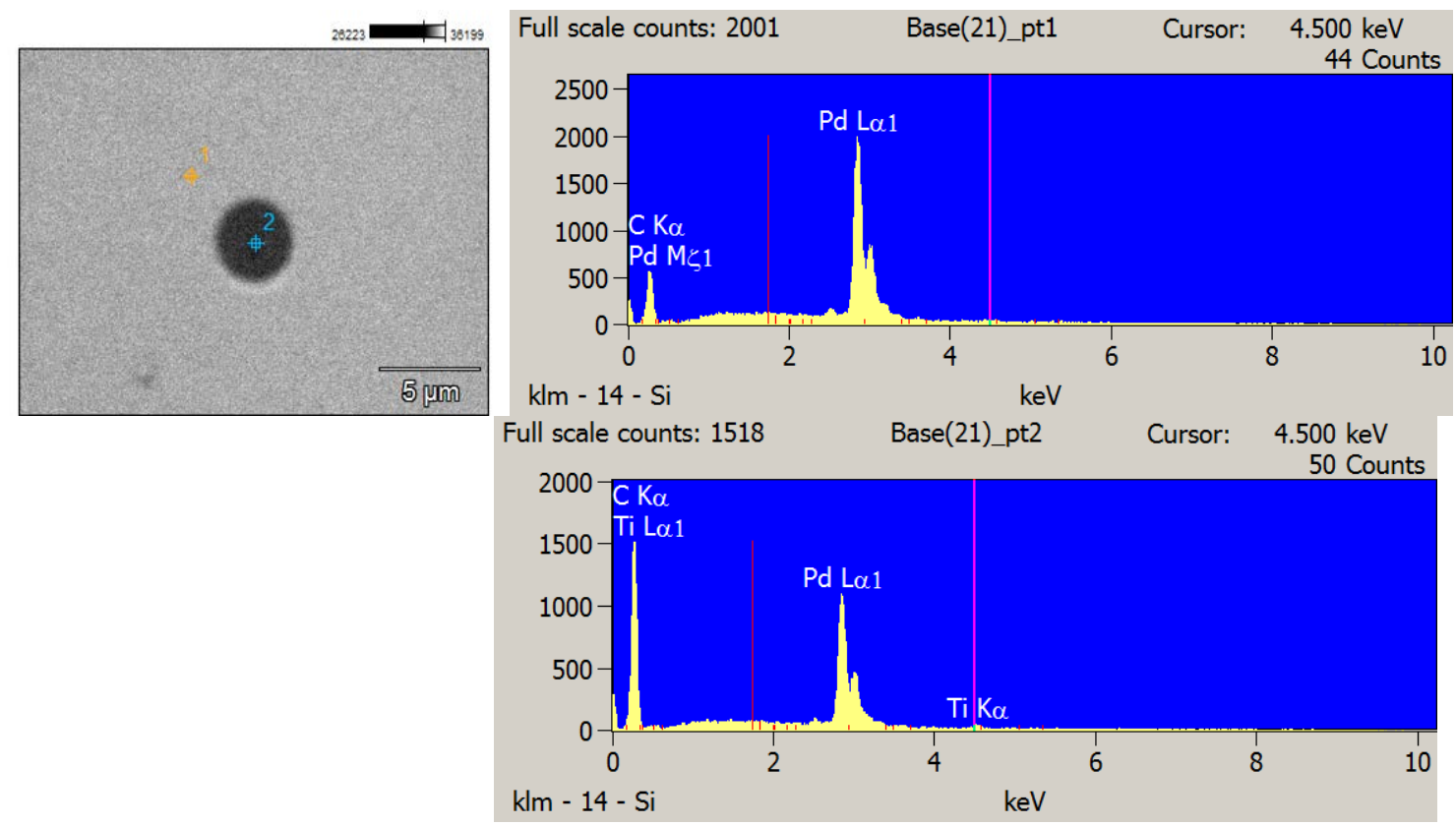

Figure 36: SEM images of $\mathrm{Ti} / \mathrm{Pd}_{1-1}$ detector using EDS to analyze the metal surface after deuterium gas loading in Experiment-1. 


\subsubsection{Experiment-3: $\mathrm{Ti} / \mathrm{Pt} / \mathrm{Au} / \mathrm{Ni}_{1-2}$}
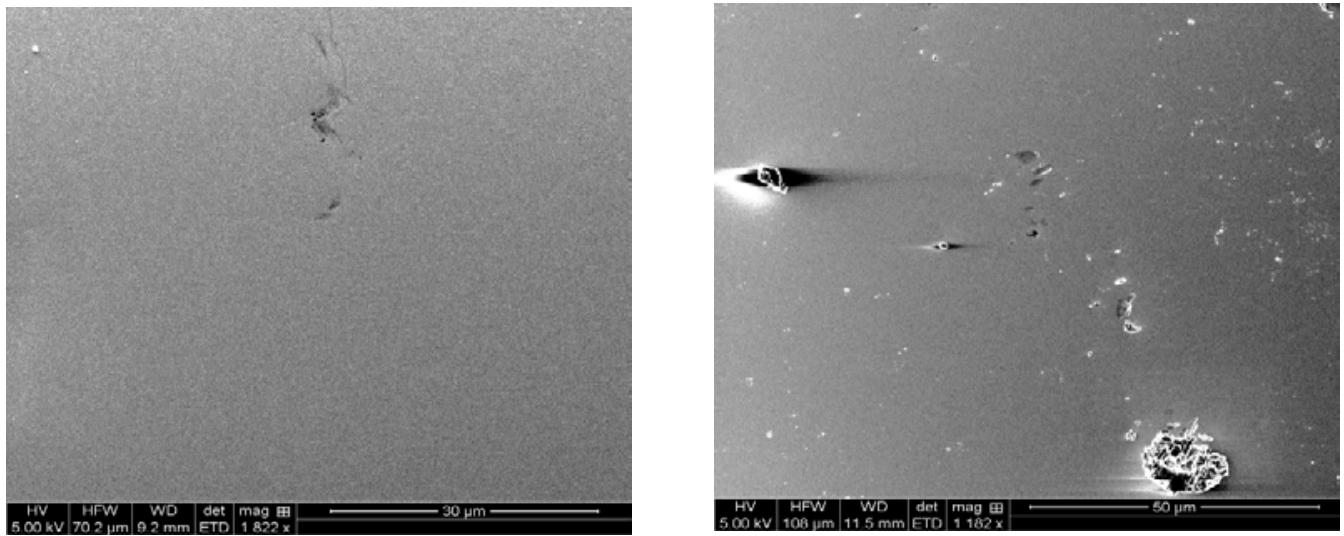

a) Before gas loading
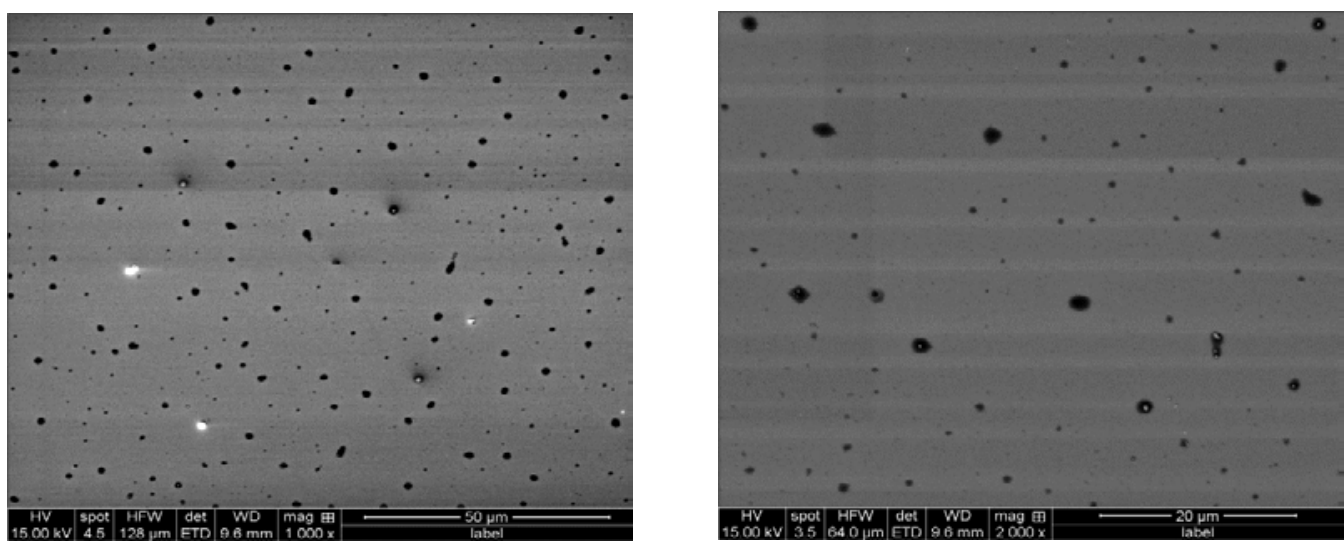

b) After deuterium gas loading

Figure 37: SEM images of Ti/Pt/Au/Ni $\mathrm{Ni}_{1-2}$ detector before and after He, H2, D2 gas loadings.

Figure 37 displays interesting SEM images of $\mathrm{Ti} / \mathrm{Pt} / \mathrm{Au} / \mathrm{Ni}_{1-2}$. It clearly shows the porosity all over the metallization layer after helium, hydrogen and deuterium gas loadings. It is hard to conclude that that the metal layers affected from the gas loading stage or from one or more interactions of host metals with hydrogen or deuterium gas. 


\subsubsection{Experiment-4: $\mathbf{T i} / \mathbf{P d}_{2-2}$}
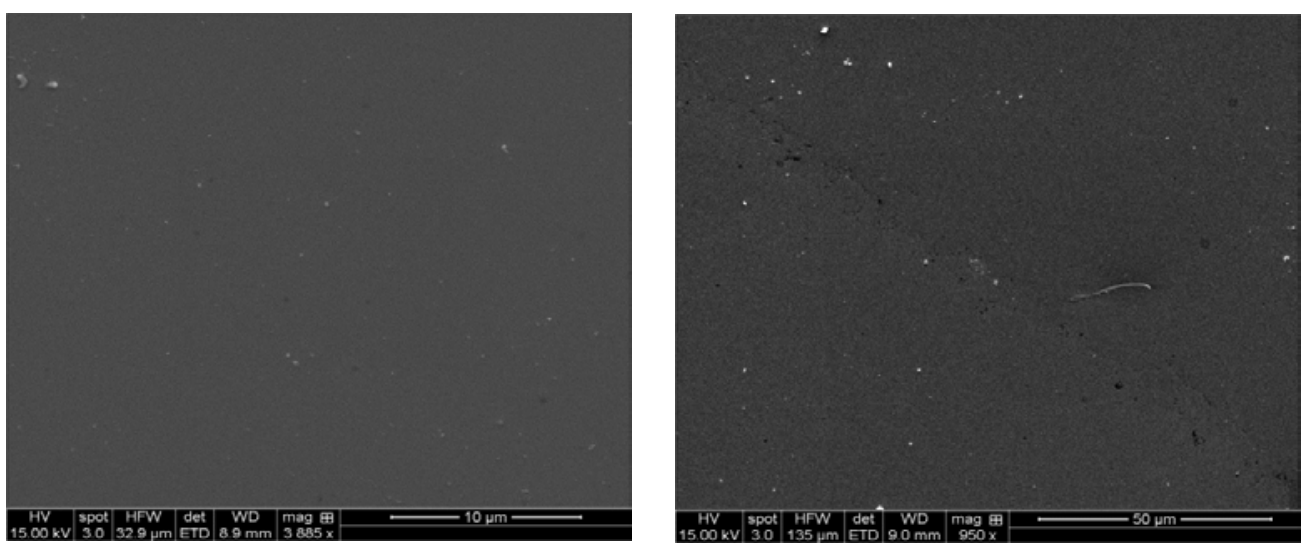

a) Before gas loading
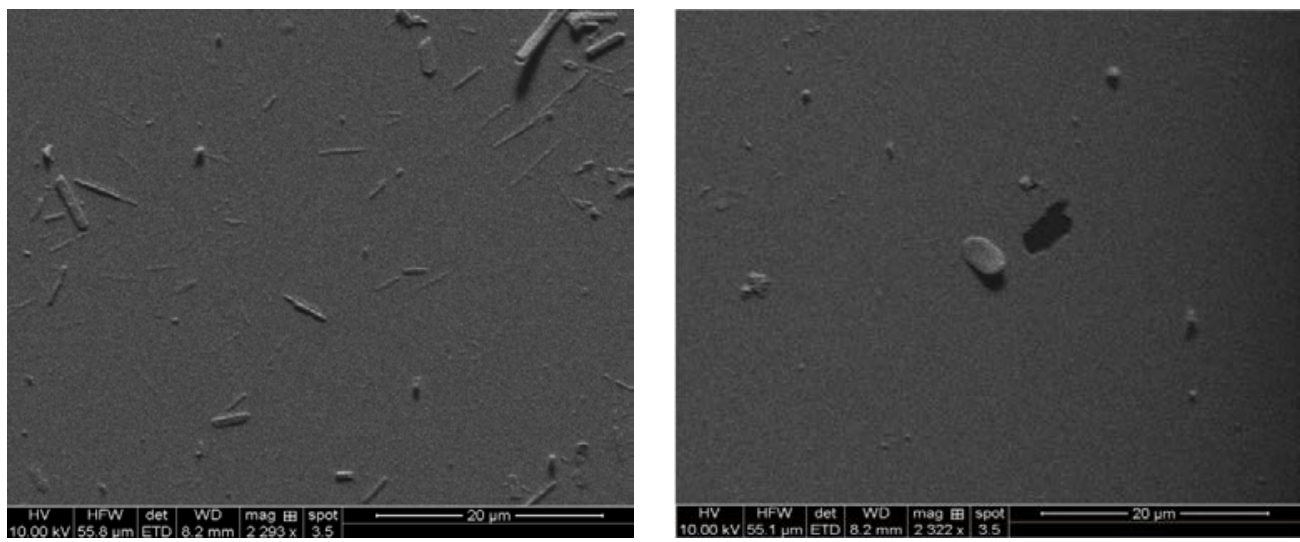

b) After gas loading

Figure 38: SEM images of Ti/Pd 2 -2 detector before and after $\mathrm{D} 2$ and He gas loadings.

The SEM images of $\mathrm{Ti} / \mathrm{Pd}_{2-2}$ in Experiment-4 (see Figure 38) did not present any holes or significant tracks as seen previously in Experiment-1 and Experiment-3. There were small fractures randomly scatter on the surface, but none of the supported concepts can explain this phenomenon. 


\subsection{Detector Response to Radiations (Alpha and Beta)}

\subsubsection{Simulation with Alpha and Beta}

Simulation software called Transport of ions in matter (TRIM) was used to estimate the track of an alpha particle within a CVD diamond plate. As seen in Figure 39, alpha particles at 5.24 MeV have tracks through the CVD diamond plate of $12.7 \mu \mathrm{m}$ whereas the CVD diamond plate thickness is $50 \mu \mathrm{m}$.
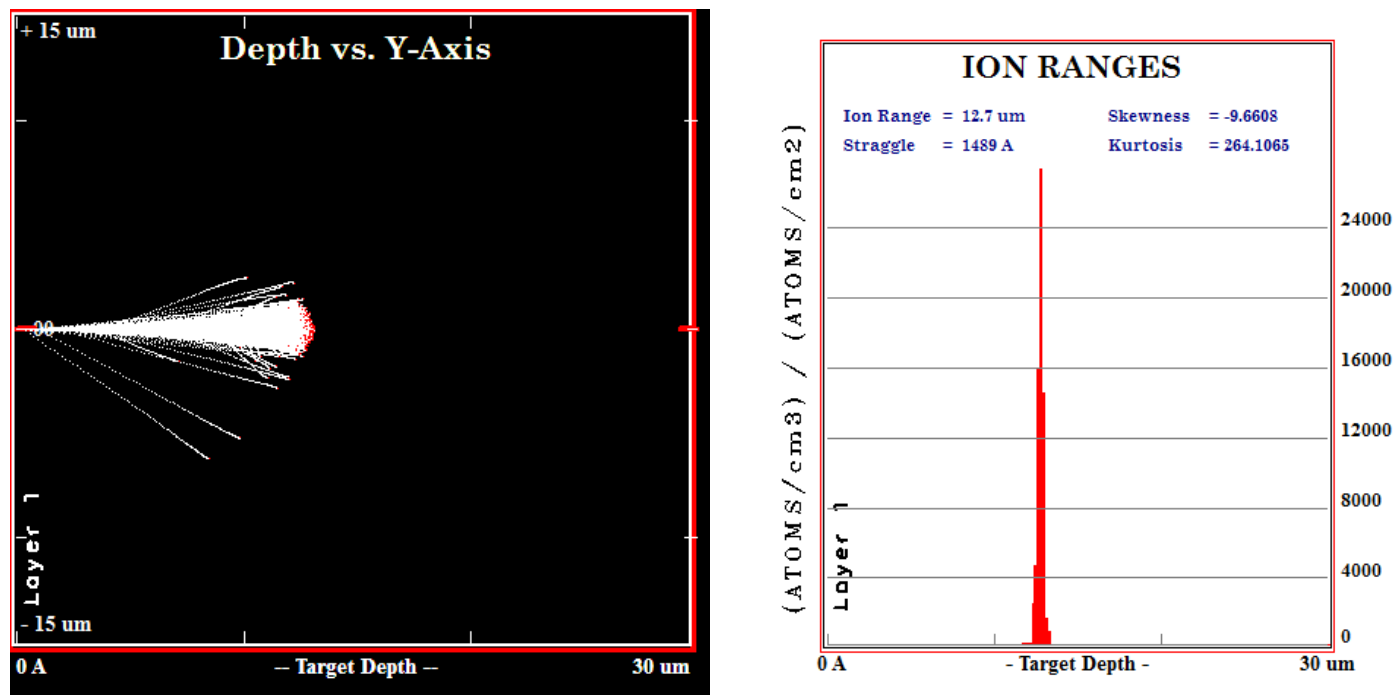

Figure 39: The TRIM results of Pu-239 alpha travel within a diamond plate.

Besides, Monte Carlo N-Particle code (MCNP) was used to simply simulate interactions of carbon atoms, as comparable as diamond, with alpha and beta particles. Three simulation radiation sources; Plutonium-239, Strontium-90 and Promethium-147 were run to estimate the energy spectrums with these charged particles. Figure 40 displays the energy spectrum of Pu-239, Sr-90 and Pm-147 with a diamond plate, respectively. 


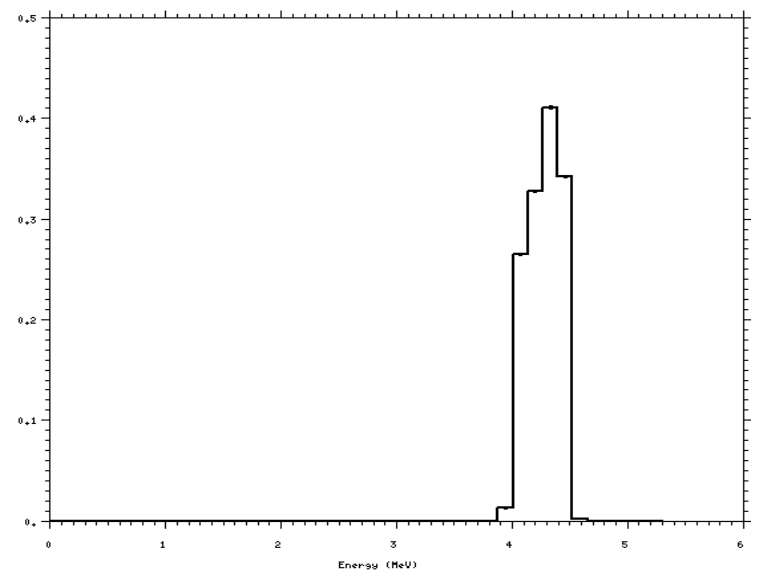

a) $\mathrm{Pu}-239 \mathrm{E}=5.24 \mathrm{MeV}$

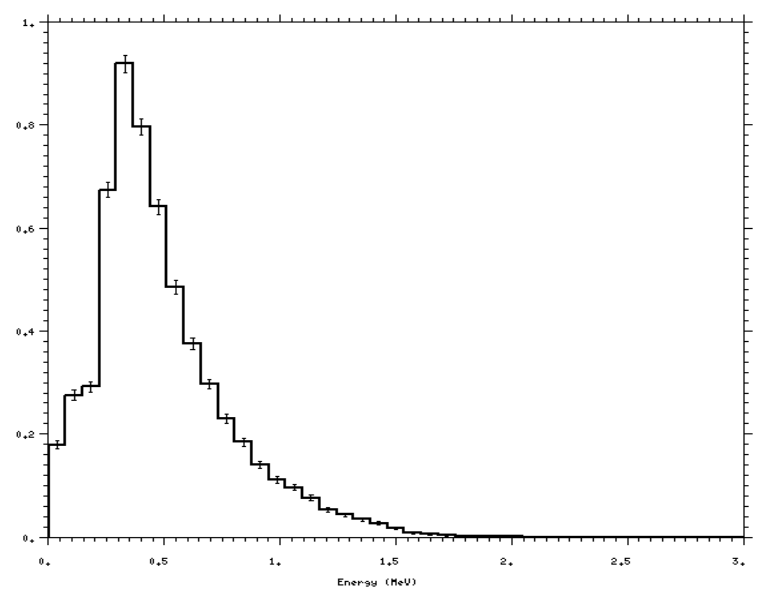

b) $\mathrm{Sr}-90 \mathrm{E}_{\max }=546 \mathrm{keV}$

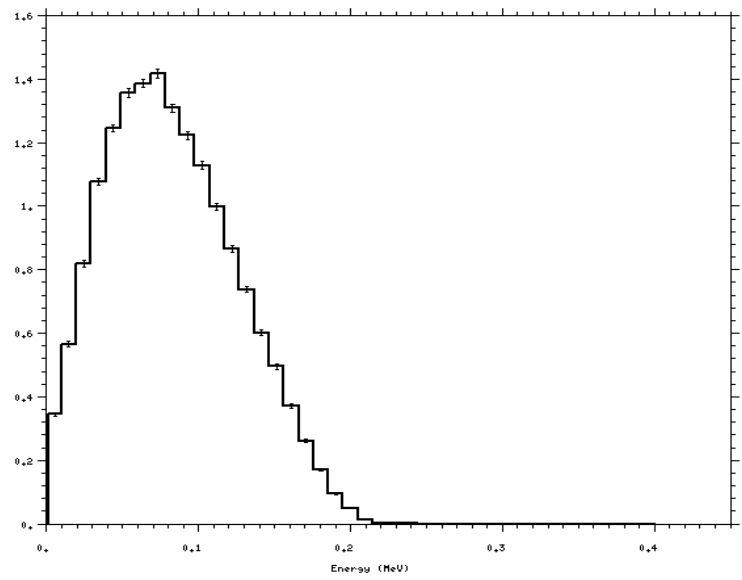

c) $P m-147 E_{\max }=225 \mathrm{keV}$

Figure 40: The MCNP energy spectrum of alpha and beta particles interacting with carbon atoms in a diamond plate. 


\subsubsection{Alpha exposure to CVD diamond detector}

The Ti/Pd detector was selected to test in the radiation response experiment. Two alpha radiation sources Plutonium-239 and Americium-241 were utilized at a fixed distance of $5 \mathrm{~mm}$. The varying voltages between 100-500 V were supplied to the Ti/Pd detector. The energy spectra of the diamond detector with Pu-239 and Am-241 at different supplied voltages are shown in Figure 41-42. It can be seen that at $200 \mathrm{~V}$ the spectrum starts to display a maximum charged collection efficiency. At higher than 200 V between 300 to $500 \mathrm{~V}$, the spectrums still show the maximum charged collection efficiency, however, at higher voltages there is an increase in noise. Consequently, $200 \mathrm{~V}$ is optimum for this CVD diamond detector.

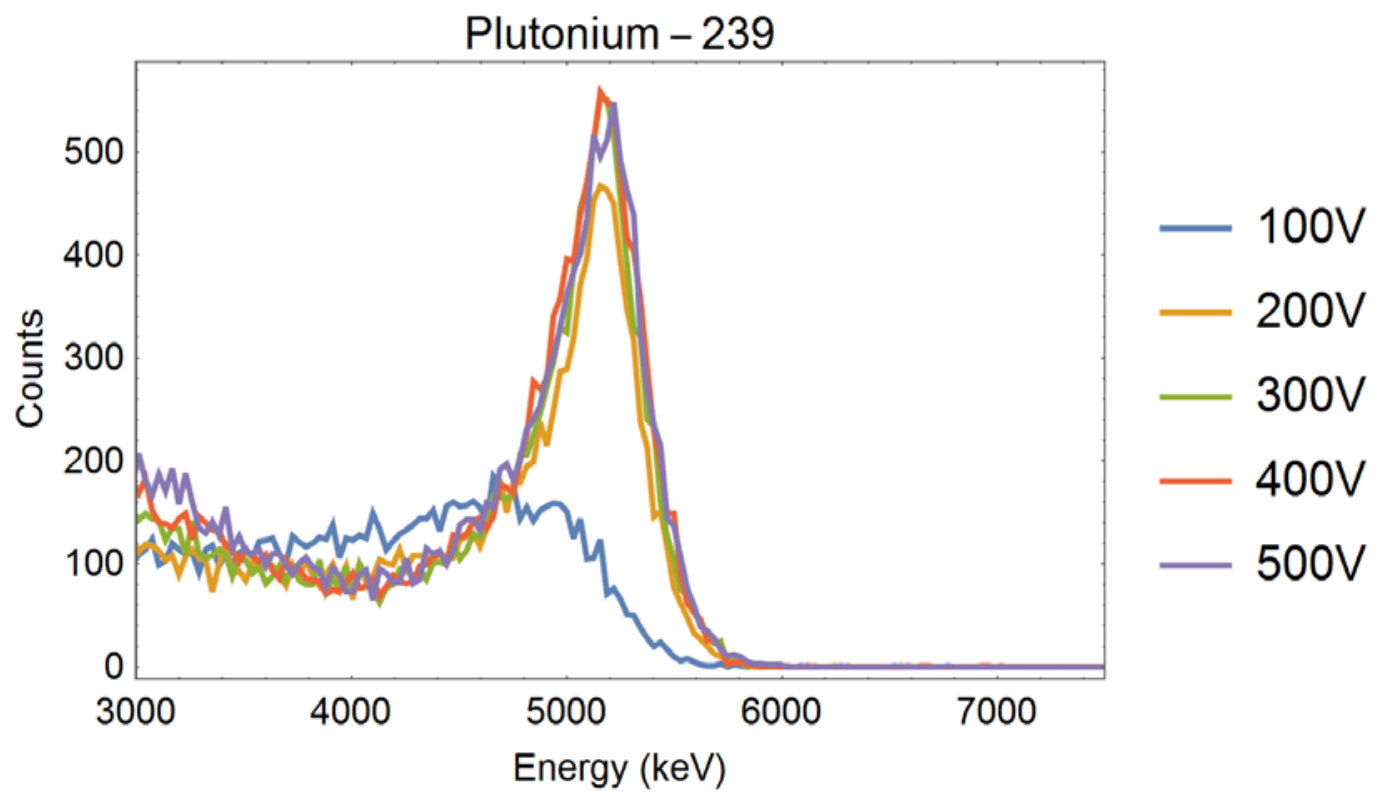

Figure 41: The energy spectra of Ti/Pd detector with Pu-239 with an applied voltage of $100-500 \mathrm{~V}$. 


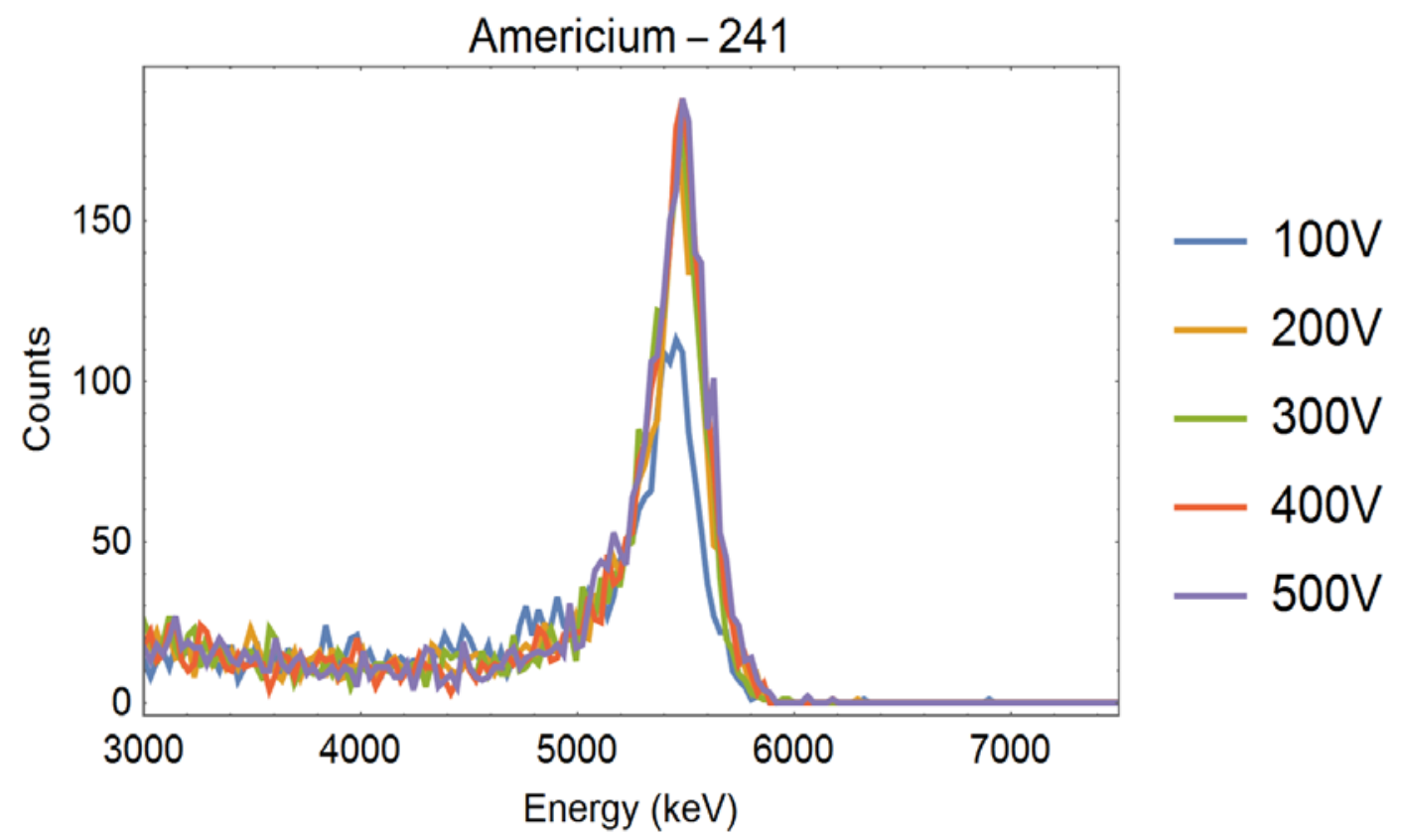

Figure 42: The energy spectra of Ti/Pd detector with Am-241 with an applied voltage of 100-500V.

\subsubsection{Beta exposure to CVD diamond detector}

The Ti/Pd detector was later tested with the beta radiation sources Sr-90 and Pm147. The detector was run using these beta sources at different voltages and a different source to detector distances. Figure 43 shows the energy spectra without beta source, and with a Sr-90 with the detector biased at 200-500 V. Like alpha particle exposure, at 200 V, the detector with Sr-90 started to have a maximum charged collection efficiency. Another test was done with Pm-147 at $200 \mathrm{~V}$ with different source to detector distance as seen in Figure 44. The results show that at a shorter source to detector distance, the detector collected higher counts from beta particles. Moreover, the shape of Sr-90 and Pm-147 energy spectra are similar to the MCNP simulation spectra in Figure 40. 


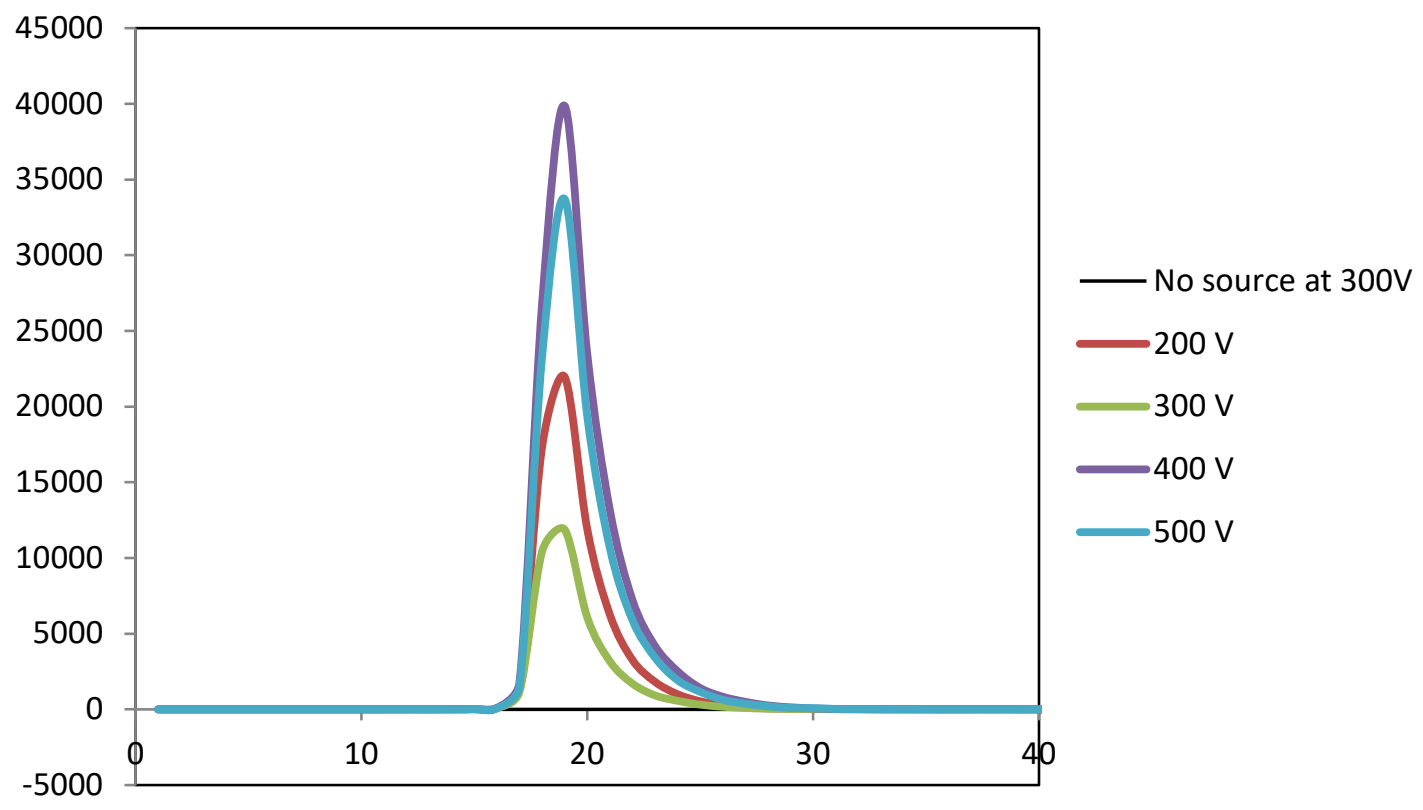

Figure 43: The energy spectra of Ti/Pd detector with Sr-90 at different applied voltages.

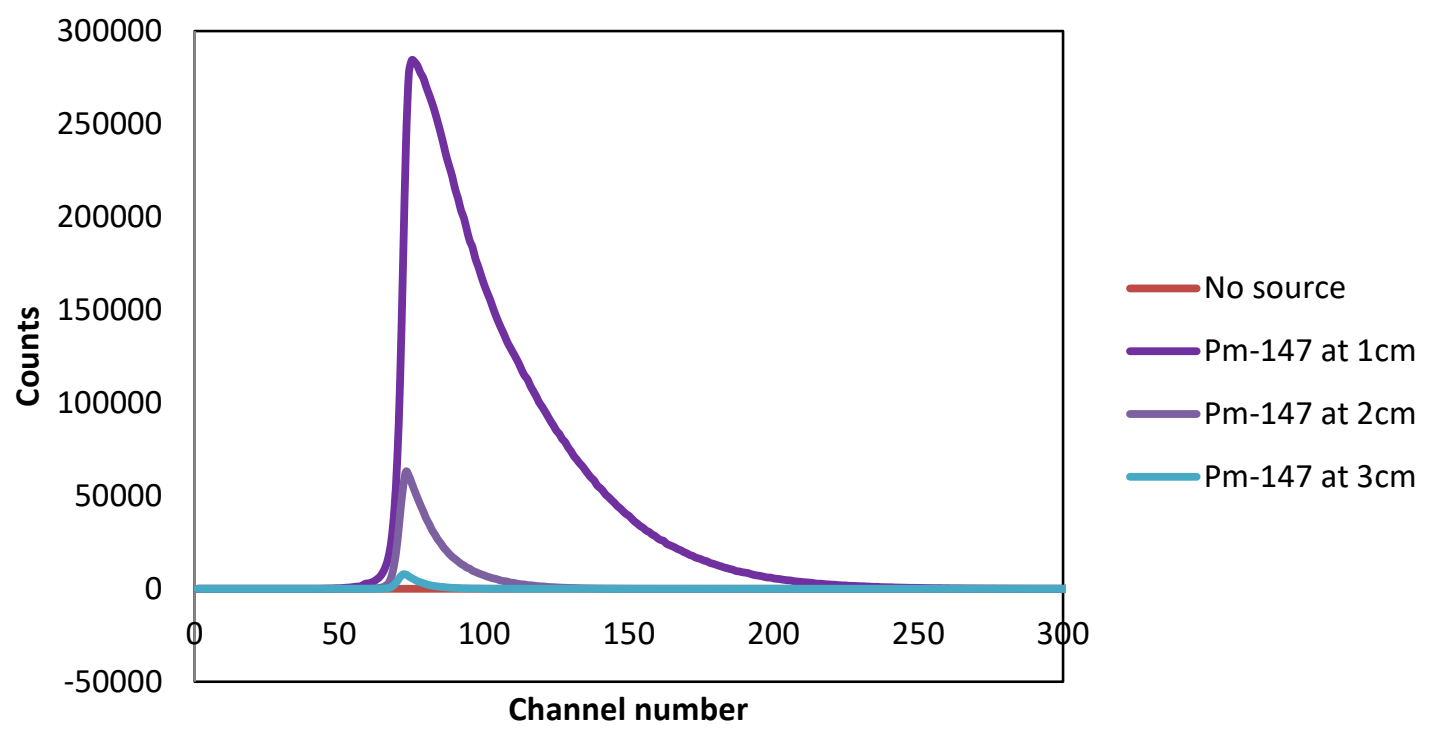

Figure 44: The energy spectra of Ti/Pd detector with Pm-147 at different source to detector distances. 


\section{CHAPTER 5}

\section{CONCLUSION}

In this work, CVD diamond detectors were designed and fabricated to detect potential radiations that would most likely occur from the reaction products of potential LENR in gas loading experiments if LENR was indeed nuclear. The detectors demonstrated reliable I-V characterizations and energy calibrations. The metal hosts deposited on the diamond surfaces were palladium and nickel by a well defined and well tested metallization procedure. The experiments ran under deuterium and hydrogen gas environments to produce deuterated palladium and hydrogenated nickel phases. As demonstrated in this work, the diamond detectors were able to measure both ion and electron spectra.

It is believed that the diamond radiation detectors observed and detected low levels of charged particle emission that occurred during the gas loading experiments at room temperature. In terms of the palladium-deuterium experiments, Experiment-1 observed significant high bursts from the SCA count rate that occurred during the three trials of deuterium gas loadings. Experiment-4 found significant bursts (low but greater than background) from both SCA and MCA from two trials of deuterium gas loadings. Regarding the nickel-hydrogen experiments, Experiment-2 showed significant count rate bursts from 1-day counting from the SCA as compared to the background and the helium control gas runs. Experiment-3 observed significant signal bursts from both the SCA and MCA in two hydrogen loading experiments. Also observed were unexpected bursts from a helium control gas loading, which did not have a correspondence between the total 
counts from the SCA and MCA. The unexpected bursts were most likely was due to system noise from an unintentional system interruption.

This work also provides data on a series of experiments in which the CVD diamond detector was used to detect charged particles such as alpha and beta radiations from Sr-90 and Pm-147. Simulations by TRIM and MCNP predicted the response of the CVD diamond sensor to alpha, and beta radiation. As seen from the different predicted and experimentally generated shapes of alpha and beta energy spectrum, it is the conclusion of this study that CVD diamond detectors can measure both alpha and beta spectra. However, for beta detection, due to the emission spectrum of beta particles, the CVD diamond detection needs additional work to acquire more complete data sets.

Finally, it is important to state that the intrinsic detection efficiency of CVD diamond spectroscopy depends on the detection system configuration connected to the diamond detector. Moreover, the larger size of the CVD diamond plate, consequently, can provide a larger of electrode and metallization area, which will increase the detection ability, sensitivity, and efficiency of the detector. Due to the cost of CVD diamond plates, the number of samples used in this work may be considered as limited. Therefore, increasing the number of the diamond detectors and doing more gas loading experiment will provide more reliable and accurate data. 


\section{BIBLIOGRAPHY}

[1] I. E. Agency, Key World Energy Statistics. Paris, 2014.

[2] W. P. Allis and E. International Conference on the Peaceful Uses of Atomic, "Nuclear fusion," Princeton, N.J.

[3] E. Storms, "The Science of Low Energy Nuclear Reactions: A comprehensive compilation of evidence and explanations about cold fusion," ed: Singapore: World Scientific Publishing, 2007.

[4] R. Tapper, "Diamond detectors in particle physics," Reports on Progress in Physics, vol. 63, p. 1273, 2000.

[5] R. Sussmann, J. Brandon, S. Coe, C. Pickles, C. Sweeney, A. Wasenczuk, et al., "CVD diamond: a new engineering material for thermal, dielectric and optical applications," IDR. Industrial diamond review, vol. 58, pp. 69-77, 1998.

[6] M. F. L'Annunziata, Handbook of radioactivity analysis: Academic Press, 2012.

[7] S. Y. Wrbanek, G. C. Fralick, J. D. Wrbanek, and J. M. Niedra, "NASA Glenn Research Center Experience with" LENR Phenomenon"," 2012.

[8] M. Fleischmann and S. Pons, "Electrochemically induced nuclear fusion of deuterium," Journal of electroanalytical chemistry and interfacial electrochemistry, vol. 261, pp. 301-308, 1989.

[9] S. E. Jones, E. P. Palmer, J. B. Czirr, D. L. Decker, G. Jensen, J. Thorne, et al., "Observation of cold nuclear fusion in condensed matter," Nature, vol. 338, pp. 737-740, 1989.

[10] S. Focardi and A. Rossi, "A new energy source from nuclear fusion," Journal of Nuclear Physics, http://www. journal-of-nuclearphysics. com, 2010.

[11] D. G. Bettini and S. SpA, "How can 30\% of nickel in Rossi's reactor be transmuted into copper?."

[12] E. Stremmenos, "Hydrogen/Nickel cold fusion probable mechanism," $w w w$. journal-of-nuclearphysics. com, 2011.

[13] S. Focardi, V. Gabbani, V. Montalbano, F. Piantelli, and S. Veronesi, "Large excess heat production in Ni-H systems," NUOVO CIMENTO-SOCIETA ITALIANA DI FISICIA SEZIONE A, vol. 111, pp. 1233-1242, 1998. 
[14] G. C. Fralick, A. J. Decker, and J. W. Blue, "Results of an attempt to measure increased rates of the reaction $2 \mathrm{D}+2 \mathrm{D}-3 \mathrm{He}+\mathrm{n}$ in a non electrochemical] cold fusion experiment," NASA Technical Memorandum, vol. 102430, pp. 1-15, 1989.

[15] Y. Iwamura, T. Itoh, N. Gotoh, and M. Sakano, "Detection of anomalous elements, X-ray and excess heat induced by continuous diffusion of deuterium through multi-layer cathode (Pd/CaO/Pd). Infinite Energy," 1998.

[16] Y. Arata and Y.-C. Zhang, "Deuterization and Deuterium Reactions in the Electrolyses of D2O with the double Structure Cathode and the Bulk Cathode," Japanese Journal of Applied Physics, vol. 39, p. 4198, 2000.

[17] Y. Arata and Y. Zhang, "The special report on research project for creation of new energy," J. High Temp. Soc.(1), 2008.

[18] M. A. Prelas and E. Lukosi, "Neutron emission from cryogenically cooled metals under thermal shock," in Proceedings 17 th International Conference on Cold Fusion, Daejeon/Korea, 2012, pp. 13-17.

[19] A. Galbiati, "Diamond Neutron Detectors as He-3 alternative," in Nuclear Science Symposium and Medical Imaging Conference (NSS/MIC), 2013 IEEE, 2013, pp. $1-1$.

[20] M. A. Prelas, G. Popovici, and L. K. Bigelow, Handbook of industrial diamonds and diamond films: CRC Press, 1997.

[21] S. Koizumi, C. Nebel, and M. Nesladek, Physics and applications of CVD diamond: John Wiley \& Sons, 2008.

[22] C. Bauer, I. Baumann, C. Colledani, J. Conway, P. Delpierre, F. Djama, et al., "Radiation hardness studies of CVD diamond detectors," Nuclear Instruments and Methods in Physics Research Section A: Accelerators, Spectrometers, Detectors and Associated Equipment, vol. 367, pp. 207-211, 1995.

[23] S. Seidel, "Recent results on diamond radiation tolerance," Journal of Instrumentation, vol. 9, p. C01013, 2014.

[24] R. S. Sussmann, CVD diamond for electronic devices and sensors vol. 26: John Wiley \& Sons, 2009.

[25] E. Berdermann, K. Blasche, P. Moritz, H. Stelzer, and B. Voss, "The use of CVDdiamond for heavy-ion detection," Diamond and Related Materials, vol. 10, pp. 1770-1777, 2001. 
[26] R. Balmer, J. Brandon, S. Clewes, H. Dhillon, J. Dodson, I. Friel, et al., "Chemical vapour deposition synthetic diamond: materials, technology and applications," Journal of Physics: Condensed Matter, vol. 21, p. 364221, 2009.

[27] H. Frais-Kolbl, E. Griesmayer, H. Kagan, and H. Pernegger, "A fast low-noise charged-particle CVD diamond detector," IEEE Transactions on nuclear science, vol. 51, pp. 3833-3837, 2004.

[28] H. Pernegger, S. Roe, P. Weilhammer, V. Eremin, H. Frais-Kölbl, E. Griesmayer, et al., "Charge-carrier properties in synthetic single-crystal diamond measured with the transient-current technique," Journal of Applied Physics, vol. 97, p. 073704, 2005.

[29] E. Lukosi, M. Prelas, J. Shim, H. Kasiwattanawut, C. Weaver, C. J. Mathai, et al., "Diamond-based Radiation Sensor for LENR Experiments. Part 1: Sensor Development and Characterization," 2013.

[30] M. Pillon, M. Angelone, and A. Krasilnikov, "14 MeV neutron spectra measurements with $4 \%$ energy resolution using a type IIa diamond detector," Nuclear Instruments and Methods in Physics Research Section B: Beam Interactions with Materials and Atoms, vol. 101, pp. 473-483, 1995.

[31] National Nuclear Data Center. Available: www.nndc.bnl.gov

[32] E. Lukosi, M. Prelas, and J. Palsmeier, "Monte Carlo simulations of multiplexed electronic grade CVD diamond for neutron detection," Radiation Measurements, vol. 47, pp. 417-425, 2012. 


\section{VITA}

Haruetai Kasiwattanawut is from Bangkok, Thailand. She earned a BS in Physics from Silpakorn University, Nakornpathom, in 2003 and a MS in Radiological Science from Mahidol University, Bangkok, in 2007. Haruetai worked for ten years as a private tutor for elementary students in Bangkok on weekends. She was a Royal Thai Government scholar and attended the University of Missouri-Columbia to pursue her Master of Science and Doctor of Philosophy in Nuclear Engineering. She is interested in playing the ukulele and interior decoration. While attending the University of Missouri, she married Sirichai Theirrattanakul. And her daughter, Lynyada Theirrattanakul, was born in Columbia in 2016. 